\title{
Analysis of Myelin Membrane Growth in Oligodendrocytes
}

\author{
Dissertation \\ for the award of the degree \\ „Doctor rerum naturalium (Dr.rer.nat.)“ \\ of the Georg-August University Göttingen \\ within the doctoral program Biology \\ of the Georg-August University School of Science (GAUSS) \\ submitted by \\ Sebastian Schmitt \\ born in \\ Oldenburg, Germany
}

Göttingen, 2014 


\section{Thesis Committee:}

Prof. Dr. Dr. Hannelore Ehrenreich

Clinical Neurosciences

Max-Planck-Institute of Experimental Medicine

Prof. Dr. Nils Brose

Molecular Neurobiology

Max-Planck-Institute of Experimental Medicine

Dr. Mikael Simons

Department of Neurology,

Max-Planck-Institute of Experimental Medicine

\section{Members of the Examination Board}

Reviewer: $\quad$ Prof. Dr. Dr. Hannelore Ehrenreich

Clinical Neurosciences

Max-Planck-Institute of Experimental Medicine

Second Reviewer: Prof. Dr. Nils Brose

Molecular Neurobiology

Max-Planck-Institute of Experimental Medicine

\section{Further members of the examination board:}

Dr. Mikael Simons

Department of Neurology, University of Göttingen

Max-Planck-Institute of Experimental Medicine

Prof. Dr. Klaus-Armin Nave

Department of Neurogenetics

Max-Planck-Institute of Experimental Medicine

Dr. Manuela Schmidt

Emmy-Noether research group Somatosensory Signaling

Max-Planck-Institute of Experimental Medicine

Prof. Dr. Ralf Heinrich

Cellular Neurobiology, Schwann-Schleiden-Research Center

University of Göttingen

Date of the oral examination: 12.12 .2014 


\section{Contents}

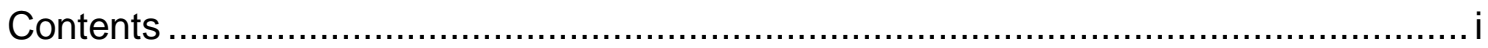

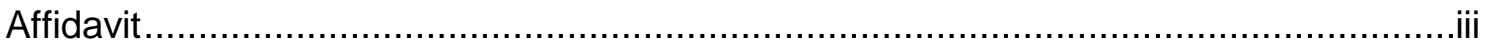

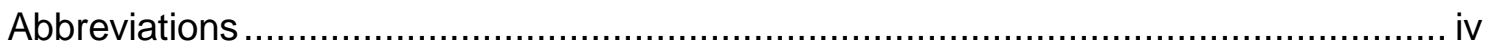

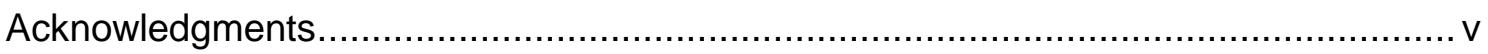

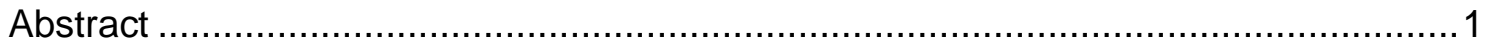

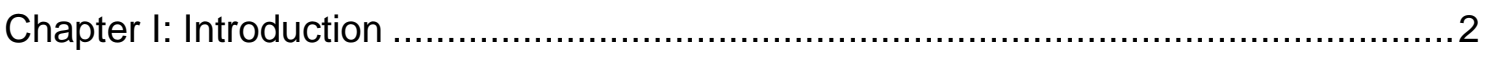

1.1 Biological membranes serve as permeable barriers .....................................

1.2 Regulated transport is the basis of nerve cell conduction ............................... 2

1.3 Myelination accelerates nerve cell conduction .............................................. 3

1.4 Oligodendrocytes are crucial for the function of the brain .............................. 5

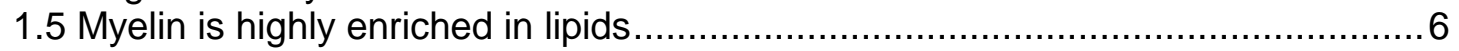

1.6 Myelin has a specific protein composition................................................. 7

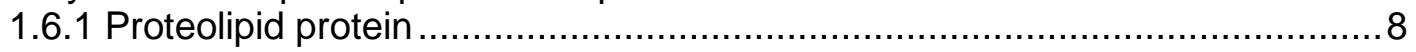

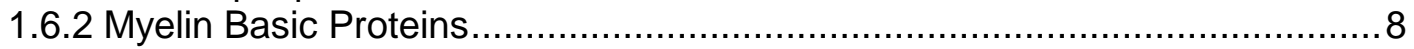

1.6.3 Cyclic nucleotide phosphodiesterase ..................................................... 9

1.6.4 Myelin-oligodendrocyte glycoprotein .................................................. 9

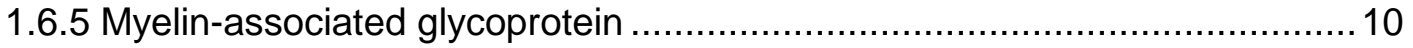

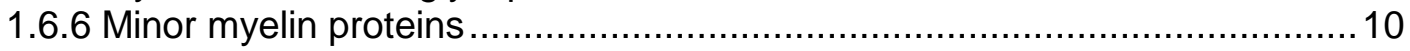

1.7 Recent views on myelin protein composition ............................................. 11

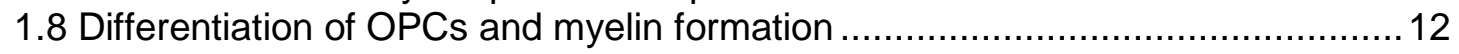

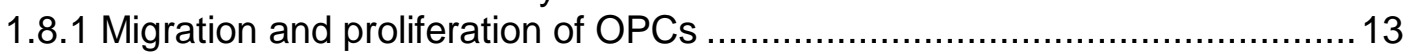

1.8.2 Inhibitory signals keep OPCs in the precursor state ............................... 14

1.8.3 Chromatin remodeling is a first step towards differentiation of OPCs .......... 15

1.8.4 Intrinsic Factors actively promote oligodendrocyte differentiation................. 15

1.8.5 Myelination - Contact formation, wrapping, trophic support ..................... 18

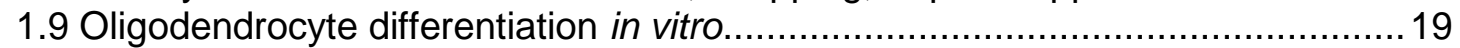

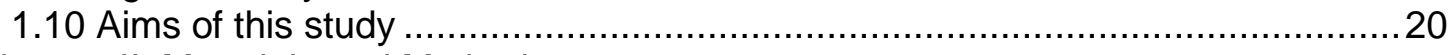

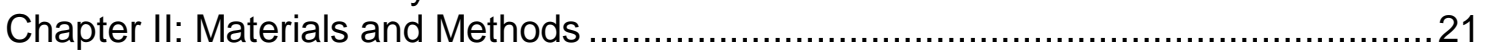

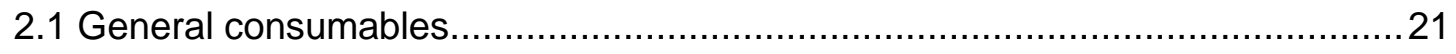

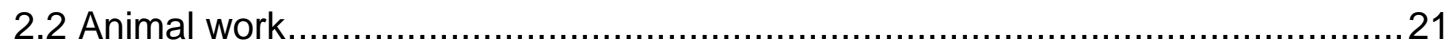

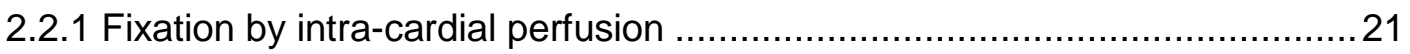

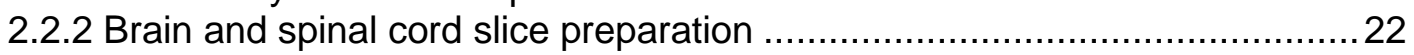

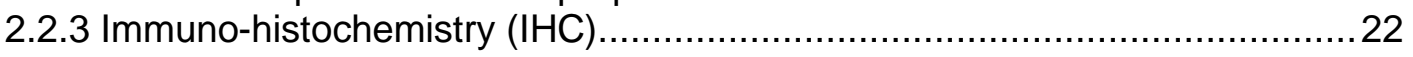

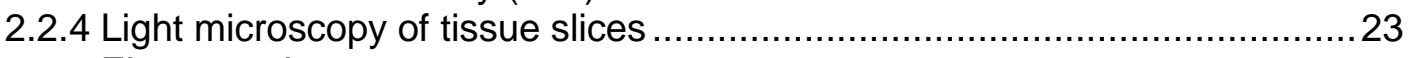

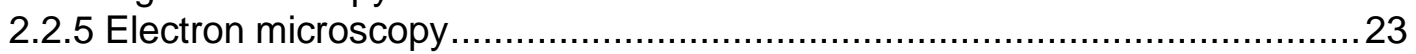

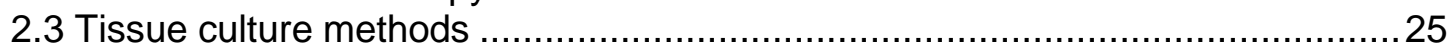

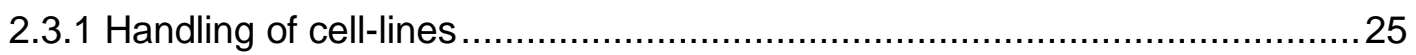

2.3.2 Cryo-preservation of mammalian cell lines ............................................26

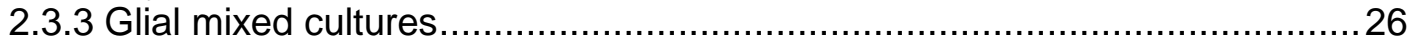

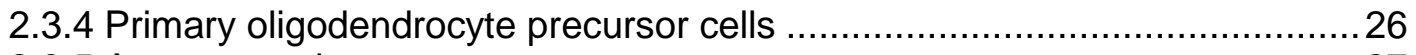

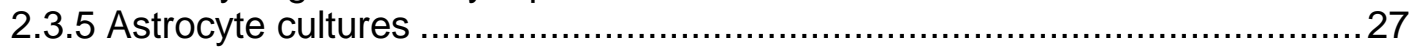

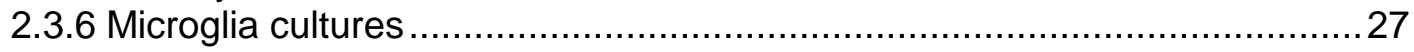

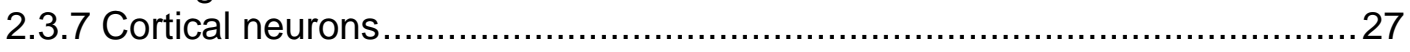

2.3.8 Preparation of mouse embryonic fibroblasts ...................................... 28

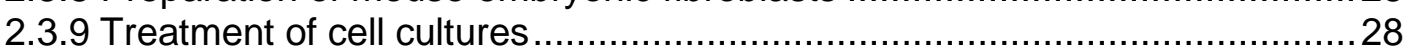

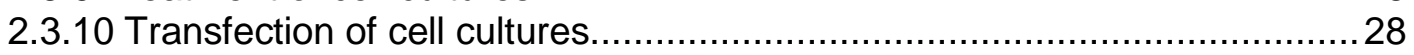

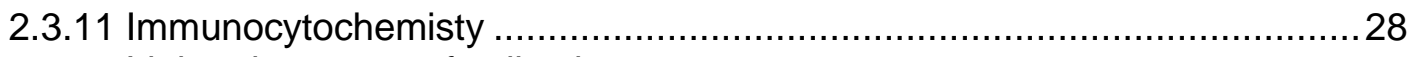

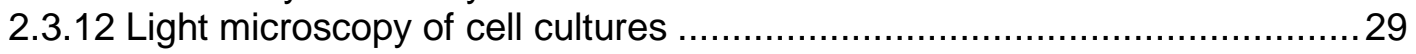

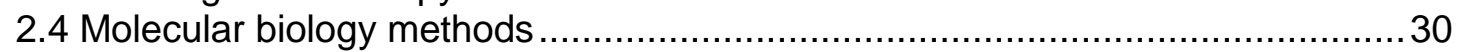


2.4.1 Isolation of genomic DNA from mouse tail tips ........................................ 30

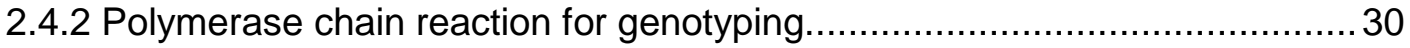

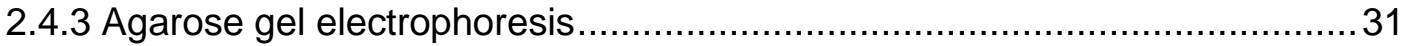

2.4.4 High-fidelity polymerase chain reaction for cloning ................................. 31

2.4.5 Enzymatic digestion of PCR products and plasmids ............................... 31

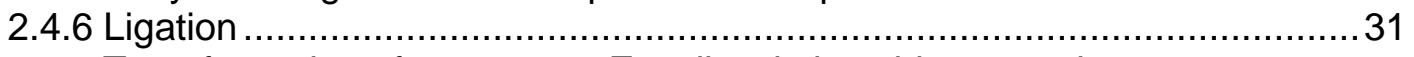

2.4.6 Transformation of competent $E$. coli and plasmid preparation ..................... 31

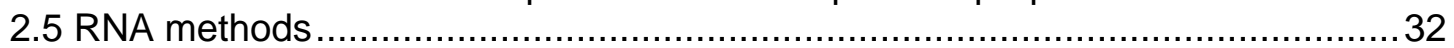

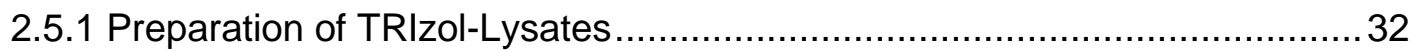

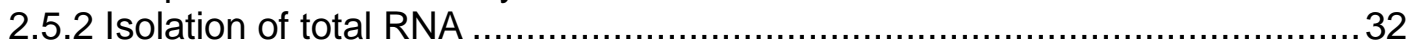

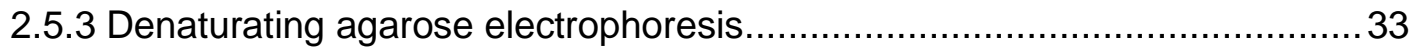

2.5.4 Reverse-transcription quantitative real-time PCR ................................. 34

2.5.5 RNA-extraction, generation of the cDNA libraries and Illumina RNA-

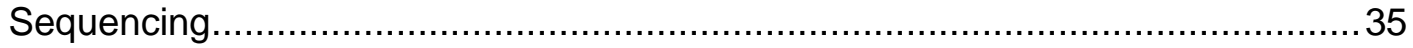

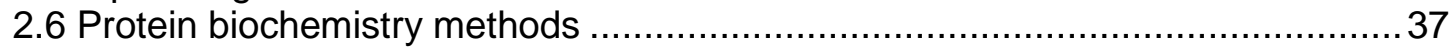

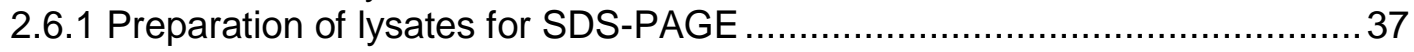

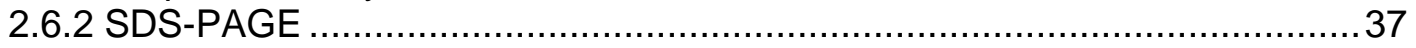

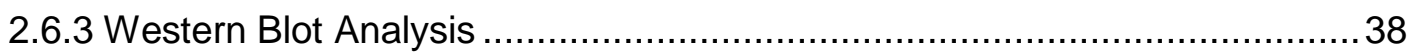

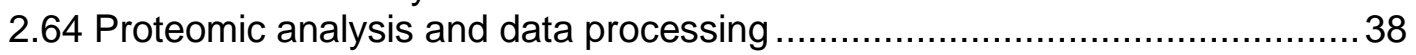

2.6.5 Fc-fusion protein generation and purification........................................... 39

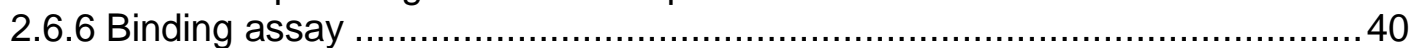

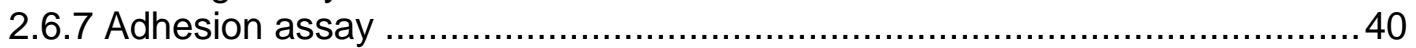

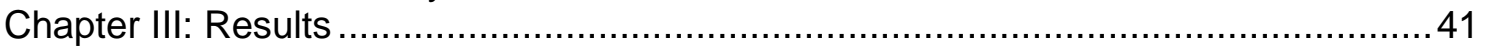

3.1 Generation of highly pure primary cell cultures ............................................ 41

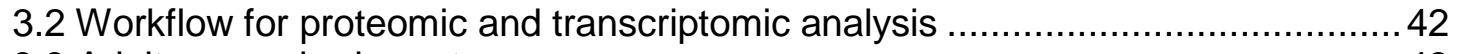

3.3 Adult mouse brain proteome..................................................................... 43

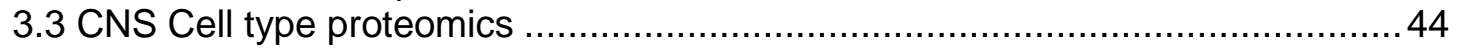

3.3 Proteins can be clustered according to their expression in cell types.................46 46

3.3 Pathways highly enriched in specific cell types............................................. 47

3.4 Determination of new, cell-type specific marker proteins ............................... 49

3.5 Col11a1 as a new marker for immature oligodendrocytes ..............................5 54

3.6 Bcas1 as a new marker for oligodendrocytes .............................................56

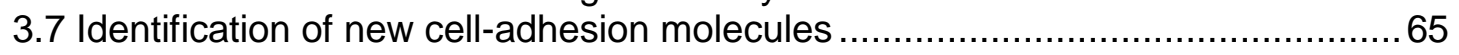

Chapter IV: Discussion and future directions ................................................. 71

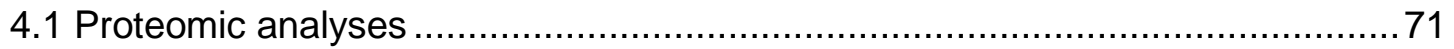

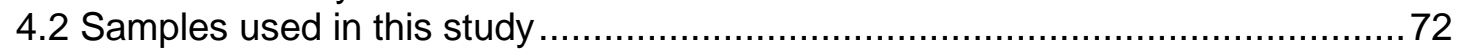

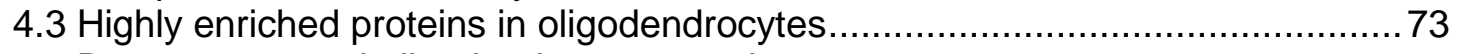

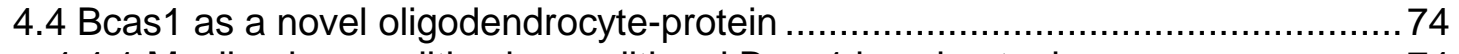

4.4.1 Myelin abnormalities in conditional Bcas1 knockout mice ......................... 74

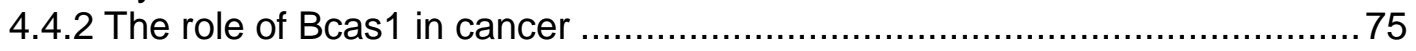

4.5 Proteomic analysis identifies the IgLON cluster of cell adhesion molecules........76

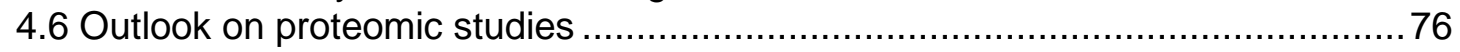

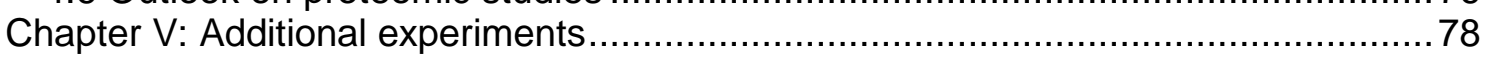

Generation of a mouse model to study actin dynamics in-vivo ............................. 78

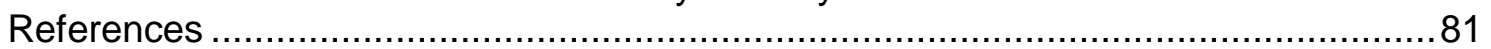

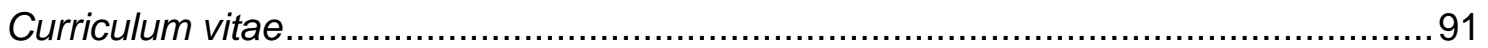




\section{Affidavit}

Here I declare that my doctoral thesis entitled "Analysis of Myelin Membrane Growth in Oligodendrocytes" has been written independently with no other sources and aids than quoted.

Sebastian Schmitt

Bonn, 27.October 2014 


\section{Abbreviations}

APS Ammoniium peroxodisulfate

AraC Arabinosyl-Cytosine

Bcas1 Breast carcinoma amplified sequence 1

bp base pairs

BSA Bovine serum albumin

cDNA complementary DNA

Col11a1 Collagen XI a1

CNP 2', 3'-cyclic nucleotide 3' phosphodiesterase

CNS Central nervous system

DMBA dimetylbenz[a]anthracene

DMEM Dulbecco's modified eagle medium

DMSO Dimethylsulfoxide

FCS Fetal calf serum

GFAP Glial fibrillary acidic protein

GFP Green fluorescent protein

HBSS Hank's buffered saline solution

KO knockout

LB Lysogeny broth

LC-MS/MS Liquid chromatography with tandem mass spectrometry

Lsamp Limbic system-associated membrane protein

MAG Myelin-associated glycoprotein

MAL Myelin and lymphocyte protein

MBP Myeelin basic protein

MPA medroxyprogesterone acetate

MOG Myelin oligodendrocyte protein

MS Multiple Sclerosis

OPC Oligodendrocyte precursor cell

Opclm Opioid binding cell adhesion molecule

PAGE Polyacrylamide gel electrophoresis

PLL Poly-L-Lysine

SDS Sodium dodecyl sulfate

sgRNA single guide RNAs

wt

wildtype 


\section{Acknowledgments}

I am grateful to my thesis advisor, Mikael Simons, for interesting projects, constant encouragement and for providing outstanding working conditions. I would also like to thank Hannelore Ehrenreich, not only for being first supervisor for my PhD thesis committee, but also for unwavering, personal support. I am further grateful to Nils Brose for being the second supervisor of my $\mathrm{PhD}$ thesis and personal support.

I am thankful to co-workers and collaborator who helped me in countless ways with my projects and this thesis. Kirti Sharma performed the proteomics, Caroline Bergner and Natalia Manrique provided helpful discussions and important data about Lsamp. Nirmal Kannaiyan and Moritz Rossner help with the Illumina Sequencing. Torben Ruhwedel, Christian Maak, Bogusha Sadowski and Wiebke Möbius helped me exploring the enigmatic world of electron microscopy, I really enjoyed the productive time downstairs. Furthermore, I would like to mention Julia Sondermann and Leon Hosang, who worked with me in their Bachelor and Lab rotation projects and did a really great job.

I am also grateful to Giselheid Schulz for their excellent technical and personal support, as well as philosophical discussions in the cell culture room, for providing all kinds of "motivases" and saccharine knockout mice.

I am also thankful to the staff of the animal facility for a productive work together, in particular Rainer Libal, Ursula Fünfschillig, Bianca Nickel, Marion Wehe, Sabrina Nehrkorn, Nadja Hoffmeister, Steffi Thiel, Nadine Jagaschewskie and Olivia Schulze.

Moreover, I would like to mention previous and current members of AG Simons that made life inside and outside the lab so much fun and became close friends - Karla Hans, Larisa Yurlova, Chieh Hsu, Holger Budde, Dirk Fitzner, Katrin Strauss, Mareike Schnaars, Mostafa Bakhti, Natalia Manrique-Hoyos, Hannes Treiber, Johannes Zimmermann, Aniket Ghosh, Nils Halbsgut, Tina Kling, Nicolas Snaidero, Olena Steshenko, Caroline Velte, Shima Safaiyan, Caroline Bergner, Michael Wollring, Xingwen Sun, Anshu Singh, Maryam Khojasteh, Paula Sanchez, Ludovico Cantuti, Gustavo D'romeda, and Marie Weil. I really enjoyed spending the time with you.

I especially want to thank Katrin Strauss and Mareike Schnaars for welcoming me in Göttingen and accompanying me through the first half of my PhD. I am also grateful to Marie Weil for all your friendship and support and for making the second half of my PhD such a great time.

I am grateful for everything that my parents have done for me, for their unconditional support and confidence in me. Furthermore, I would like to thank Manuel Meira Sanchez for his support, sharing wonderful moments, and for his patience. 


\section{Abstract}

Nervous systems of mammalian organisms are composed of various cell types with different morphology, function and connectivity. Understanding this complicity from a molecular point of view requires the application of systematic, large-scale approaches. Several initiatives already analyzed mRNA expression in different brain regions, at different time points and in different cell types. However, what is missing so far is a comprehensive analysis of the brain proteome and proteomic profiles of distinct cell types of the brain. This is challenging, since the tight interact tightly of these cells makes it difficult to separate them.

Here, we performed label-free quantitative proteomics to generate an inventory of $>10,000$ proteins in astrocytes, oligodendrocytes, microglia and neurons. Analysis of our datasets identified novel proteins in these cell types. For example, we identified Col11a1 and Bcas1 as novel oligodendrocyte proteins. Extending our analysis to proteins expressed by both neurons and oligodendrocytes, we found Lsamp as a negative regulator for myelination. These examples demonstrate how our datasets can be used as a valuable resource to study development and function of brain cells. 


\section{Chapter I: Introduction}

\subsection{Biological membranes serve as permeable barriers}

All living organisms are composed of cells that are surrounded by biological membranes. These membranes are crucial to separate the cell from the environment to enable a controlled access of water, ions and nutrients. Intracellular membranes further sub-divide cells into compartments with distinct biological functions. Compartmentalization therefore allows various biological processes to take place at the same time.

Membranes do not only separate distinct reaction volumes, but they are also the sites where biological processes such as oxidative phosphorylation and cell-cellcommunication take place. Despite these different functions, all biological membranes are mainly composed of the same building blocks: Phospholipids, such as phosphatidyl-choline and phosphatidyl-ethanolamine, are the major components of all cell membranes. In the plasma membrane they make up to $70 \%$ of all lipids, the remaining 30\% are mainly composed of sphingomyelin and cholesterol (Siegel, 1998).

In addition to lipids, membranes contain different proteins, but the protein to lipid ratio is highly variable between different membranes: While there are three times more proteins as lipids in the inner mitochondrial membrane, the plasma membrane contains more or less equal amounts of proteins and lipids. In contrast to that, the myelin membrane is highly depleted in proteins; there are four times more lipids than proteins. Since membranes separate different spaces, membrane proteins are essential for the transport of substances from one side to the other. As receptor proteins, they further allow the transduction of a signal through membranes.

\subsection{Regulated transport is the basis of nerve cell conduction}

Neurons impressively demonstrate how transport of substances across biological membrane can be involved in the transmission of information. Flow of sodium and potassium ions across the membranes is the fundamental basis of electrically currents that are used to communicate with other neurons and the rest of the body.

Without further stimulation, neurons establish a negative resting potential. To establish this resting potential, ATP-driven pumps simultaneously transport three sodium ions out of the cell and two potassium ions into the cell. This results in a high intracellular concentration of potassium and low concentration of sodium. Thereby, neurons establishes an overall negatively charge, while the outside is positively charged. 
Once a neuron receives electrical stimuli, voltage-gated ion channels will open and sodium ions can enter the cell. This influx of sodium ions will alter the charge from negative to positive and, therefore, depolarize the cell. After a short time, sodium channels will close and potassium channels will open, allowing potassium ions to leave the cell. This results in a re-polarization of the membrane. At that point, the sodiumpotassium-pumps expel sodium from the intracellular space and exchanges it by potassium to re-install the the resting potential. As the depolarization event opens sodium channels in the membrane portions ahead of the impulse, an action potential is created at this point. This action potential will depolarize the next portion of the axonal membrane and the action potential progresses along the axon (Fig. $1.1 \mathrm{a}$ ).

\subsection{Myelination accelerates nerve cell conduction}

With the evolution of bigger animals, conduction velocity had to increase. One way to speed up the transmission of information is to increase the diameter of an axon; the thicker an axon is, the faster is the speed of the conduction. Consistently, huge axons with a diameter of up to $1 \mathrm{~mm}$ are found in various invertebrates including giant squids and lobsters.

A different mechanism to speed up action potentials can be found mainly in vertebrates. Many vertebrate axons are surrounded by a multi-layered, insulating structure, the myelin sheath (Fig. 1.1 c, d). Between the myelinated tracts are several small gaps which are called the nodes of Ranvier. Ion channels involved in the action potential are clustered in these nodes. Therefore, the action potential cannot propagate continuously along the axon, but "jumps" from one node to the other. This process is called saltatory conduction and allows rapid transmission of impulses along relatively thin axons and requires considerably less energy (Fig. 1.1 b).

In order to achieve myelination, oligodendrocyte precursor cells (OPCs) need to migrate into the right regions of the brain, neurons and oligodendrocytes must differentiate in a timely manner and both cell types have to recognize each other. The program of myelination involves signaling effects between both cell types, transcriptional regulation and eventually leads to a dramatic change of oligodendrocyte morphology. All of these steps are fascinating cell biological processes. 
a

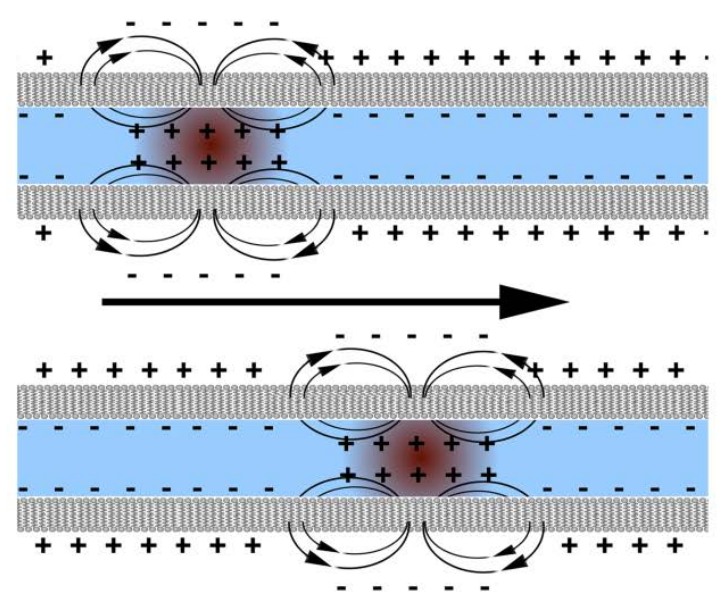

C

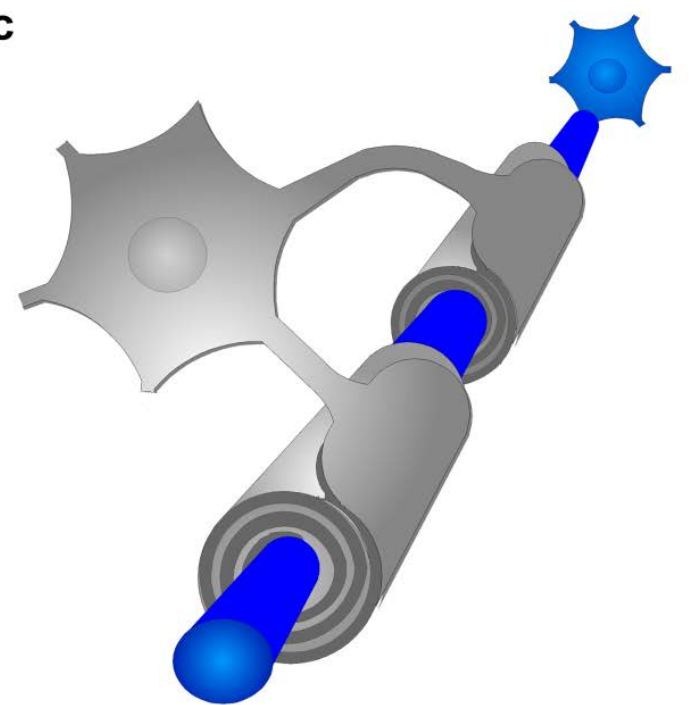

b
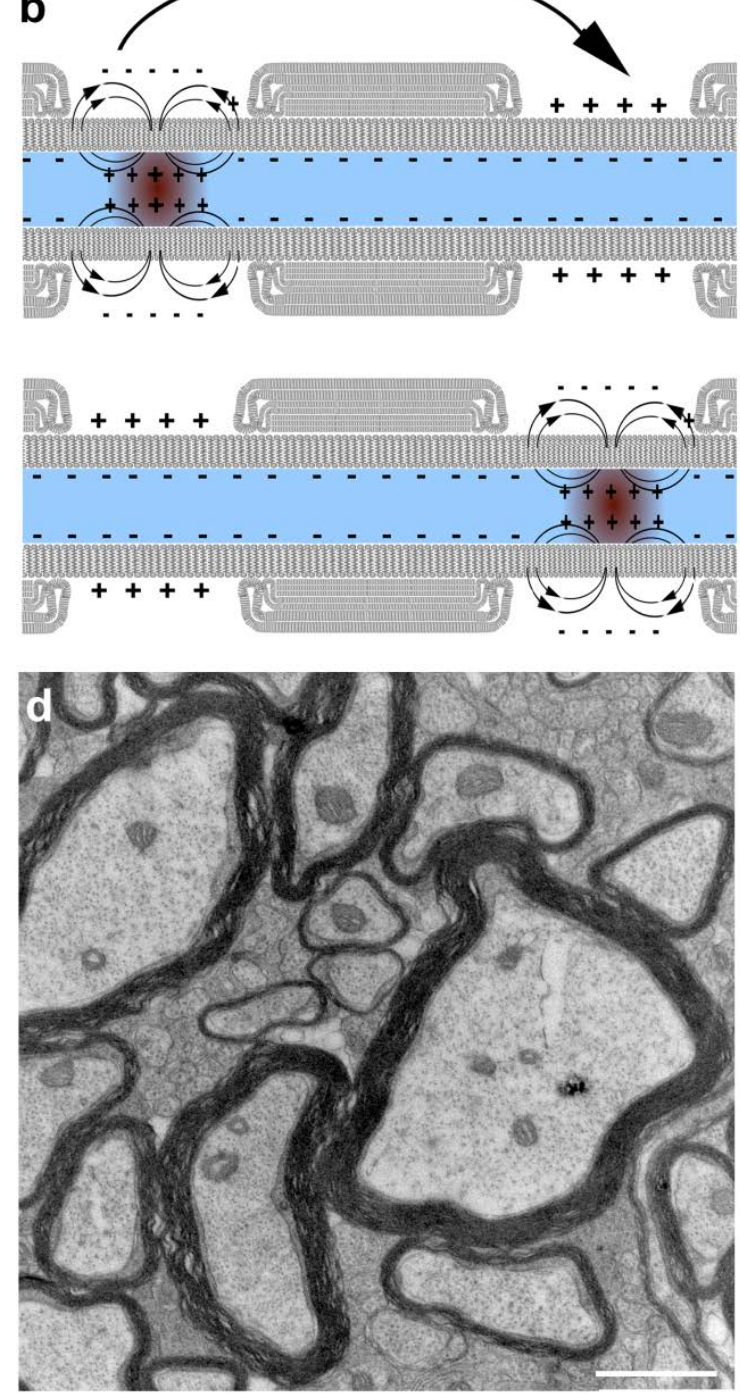

Fig. 1.1: Myelination allows fast nerve cell conduction Action potentials propagate in a continuous manner along unmyelinated axons (a), while they "jump" from one node to another in myelinated axons (b). Oligodendrocytes myelinate several tracts of different axons (c); the layers of myelin can be visualized by electron microscopy (d) [lllustrations were prepared with Adobe Photoshop, EM of myelin in the optic nerve, Scale bar: $1 \mu \mathrm{m}]$. 


\subsection{Oligodendrocytes are crucial for the function of the brain}

When myelination is impaired or myelin integrity is disturbed, severe medical problems arise. These problems highlight the importance of myelin for the nervous system.

One example is neonatal ischemia, which leads to a massive loss of OPCs. As a consequence, patients show hypo-myelination and suffer from neurological problems, such as seizures. The extent of OPC death and the resulting degree of hypomyelination largely determine the severity of symptoms (Rees and Inder, 2005).

Inherited leukodystrophies are further examples for failures in proper myelin formation. The most prominent example is Pelizaeus-Merzbacher-disease (PMD). Patients with PMD often show a duplication of the PLP1 gene, which encodes for one of the major myelin proteins. Also point mutations in the PLP1 gene can be associated with PMD (Saugier-Veber et al., 1994). In any case, altered levels of the PLP1 protein seem to affect myelin stability, which in turn results in dys- or hypo-myelination. The same was observed in genetically modified mice that overexpress PLP1 (Karim et al., 2007).

Even if myelin is correctly formed in the first place, it can be lost later. Such conditions are called demyelinating diseases; the most prominent example is Multiple Sclerosis (MS). MS is a multifactorial autoimmune disease that is characterized by inflammatory events in the central nervous system (CNS) and leads to a loss of myelin. Astrocytes can grow into these areas and thereby lead to glial scarring. Inflammation and demyelination in MS occur in distinct focal points throughout the entire CNS. The localization of these lesions determines the clinical symptoms during a clinical episode, but lesions can also be clinically silent. Symptoms can occur in isolated clinical episodes (relapsing forms) that remit completely. In progressive forms of MS, symptoms increase over time. However, in later stages, relapsing-remitting forms of MS can also go over into progressive disease forms with permanent disabilities. This can be explained by axonal loss and neuronal cell death in the course of the disease. For a previous review on clinical course of $M S$, as well as the interplay between inflammation and neurodegeneration, see Trapp and Nave, 2008.

Histopathological examinations of MS lesions showed that OPCs can migrate into these areas and repair lesions. However, in the course of the disease, OPCs fail to differentiate so that remyelination is not possible any more. As a consequence, axons lack the trophic support of myelin and degenerate. This eventually leads to neuronal loss and permanent disability of the patient (Wolswijk, 2000; Kuhlmann et al., 2008).

Understanding the molecular mechanisms of oligodendrocyte differentiation, therefore, is a pre-requisite to find targets for the pharmacological treatment of demyelinating diseases. 


\subsection{Myelin is highly enriched in lipids}

In order to understand how myelin can fulfill its functions, it is necessary to take a closer look into its molecular composition. As myelin mainly functions as an electric insulation, it is not surprising that $70 \%$ of its the dry weight consist of lipids, while proteins only account to $30 \%$. None of the lipids is unique for myelin, but certain lipids are clearly enriched. Among these lipids are cholesterol, cerebrosides (e.g. galactosylcerebroside, GalC), sulfatides, and galactolipids in general, while the overall amount of lecithin and ethanolamine is reduced (Siegel, 1998).

The importance of the special lipid composition can be observed in knockout mice. The enzyme ceramide-galactosyl-transferase (CGT) is crucial for the synthesis of GalC, as this enzyme transfers a galactose-residue from UTP-Gal to ceramide. Animals lacking this enzyme show seizures and a reduced lifespan. Nerve cell conduction is reduced in these animals and, upon aging, they develop hindlimb paralysis and abnormalities within the spinal cord (Coetzee et al., 1996).

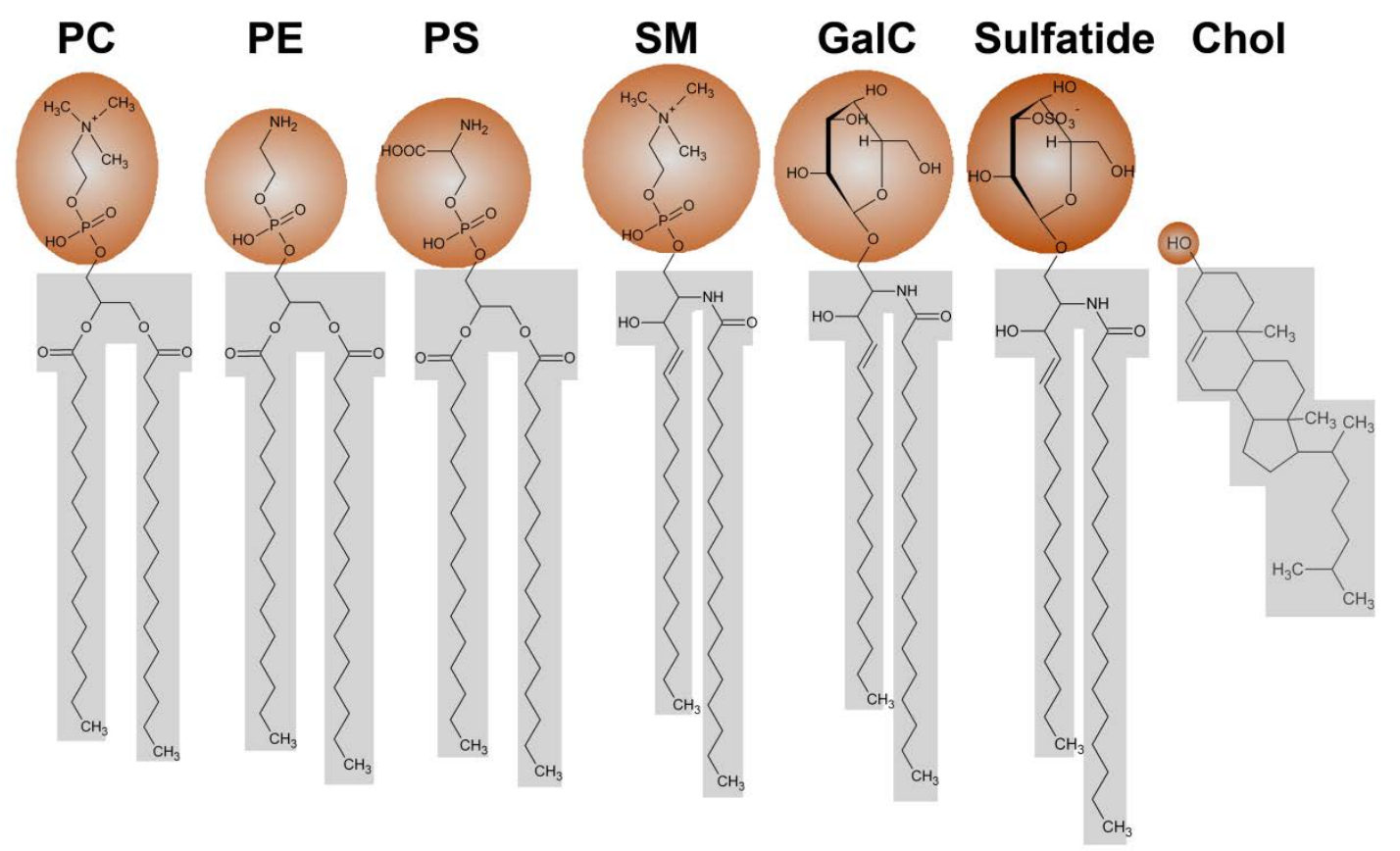

Fig. 1.2: Major lipids of myelin Myelin is mainly composed of phosphatidyl choline (PC), phosphatidylethanol amine (PE), phosphatidyl serine (PS), sphingomyelin (SM), galactosyl cerebrosides (GalC), sulfatides and cholesterol (Chol). [lllustrated using Adobe Photoshop].

This example demonstrates the importance of certain lipids for proper myelination, however, much more is known about the importance of specific proteins in myelin formation and maintenance. 


\subsection{Myelin has a specific protein composition}

Even though myelin consists to only $30 \%$ of proteins, these proteins are rather specific and important for the function of the myelin sheath. Already in the 1970s, CNS myelin was biochemically purified, separated by gel electrophoresis and stained with dyes such as Coomassie Brilliant Blue. These early experiments suggested that the major proteins in myelin are the proteolipid protein (PLP1) and its smaller splicing isoform DM20 (together 30-45\%), the different isoforms of the myelin basic protein (MBP, 22$35 \%$ ), and 2',3'-Cyclic nucleotide 3'-phospho-diesterase (CNP, 4-15\%).

The remaining $5-25 \%$ are thought to be composed of all other myelin proteins: Among these are the myelin oligodendrocyte glycoprotein (MOG), myelin oligodendrocyte basic protein (MOBP), the isoforms of the myelin associated glycoprotein (MAG) and Claudin 11. The function of these proteins will be shortly summarized in the following paragraphs. This knowledge will be important in Chapter II, when I will present data from our own proteomic analysis on oligodendrocytes.

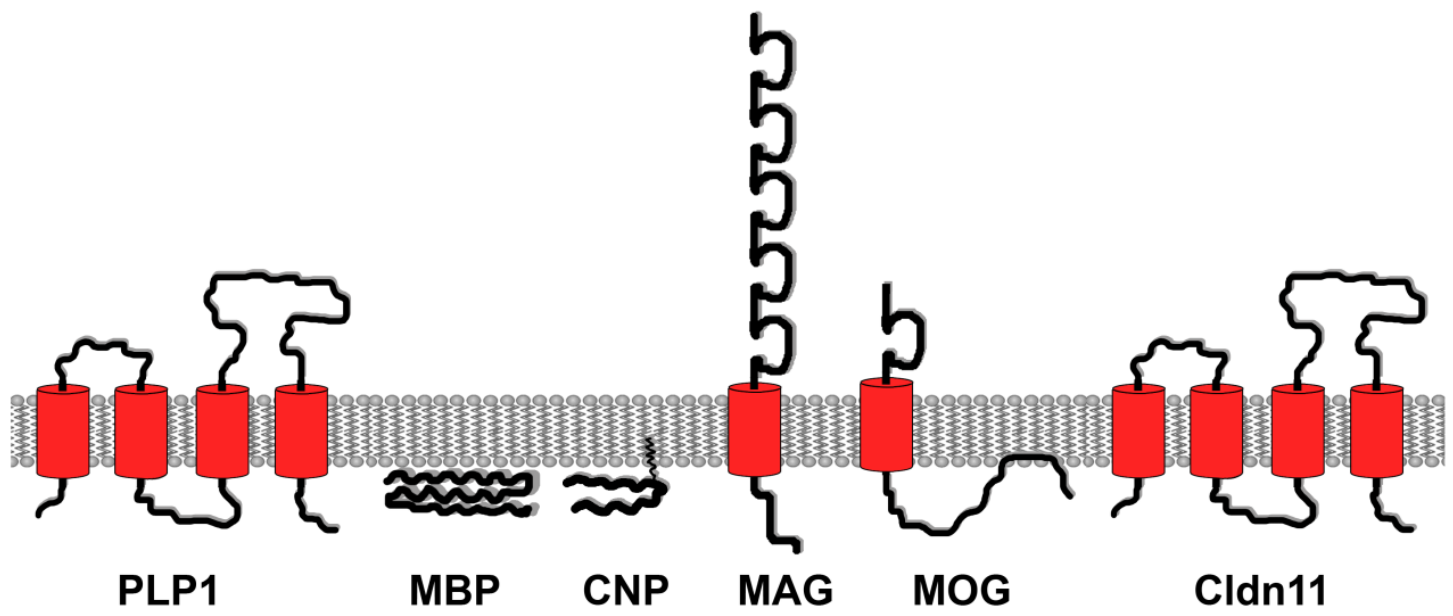

Fig. 1.3: Proteins highly enriched in myelin. The most abundant proteins of myelin are the tetraspanin PLP1 and MBP. The membrane-associated protein CNP1, the single-pass transmembrane proteins MOG and MAG are found in smaller amounts. This also applies to other tetraspanins such as Cldn11. [lllustrated using Adobe Photoshop]. 


\subsubsection{Proteolipid protein}

The $30 \mathrm{kDa}$ tetraspanin PLP1 and its $26 \mathrm{kDa}$ splicing isoform DM-20 together constitute up to $50 \%$ of all CNS myelin proteins. Mutations in the PLP1 gene have been described in patients with Pelizaeus-Merzbacher disease (PMD). The disease usually starts in early childhood and is characterized by developmental retardation, tremor, general weakness and ataxia. Certain aspects of PMD can be modeled using naturally occurring or genetically generated animal models:

Models based on spontaneous mutations include Jimpy mice, myelin deficient rats and shaking pup dogs. Jimpy mice carry a point mutation that causes a deletion of exon 5 and, as a consequence, leads to a frame shift and premature termination of PLP1 translation (Nave et al., 1986). Myelin deficient rats and shaking pups show only point mutations resulting in single amino acid substitutions (Yool et al., 2000). All of these mutations result in severe dysmyelination of the CNS, tremor and early death (Nadlon et al., 1990).

Giving the severity of these phenotypes, it is surprising that PLP1 knockout mice are fully myelinated, but have only a reduced level of cholesterol in their myelin. Double knockout mice lacking both PLP1 and the PLP-related glycoprotein M6B are severely hypo-myelinated. These finding support the model that PLP1 sequesters cholesterol to enable proper myelination (Werner et al., 2013). Apart from PLP1 mutant and knockout mice, also mice that overexpress PLP1 have been generated. These mice show dysmyelination (Readhead et al., 1994) and are being used as a model for PMD. In a study using these mice, it could be shown that cholesterol-feeding drastically improves morphological and clinical outcome of these animals (Saher et al., 2012).

\subsubsection{Myelin Basic Proteins}

All members of the MBP family are produced by alternative splicing. The MBP gene is part of a larger gene complex, called Golli, which regulates the expression of the Golliand MBP-transcripts. In mice, five different classical MBP-isoforms are known; these can be distinguished into the $21.5 \mathrm{kDa}, 18.5 \mathrm{kDa}, 17.22 \mathrm{kDa}, 17.24 \mathrm{kDa}$ and $14 \mathrm{kDa}$ isoform. The expression of these isoforms varies during brain development, with 18.5 and $14 \mathrm{kDa}$ isoforms being most abundant in adult mice (Siegel, 1998).

As the name indicates, MBP is highly basic; at physiological $\mathrm{pH}$ the protein has a net charge of +19 , which allows MBP to bind to negatively charged lipids and probably to anionic proteins. This binding to biological membranes seems to induce the formation of stable conformations of MBP, while the protein lacks a well-defined 3D structure in solution. Negatively charged lipids, such as Phosphatidyl-inositol(4,5)-diphosphate (PIP2), seems to be essential for proper folding of MBP (Boggs, 2006). 
MBP is important for the compaction of myelin membranes. The high-affinity binding to membranes allows MBP to zip together two membranes and to squeeze out the cytoplasm. During this process, MBP molecules interact with each other to form a meshwork that hinders other proteins from entering into compacted regions (Aggarwal et al., 2013).

One interesting feature of MBP is that its mRNA is transported in form of granules and that MBP is translated locally. Due to the tight binding of MBP to membranes, the local translation is probably necessary to enable a correct localization of the protein.

The importance of MBP is highlighted by the naturally occurring Shiverer mutant mice. These animals carry a mutation in the MBP gene and lack most MBP isoforms. As a result, myelin in homozygous shiverer mice cannot be compacted properly and these mice suffer from convulsions and die at a very young age (Chernoff, 1981).

\subsubsection{Cyclic nucleotide phosphodiesterase}

Two isoforms of the 2',3'-cyclic-nucleotide 3'-phosphodiesterase are known; the $45 \mathrm{kDa}$ protein CNP1 and the $47 \mathrm{kDa}$ protein CNP2. As the name indicates, CNP exhibits enzymatic activity and was shown to hydrolyze artificial substrates. However, neither the natural substrate nor the biological function in oligodendrocytes has been identified so far (Sprinkle, 1989).

CNP is localized in non-compacted myelin and stays associated with the membrane by an isoprenyl-anchor. CNP1-deficient mice appear healthy and myelin structure seems normal, but upon aging, these animals develop axonal degeneration (Lappe-Siefke et al.; 2003; Radband et al.; 2005; Edgar et al., 2009). Interestingly, CNP1 deficient mice seem to be highly susceptible to further damages. The application of a relatively mild cryo-lesion in CNP1-deficient mice resulted in enhanced astrogliosis and axonal degeneration (Wieser et al., 2013). A recent study from our lab further revealed that CNP1-deficient mice at P10 have less non-compacted myelin. In contrast to this, heterozygous shiverer mice, which have a lower level of MBP, showed more noncompacted myelin. This indicates that CNP1 and MBP could be functional antagonists that regulate myelin compaction (Snaidero et al., 2014).

\subsubsection{Myelin-oligodendrocyte glycoprotein}

The myelin-oligodendrocyte-glycoprotein (MOG) is a single-pass transmembrane protein that belongs to the immunoglobulin superfamily of cell adhesion molecules. This $28 \mathrm{kDa}$ protein is specifically expressed in mature oligodendrocytes. The biological function of MOG is not yet known, but it might have adhesive functions. 
MOG-deficient mice appear healthy and show no pathological abnormalities (Delarasse et al., 2003).

An interesting feature of MOG is that it can function as an auto-antigen. In patients suffering from MS, auto-antibodies against MOG have been found. Furthermore, the immunization of mice with MOG peptides results in an inflammatory, demyelinating disease called Experimental autoimmune encephalomyelitis (EAE), which is used as an animal model for inflammatory events in MS (Zamvil and Steinman, 1990).

\subsubsection{Myelin-associated glycoprotein}

Similar to MOG, the Myelin-associated glycoprotein (MAG) is a transmembrane protein of the Immunoglobulin superfamily and shows significant homology to the neural cell adhesion molecule (NCAM). Two different isoforms are known; the small S-MAG and the larger L-MAG. Theoretically, these proteins have a molecular weight of $64 \mathrm{kDa}$ and $69 \mathrm{kDa}$, but are much heavier due to a high degree of glycosylation.

MAG knockout mice show only mild neurological pathologies, in particular, CNS myelination is delayed and the animal exhibit abnormal formation of paranodal loops (Montag et al., 1994; Li et al., 1998).

\subsubsection{Minor myelin proteins}

Several other proteins are highly enriched in myelin, but show lower abundance. Tmem10 (Opalin), a type I single pass transmembrane protein, is one of these proteins (Kippert et al., 2008, Yoshikawa et al., 2008, Golan et al., 2008). Tmem10 is highly enriched in oligodendrocytes, it might interact with the actin cytoskeleton, but the physiological function of this protein is unknown (Kippert et al., 2008). Tmem10knockout mice do not exhibit any obvious phenotype.

Other myelin proteins have four transmembrane domains and belong to the family of tetraspanins. Examples are Claudin 11, MAL, CD81, and CD9. Claudin 11 has a molecular weight of $22 \mathrm{kDa}$ and belongs to the tight junction proteins. It is expressed in the brain, but also in testis. Knockout mice lack tight junctions in CNS myelin and between sertoli cells, these animals have mild neurological deficits such as hindlimb weakness and are infertile (Gow et al., 1999). The mice suffer from deafness due to the lack of tight junctions between basal cells (Gow et al., 2004, Kitajiri et al., 2004). Claudin 11 and PLP1 are both tetraspanins and knockout of both of these genes alone results in relatively mild phenotypes. Therefore, Chow et al. (2005) generated double knockout mice for PLP1 and Claudin 11. These mice had severe neurological problems including abnormal myelin compaction. 
The myelin and lymphocyte protein (MAL) is a lipid-raft-associated protein and predominantly expressed by Schwann cells and oligodendrocytes. An interesting point about this protein is that it seems to have different functions in CNS and PNS. Overexpression of MAL induces hypo-myelination in the PNS, while knockout animals show accelerated myelination, but nerves appear normal (Buser et al., 2009). The morphology of CNS nerves, however, seems to be altered in MAL knockout mice (Schaeren-Wiemers et al., 2004).

\subsection{Recent views on myelin protein composition}

As described above, previous studies on the abundance of myelin proteins were done by gel-based separation and staining for proteins. Based on these results, PLP1 and MBP isoforms would make up to $80 \%$ of total myelin proteins, while CNP1 would account for another 4-15\%. All other proteins were thought to have very low abundance. A recent proteomic study, however, revealed that these numbers are probably wrong. Jahn et al. (2009) purified myelin biochemically and performed labelfree, mass spectrometric quantification experiments. They found that PLP1, MBP and CNP1 together only contribute to $29 \%$ of all myelin proteins. As MOG, MAG, Sirtuin-1 and Claudin-11 account for only $1 \%$ each, there are at least another $67 \%$ of other proteins in myelin. The authors explained this difference by a low resolution of 1-D gel electrophoresis and the low dynamic range of protein staining.

These experiments question the predominant role of classical myelin proteins in oligodendrocyte biology. For instance, previously unrecognized proteins could contribute to the adhesive functions of PLP1.

As a consequence, these experiments indicate a previously underestimated contribution of other myelin proteins. Moreover, approximately $67 \%$ of other myelin proteins leave room for new, previously uncharacterized myelin proteins. 


\subsection{Differentiation of OPCs and myelin formation}

So far, I described the function and molecular composition of myelin. Next, I will explain where myelinating cells come from and how differentiation of these cells is regulated.

In the CNS, oligodendrocytes originate mainly from Subventricular Zone (SVZ) cells. These cells differentiate into OPCs. While some of the OPCs persist as adult oligodendroglial precursors, the majority of OPCs migrates within the brain, maturates to oligodendrocytes and eventually starts myelination. One oligodendrocyte can form several processes and myelinate up to 50 axonal tracts. This is a specific feature of oligodendrocytes, while Schwann cells can wrap their membrane only around one axonal segment.

The detailed timing of myelination varies between different regions of the nervous system; it starts in early postnatal life and usually continues into adulthood. In mice, spinal cord myelination takes starts around the postnatal day 4 (P4). Myelination of the corpus callosum starts about P14 and is mainly completed at P28 (W. Möbius, personal communications).

Once OPCs have been formed, these cells proliferate and migrate to the appropriate axons. They differentiate into pre-myelinating oligodendrocytes; which are more ramified cells that extend processes in order to find axons. After an initial contact has been established, oligodendrocytes start myelinating the axonal segment. The mature myelin sheath does not only enable rapid nerve cell conduction, but is also important for trophic support of the axon.

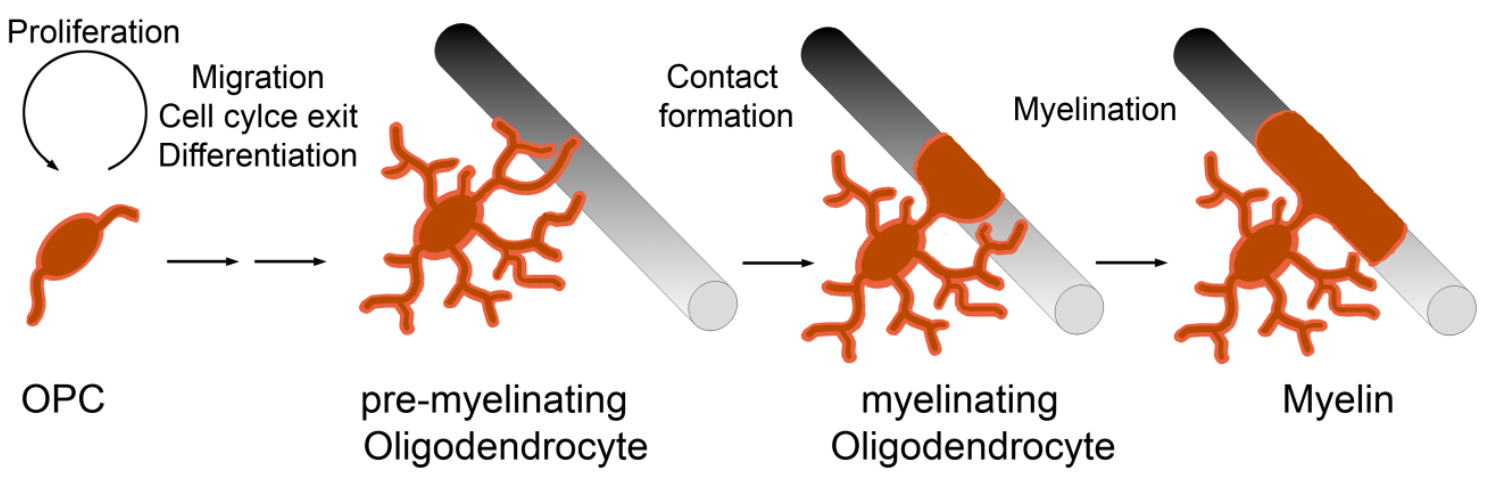

Fig. 1.4: Model of oligodendrocyte differentiation and myelination. OPCs migrate through the CNS, proliferate and differentiate into pre-myelinating oligodendrocytes. The oligodendrocytes extend numerous processes and contact neuronal axons. After an initial contact, oligodendrocytes start myelinating the axons. Established myelin sheaths enable rapid conduction of action potentials and provide trophic support [lllustrated using Adobe Photoshop]. 


\subsubsection{Migration and proliferation of OPCs}

Even though OPCs arise from the SVZ, oligodendrocytes in adults are distributed throughout the brain. Therefore, migration of OPC is an important step in the development of the nervous system.

It is not surprising that axonal proteins can mediate the migration of OPCs. Also different components of the extracellular matrix, such as fibronectin, can regulate OPC migration. Furthermore, secreted molecules from different sources influence OPC migration. Among these factors are the platelet-derived growth factor (PDGF), which is secreted by neuronal cells, the fibroblast growth factor 2 (FGF2) and the epidermal growth factor (EGF). PDGF and FGF2 work together to promote OPC migration, proliferation and differentiation. Detailed aspects of OPC migration have been reviewed by de Castro and Bribian (2005), Rajasekharan (2008) and de Castro et al. (2013).

OPCs cultured in the presence of PDGF proliferate but do not differentiate, while PDGF withdrawal induces cell cycle arrest (Raff et al., 1988). In-vivo studies with mice lacking PDGF showed premature cell cycle exit of OPCs, while overexpression of PDGF in neurons increased the number of OPCs (Fruttiger et al., 1999).

The presence of other growth factors such as FGF2 can even increase the proliferative effect of PDGF. When OPCs are treated with FGF2, the expression of PDGF-receptor alpha (PDGF-R $\alpha$ ) is increased, which might explain the synergistic effect of both factors (McKinnon et al., 1990). Even when OPCs are grown in the presence of PDGF and thyroid hormones in-vitro, they will eventually exit cell cycle and start to differentiate. An intrinsic mechanism called the "timer" limits the number of cell divisions or the time of proliferation.

Components of the timer are cyclin-dependent kinase inhibitors (CKIs), since these proteins regulate cell cycle progression by modulation of cyclins and cyclin-dependent kinases (Cdks). Tokumoko et al. (2002) identified the cyclin-dependent kinase inhibitors p27/Kip1 and p18/INK as components of the timer. Levels of both proteins increase during OPC proliferation and overexpression greatly slows down proliferation (Tokumoto et al., 2002). p57/Kip2 was found to be another component of the timer, it also accumulates during OPC proliferation and determines how many times OPCs can proliferate (Dugas et al., 2007).

While components of the timer regulate the number of cell divisions, exiting the cell cycle alone is not sufficient to induced oligodendrocyte differentiation. This can be explained by extrinsic and intrinsic signals that inhibit OPC differentiation. 


\subsubsection{Inhibitory signals keep OPCs in the precursor state}

OPCs are maintained in a precursor state by various signaling pathways; overcoming these inhibitory signals and further activation is necessary for differentiation. Therefore, I will briefly introduce the three major repressors of differentiation; these are the Notch/Hes5 pathway, the Wnt/beta-catenin pathway and the BMP/ID-pathway.

The single-pass transmembrane receptor Notch is involved in various differentiation processes. Most ligands for this receptor are also transmembrane proteins, such as Delta-like proteins (DLLs), Jagged-proteins and probably F3/contactin (Lai et al., 2004). Notch on OPCs can be activated by Jagged-1, which is present on neuronal axons, and that this interaction represses OPC differentiation (Wang et al., 1996).

Studies in knockout mice further showed that a conditional inactivation of Notch-1 in OPCs leads to a premature oligodendrocyte differentiation (Genoud et al., 2002). The downstream effector of Notch is the transcription factor Hes5, which has an inhibitory effect on myelin gene expression. Consistent with this, Hes5 knockout mice show increased levels of myelin proteins (Liu et al., 2006). Surprisingly, Hu et al. (2003) found that the binding of a different Notch ligand, F3/contactin, can facilitate oligodendrocyte maturation.

The second inhibitory pathway for OPC differentiation is the Wnt signaling. The family of Wnt ligands comprises 19 secreted proteins. These proteins can control cellular processes by canonical and non-canonical pathways. In the canonical pathway, Wnt binds to its receptors frizzled and induces the stabilization of beta-catenin in the cytoplasm. This stabilization is achieved by the inactivation of a catenin-destruction complex. Upon accumulation in the cytoplasm, beta-catenin can translocate into the nucleus and activate transcription factors of the TCF-family. In OPCs, canonical Wnt signaling leads to an activation of TCF4. TCF4, in turn, induces the expression of the inhibitory proteins ID2 and ID4.

Together with bone morphogenic proteins (BMPs), ID2 and ID4 build the third line of differentiation inhibitions. These proteins bind to the myelin transcription factors Olig1, Olig2 and Ascl1/Mash1 and impede their activity.

Taken together, Notch-signaling, canonical Wnt signaling and BMP/ID-proteins are responsible to prevent a premature differentiation of oligodendrocyte precursor cells. At the right time point, these repressive mechanisms need to be overcome to allow oligodendrocyte differentiation. This is, in part, mediated by chromatin remodeling. 


\subsubsection{Chromatin remodeling is a first step towards differentiation of OPCs}

Even though all cells in the body share the same genomic information, cellular identity is obtained by the expression of particular gene products. In stem and precursor cells, specific signaling pathways hinder the expression of lineage specific genes and thereby block differentiation. This very general principle also applies to OPCs.

The first step towards lineage specification and differentiation is the epigenetic inactivation of inhibitory signals. The DNA binding histone proteins are usually acetylated in order to weaken the interaction with the DNA; this allows an expansion of the DNA and permits transcription of these unpacked regions. Histone deacetylases (HDACs) in turn can remove the acetyl residues of histones, which increases their binding to DNA and, as a consequence, blocks the transcription.

When HDACs become active in OPCs, they can silence the inhibitory pathways that keep the cells in a precursor state, and therefore enable differentiation. Treatment of OPCs with HDAC inhibitors, in turn, leads to impaired differentiation (Marin-Husstege et al., 2002). Moreover, conditional knock-out of HDACs in Schwann cells resulted in severe hypo-myelination and early death of the animals (Chen et al., 2011).

\subsubsection{Intrinsic Factors actively promote oligodendrocyte differentiation}

\section{Retinoic acid and thyroid hormone receptors}

Once the inhibitory signals that maintain OPCs in the precursor state are overcome, certain factors within the cells promote oligodendrocyte differentiation and myelination. Among these factors are nuclear hormon receptors such as retinoic acid receptors and thyroid hormone receptors. It was shown for instance that retinoic acid triggers differentiation of the OPC-derived Oli-neu cells (Gobert et al., 2009) and accelerates CNS remyelination (Huang et al., 2011).

The role of thyroid hormones in oligodendrocyte differentiation was demonstrated in various animal models: Hypo-thyroid rodents are hypo-myelinated and have decreased numbers of oligodendrocytes in the optic nerve (Ahlgren et al., 1997). The same observations were made in thyroid hormone receptor deficient mice (Baas et al., 2002). Consistent with these data, hyperthyroid mice exhibit faster oligodendrocyte differentiation and accelerated rates of myelination (Walters and Morell, 1981).

While these effects of retinoic acid and thyroid hormones are known, the downstream gene targets of their receptors still have to be identified. 


\section{Basic helix-loop-helix transcription factors}

Basic helix-loop-helix (bHLH) transcription factors are a class of transcription factors that are in general important for development and cell differentiation. Members of this class are for instance c-Myc and n-Myc, which have been linked to cancer, but also the hypoxia-inducible-factor (HIF). In oligodendrocytes, the bHLH-transcription factors Olig1, Olig2 and Ascl1/Mash1 play important roles.

Two different Olig1 knockout mice with different phenotypes have been described: The first Olig1-deficient mouse was described to develop normally, but after demyelination these animals failed to remyelinate (Arnett et al., 2004). A second Olig1knockout mouse was generated in a different group. These mice exhibit severe neurological symptoms such as tremor and seizures and die within 17 days after birth (Xin et al., 2005). In Olig1/Olig2 double knockout mice, oligodendrocyte precursor cells are completely abolished, but also motor neurons are largely missing. The authors suggest that Olig1 and Olig2 together are responsible for differentiation of progenitors into glial subtypes and neurons (Zhou and Anderson, 2002).

Originally, Ascl1/Mash1 has been described in neuronal precursor cell differentiation. Homozygous Ascl1-knockout mice die at birth, probably due to breathing problems (Guillemont et al., 1993). In later experiments, cells of Ascl1-deficient mice were transplanted into the subventricular zone of wildtype mice and found a drastically reduced formation of mature oligodendrocytes. Therefore, the authors concluded that Ascl1/Mash1 is important for oligodendrocyte differentiation (Parras et al., 2004). Later experiments confirmed that Ascl1 is necessary for oligodendrocyte differentiation in the spinal cord (Sugimori et al., 2008).

\section{Sox-family transcription factors}

All Sox proteins are transcription factors with a homologous sequence called highmotility group (HMG). There are more than 20 Sox proteins, and all of them are involved in different aspects of development. This particular family of transcription factors has been extensively studied by Michael Wegner's group. Especially Sox10 seems to be a key transcription factor in oligodendrocyte differentiation. A recent review summarizes the current knowledge of Sox-proteins and highlights important roles of Sox10 in chromatin remodeling and discusses interactions with other protein complexes (Weider, 2013). 


\section{Zinc finger transcription factors}

At least three zinc finger proteins are known to mediate myelin gene expression: Yin-yang-1 (Yy1), the Zinc finger protein 488 (Zfp488) and the Myelin transcription factor 1 (Myt1).

The protein Yy1 is a transcription factor, but also exhibits other biological functions: It is, for instance, involved in chromatin remodeling. In oligodendroglial cell lines, Yy1 was shown to bind to the PLP1 promoter and enhances PLP1 transcription (Berndt et al., 2001). Other studies, however, showed that Yy1 can also function as a repressor of PLP1 gene expression (Zolova and Wight, 2011).

Inactivation of Yy1 in the oligodendrocyte lineage using CNP-Cre resulted in mice with ataxia, tremor and overall defects in myelination. Yy1 further functions as a repressor of the differentiation-inhibitors ID4 and TCF4 (He et al., 2007).

Recent studies even indicate an involvement of Yy1 in adult-onset autosomal-dominant leukodystrophy (ADLD), a disease with loss of white matter in the CNS. This disease is caused by a duplication of the lamin B1 gene. Heng et al. (2013) generated mice overexpressing lamin B1 and found a down-regulation of PLP1 and that this effect is may be caused by a reduced binding of Yy1 to the PLP1 promoter region.

Relatively little is known about molecular aspects of zinc finger protein Zfp488. This protein was identified by Wang et al. (2006), when they searched for genes downregulated in Olig1-deficient mice. The co-expression of Zfp488 and Olig2 in neural tubes of chicken embryos let to ectopic and precocious oligodendrocyte differentiation. They further found that Olig2 and Zfp488 physically interact and that siRNA-mediated knockdown of Zfp488 in an oligodendroglial cell line decreased myelin gene expression. In further experiments, Zfp488 was overexpressed in the subventricular zone of adult mice and demyelination induced via Cuprizone treatment. In this study, Zfp488-transduced mice showed a significantly improved restoration of motor function. These findings might indicate an involvement of Zfp488 in remyelination (Soundarapandian et al., 2011).

The Myelin transcription factor 1 (Myt1) was found in brain tumor samples by Armstrong et al. (1997). This protein can bind to the PLP1 promoter (Kim et al., 1997) and seems to modulate oligodendrocyte proliferation and differentiation (Nielsen et al., 2004). Vana et al. (2007) infected mice with murine hepatitis virus A59 to induce demyelination of the spinal cord. They found an upregulation of Myt1 in these lesions and during remyelination. Similar observations were made in multiple sclerosis lesions, which suggest an involvement of Myt1 in both murine and human remyelination. 


\section{Myelin Gene Regulatory Factor}

A potential master regulator of oligodendrocyte differentiation was found by Emery et al., 2009. They performed expression profiling of immuno-panned brain cells and identified MRF as an oligodendrocyte-specific transcription factor. RNAi-mediated knockdown resulted in a diminished differentiation of oligodendrocytes. Overexpression of MRF resulted in myelin gene expression in spinal cords of chicken embryos. Conditional knockout of MRF in mice led to severe dysmyelination and death of the animals within the first three weeks of life.

In a recent follow up study, an inducible PLP1-Cre was used to inactivate MRF in oligodendrocytes of adult mice. The inactivation resulted in demyelination, inhibition of myelin gene expression and, eventually, loss of mature oligodendrocytes. These findings suggest that MRF is not only necessary for precursor cell differentiation, but also crucial for oligodendrocyte survival (Koenning et al., 2012).

\subsubsection{Myelination - Contact formation, wrapping, trophic support}

After differentiation, oligodendrocytes extent huge amounts of membrane, which can be spirally wrapped around axonal tracts. Several models for the wrapping process have been suggested (Bauer et al., 2009). Recent electron microscopy studies show that the myelin membrane wraps in several layers, before compation actually starts from the outer part of the myelin sheath (Snaierdo et al., 2014).

More important for us is, how oligodendrocyte processes recognize axons and vice versa. It is known that only axons of a certain diameter are myelinated, while thinner axons remain non-myelinated. Furthermore, it is known that electric activity of axons is important for myelination. On a molecular level, the neuronal cell adhesion molecule (PSA-NCAM), Gpr17 and Lingo seem to regulate the timing of myelination by oligodendrocytes, but they do not seem to regulate the extent of myelination (recently reviewed by Simons and Lyons, 2013).

Another open question regarding myelination is how oligodendrocytes exhibit trophic support towards neurons. While it has been shown that oligodendrocytes are metabolically coupled to axons (Fünfschilling et al., 2012), it is not clear if there are additional oligodendroglial factors that mediate axonal integrity and survival of neurons. 


\subsection{Oligodendrocyte differentiation in vitro}

Myelination in-vivo obviously requires the presence of axons which can be enwrapped by oligodendrocyte membrane. However, differentiation of oligodendrocytes per se can also be observed in primary cell cultures of OPCs without neurons.

OPCs can be harvested from glial mixed cultures and maintained in vitro. When cultured in an appropriate medium with thyroid hormones, insulin and transferrin, these cells can differentiate into mature oligodendrocytes (Sommer and Schachner, 1981).

Cultured OPCs first show a bipolar morphology and are immuno-reactive for markers such as the platelet-derived growth factor receptor alpha (PDGFR $\alpha$ ). Within one day, processes branch out and cells form a complex network. At this point, cells become immuno-reactive for the $\mathrm{O} 4$ antibody, which recognizes sulfatides. The cells continue to branch and express galactosyl lipids that can be recognized by $\mathrm{O} 1$ antibody. After approximately four days in culture, oligodendrocytes exhibit flat, MBP-positive membrane sheets and non-compacted, CNP1-positive channels (Fig. 1.4).

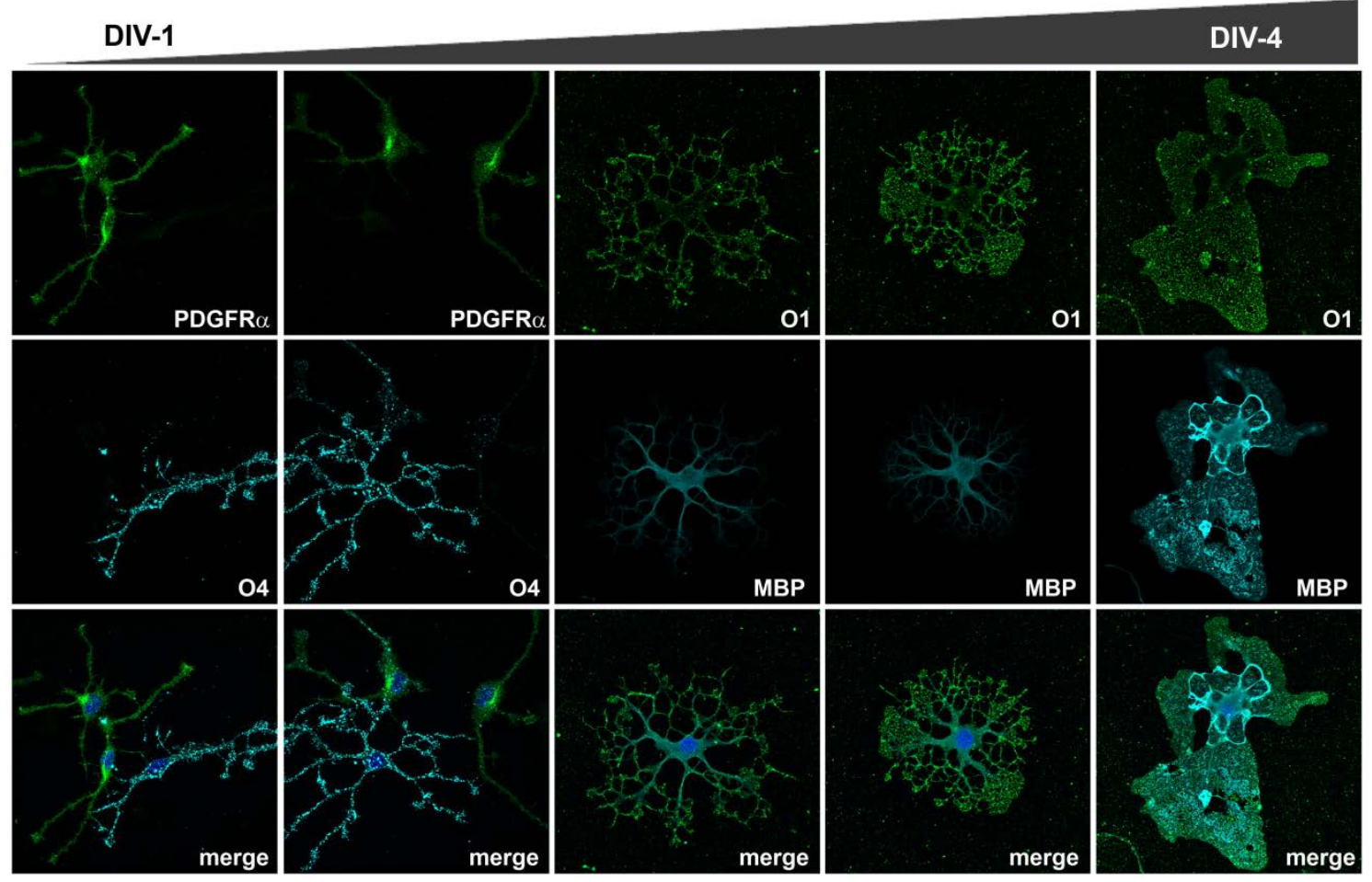

Fig. 1.4: Stages of oligodendrocyte differentiation. Very young oligodendrocytes are positive for PDGFR $\alpha$. A little later, they become O4-positive and PDGFR $\alpha$-negative. Upon further differentiation, cells are O1-positive and, subsequently, start expressing MBP.

Previous studies from our lab showed that oligodendrocytes differentiated in vitro basically resemble oligodendrocytes in vivo regarding protein composition and polarization. Therefore, we see oligodendrocytes in vitro as a model system to study the influence of different factors on oligodendrocyte differentiation. 


\subsection{Aims of this study}

Oligodendrocytes are the myelin forming cells in the CNS and a target in demyelinating diseases such as MS. Oligodendrocyte differentiation can be studied in-vitro using primary OPC cultures. Even in the absence of neurons, these cells form large, myelinlike membrane sheets. The overall goal of this thesis was to contribute knowledge about how oligodendrocytes in cell culture form myelin-like membrane sheets. From a molecular point of view, we wanted to know which proteins are differentially expressed during oligodendrocyte maturation and membrane sheet formation. In particular, the aims were:

Aim 1: To identify gene products differently expressed during oligodendrocyte differentiation. Previous proteomic profiling studies on oligodendrocytes and myelin struggled from low coverage of the proteome. Transcriptomic studies were limited to microarray analysis, which does not allow a really quantitative analysis. Therefore, we wanted to:

a) Perform an in-depth proteomic analysis of highly pure primary cell cultures.

b) Run transcriptomic profiling experiments using next-generation-sequencing.

c) Analyze datasets for statistically enriched, novel oligodendrocyte proteins.

Aim 2: To perform a biological characterization of a promising candidate gene. At least one candidate protein should be further characterized in biological experiments. For this we wanted to:

a) Confirm expression by quantitative real-time PCR

b) Generate a transgenic mouse model with a targeted mutation for the particular gene. This mouse should be further crossbred with appropriate cre-recombinase mice to allow oligodendrocyte-specific knockout. 


\section{Chapter II: Materials and Methods}

\subsection{General consumables}

In general, chemicals were purchased from AppliChem, Invitrogen,Merck and SigmaAldrich. Plastic-ware and other consumables were purchased from Eppendorf, Falcon and Starlab. Other companies are indicated when products are mentioned.

\subsection{Animal work}

Animals were kept in the animal facility of the Max-Planck-Institute of Experimental Medicine in a standard $12 \mathrm{~h}$ light/dark-cycle with water and food ad libidum. All procedures were performed according to the Lower Saxony State regulations for animal experimentation. Lsamp knockout mice (Innos et al., 2011) were kept and perfused in Tartu, Estonia. During this work, the following mouse lines were used:

Tab. 2.1 Mice used in this thesis

\begin{tabular}{lll}
\hline Mouse line & Description & Source \\
\hline E2A Cre & ubiquitous Cre expression under E2A promotor & provided by K.A. Nave \\
FLIR & ubiquitous expression of Flip-recombinase & provided by K.A. Nave \\
CNP-Cre & Cre expression under CNP-promotor & provided by K.A. Nave \\
BCASFX & floxed Bcas1 with LacZ/Neo casette & generated in this study \\
BCAS1 fl/fl & floxed Bcas1 without LacZ/Neo casette & generated in this study \\
BCAS1 fl/fl X CNP-Cre & conditional deletion of Bcas1 in myelinating cells & generated in this study \\
NBCAS & conventional knockout of Bcas1 & generated in this study \\
\hline
\end{tabular}

\subsubsection{Fixation by intra-cardial perfusion}

For the preparation of brain and spinal cord sections, mice were anaesthetized, blood was removed and tissue was fixed by intra-cardial perfusion.

Avertin-Solution

Phosphate-buffered saline

$16 \%$ PFA stock solution
$1.0 \mathrm{~g}$ Tribromoethanol, $0.81 \mathrm{ml}$ Amyl alcohol and $71.5 \mathrm{ml}$ Millipore- $\mathrm{H}_{2} \mathrm{O}$ are mixed and dissolved by incubating at $37^{\circ} \mathrm{C}$ for $10 \mathrm{~min}$. The solution is sterilized by filtration and stored in a dark bottle at $4^{\circ} \mathrm{C}$.

$137 \mathrm{mM} \mathrm{NaCl}, 2.7 \mathrm{mM} \mathrm{Kcl,100} \mathrm{mM} \mathrm{Na} 2 \mathrm{HPO} 4$, and $1.8 \mathrm{mM} \mathrm{KH} 2 \mathrm{PO} 4$ in dd $2 \mathrm{O}$.

$16 \mathrm{~g}$ Para-formaldehyde in approx. $70 \mathrm{ml}$ Millipore- $\mathrm{H} 2 \mathrm{O}$ were heated to $57^{\circ} \mathrm{C}$. $\mathrm{NaOH}$ was added until all PFA was dissolved. $10 \mathrm{ml}$ of $10 \mathrm{x}$ PBS were added, the $\mathrm{pH}$ was adjusted to 7.4 and the solution was filled up to $100 \mathrm{ml}$ with Millipore- $\mathrm{H}_{2} \mathrm{O}$. 
$4 \%$ PFA working solution $50 \mathrm{ml}$ of $16 \%$ PFA stock were thawn and combined with $150 \mathrm{ml}$ of $1 x$ PBS. The solution was stored at $4^{\circ} \mathrm{C}$.

Mice were anaesthetized by intra-peritoneal injection of a lethal dose of Avertin solution $(500 \mu \mathrm{l})$. To ensure that the mice were properly seduced, the toes were pinched. If the mice did not respond, abdomen was wetted with ethanol and skin was opened at the level of the diaphragm. After cutting the diaphragm, the rips were cut laterally to expose the heart. A butterfly needle was placed into the left ventricle, pump was turned on and the right artrium was right opend immediately. The animal was perfused for 5 min with PBS to wash out the blood, then perfusion was continued for another 15 min with $4 \%$ PFA/PBS.

\subsubsection{Brain and spinal cord slice preparation}

Phosphate-buffered saline see 2.2.1!

Sucrose in PBS $\quad 30 \%$ Sucrose in PBS (w/v)

Tissue-Tek® O.C.T. medium

After perfusion fixation, brains of the mice were extracted and post-fixed overnight in 4\% PFA. For cryo-sections, post-fixed brains were transferred to $30 \%$ sucrose and kept in this solution at $4^{\circ} \mathrm{C}$ until saturated (1-2 days). Then, brains were frozen on dry ice, wrapped in aluminium foil and frozen at $-80^{\circ} \mathrm{C}$ overnight. The next day, brains were transferred to $-20^{\circ} \mathrm{C}$.

For spinal cord preparation, the vertebral column of perfusion fixated animals was cut and post-fixed overnight in $4 \%$ PFA/PBS. Then, bones were cut with a pair of scissors to extract the spinal cord. Spinal cords were immersed in $30 \%$ sucrose overnight, frozen on dry ice in a line of Tissue-Tek $₫$ medium and stored at $-80^{\circ} \mathrm{C}$.

Frozen brains were cut into $25 \mu \mathrm{m}$ sections using a Leica CM 1900 Cryostate. Slices were collected in 24-well plates with PBS and stored at $4^{\circ} \mathrm{C}$ until further used.

\subsubsection{Immuno-histochemistry (IHC)}

Citrate stock solution A $\quad 100 \mathrm{mM}$ Citric acid solution in $\mathrm{dd}_{2} \mathrm{O}$

Citrate stock solution $\mathrm{B} \quad 100 \mathrm{mM}$ Sodium citrate solution in $\mathrm{dd}_{2} \mathrm{O}$

$\mathrm{NaOH}$ solution $\quad 1 \mathrm{M}$ in $\mathrm{dd}_{2} \mathrm{O}$

Citrate buffer

$3 \mathrm{ml}$ stock solution $\mathrm{A}$ and $17 \mathrm{ml}$ stock solution $\mathrm{B}$ were combined, $\mathrm{pH}$ was adjusted to 6.0 with $\mathrm{NaOH}$ and diluted 1:10 with $\mathrm{ddH}_{2} \mathrm{O}$ 
Permeabilization buffer

Blocking solution

Antibody dilution buffer

DAPI stock solution
$0.5 \%$ Triton-X-100 in PBS (v/v)

$5 \%$ Horse serum and $0.5 \%$ Triton-X-100 in PBS (v/v)

$3 \%$ Horse serum and $0.5 \%$ Triton-X-100 in PBS (v/v)

$0.25 \mathrm{~g} / \mathrm{ml} 4$, 6 -Diamidin-2-phenylindole in ddH2O

DAPI staining solutionstock solution diluted $1: 1000$ in permeabilization buffer

Mowiol mounting medium

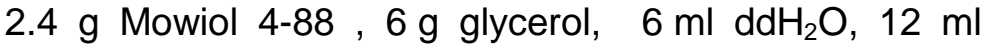
$200 \mathrm{mM}$ Tris/ $\mathrm{HCl} \mathrm{pH}$ 8.5, $2.5 \%$ DABCO

Brain slices were transferred onto Super-frost glass slides and dried over night at room temperature. Sections were rinsed three times for 5 min with PBS. For antigen retrieval, slides were transferred into Citrate Buffer and boiled in a microwave oven for $2 \mathrm{~min}$. This procedure was repeated three times with fresh buffer. Sections were chilled in $\mathrm{ddH}_{2} \mathrm{O}$ for 5 min and washed three times for 5 min with PBS.

The tissue was permeabilized by incubation with Permeabilization buffer for 60 min, blocked with Blocking solution for another $60 \mathrm{~min}$ and incubated with antibodies in antibody dilution buffer over night at $4^{\circ} \mathrm{C}$. After five consecutive washing steps with PBS for $10 \mathrm{~min}$, slices were incubated with secondary antibodies in antibody dilution buffer for $90 \mathrm{~min}$, followed by three further washing steps. For staining of nuclei, slices were incubated with DAPI staining solution for 15 min, washed five times with PBS and rinsed with ddH2O. Slices were air-dried and mounted in Mowiol medium.

\subsubsection{Light microscopy of tissue slices}

Images were obtained using a Leica DM6000 fluorescent microscope using a 20x Objective and the Leica LAS AF software package. Stitching of single images to a composite picture was performed by the software. Images were processed using Adobe Photoshop and Adobe Illustrator.

\subsubsection{Electron microscopy}

Tissue removal was basically performed as described for immunohistochemistry with some modifications. The tissue preparation and embedding was performed according to established protocols in the Electron Microscopy Facility of the MPI of Experimental Medicine (Werner et al., 2013; Snaidero et al., 2014).

$200 \mathrm{mM}$ Phosphate buffer: $20 \mathrm{ml}$ of $200 \mathrm{mM} \mathrm{NaH}_{2} \mathrm{PO}_{4}$ and $80 \mathrm{ml}$ of $200 \mathrm{mM} \mathrm{Na}_{2} \mathrm{HP}_{4}$ were combined. 
Karlsson-Schulz-Fixative

$4 \%$ PFA, $2.5 \%$ Glutaraldehyde, $1 \% \mathrm{NaCl}$ in $200 \mathrm{mM}$

Phosphate buffer

Mice were anesthetized by injection of avertine and intra-cardially perfused with $5 \mathrm{ml}$ of Hank's buffer salt solution (HBSS) followed by $40 \mathrm{ml}$ of Karlsson-Schulz fixative. Brain including optic nerve and spinal cord were extracted and post-fixed over night at $4^{\circ} \mathrm{C}$.

Tab. 2.1 Procedure of Epon embedding for electron microscopy

\begin{tabular}{lcc}
\hline Reagent & Duration & Temperature \\
\hline $100 \mathrm{mM}$ phosphate buffer & $10 \mathrm{~min}$ & $4^{\circ} \mathrm{C}$ \\
$100 \mathrm{mM}$ phosphate buffer & $10 \mathrm{~min}$ & $4^{\circ} \mathrm{C}$ \\
$100 \mathrm{mM}$ phosphate buffer & $10 \mathrm{~min}$ & $4^{\circ} \mathrm{C}$ \\
$0.2 \%$ OsO4 in $100 \mathrm{mM}$ phosphate buffer & $4 \mathrm{hrs}$ & $4^{\circ} \mathrm{C}$ \\
$100 \mathrm{mM}$ phosphate buffer & $10 \mathrm{~min}$ & $4^{\circ} \mathrm{C}$ \\
$100 \mathrm{mM}$ phosphate buffer & $10 \mathrm{~min}$ & $4^{\circ} \mathrm{C}$ \\
$100 \mathrm{mM}$ phosphate buffer & $10 \mathrm{~min}$ & $4^{\circ} \mathrm{C}$ \\
$30 \%$ ethanol & $20 \mathrm{~min}$ & $4^{\circ} \mathrm{C}$ \\
$50 \%$ ethanol & $20 \mathrm{~min}$ & $4^{\circ} \mathrm{C}$ \\
$70 \%$ ethanol & $20 \mathrm{~min}$ & $4^{\circ} \mathrm{C}$ \\
$90 \%$ ethanol & $20 \mathrm{~min}$ & $4^{\circ} \mathrm{C}$ \\
$100 \%$ ethanol & $10 \mathrm{~min}$ & $4^{\circ} \mathrm{C}$ \\
$100 \%$ ethanol & $10 \mathrm{~min}$ & $4^{\circ} \mathrm{C}$ \\
$100 \%$ ethanol & $10 \mathrm{~min}$ & $4^{\circ} \mathrm{C}$ \\
isopropanol & $10 \mathrm{~min}$ & $4^{\circ} \mathrm{C}$ \\
propylene oxide & $10 \mathrm{~min}$ & $\mathrm{RT}$ \\
propylene oxide & $10 \mathrm{~min}$ & $\mathrm{RT}$ \\
propylene oxide & $10 \mathrm{~min}$ & $\mathrm{RT}$ \\
propylen oxide / Epon $(2: 1)$ & $2 \mathrm{hrs}$ & $\mathrm{RT}$ \\
propylen oxide / Epon $(1: 1)$ & $2 \mathrm{hrs}$ & $\mathrm{RT}$ \\
propylen oxide / Epon $(1: 2)$ & $4 \mathrm{hrs}$ & $\mathrm{RT}$ \\
Epon & $4 \mathrm{hrs}$ & $\mathrm{RT}$ \\
\hline
\end{tabular}

Entire nerves or brain punches were embedded in Epon (Tab. 2.2), ultrathin sections were prepared and contrasted with 1\% uranyl acetate and lead citrate. Electron micrographs were taken on a LEO 912AB electron microscope (Zeiss) using an on-axis $2048 \times 2480$ charge coupled device camera (Proscan).

The areas of both axon alone and axon with myelin sheath were measured, diameter of a circle with the area was calculated and g-ratio was determined by dividing axonal diameter by myelinated diameter. 


\subsection{Tissue culture methods}

All cell culture techniques were performed in a Class II biological safety cabinet. All materials, media and solutions were sterilized by autoclaving or filtration. Cell culture solutions, such as HBSS, Trypsin/EDTA, GlutaMAX, antibiotics and supplements were purchased from Gibco/Invitrogen. Generally used solutions included:

Poly-L-lysine stock (50 x) $1.0 \mathrm{~g}$ Poly-L-Lysine hydrobromide in $250 \mathrm{ml}$ PBS

PLL for primary cells $\quad 10 \mathrm{ml}$ of $50 \times$ PLL stock in $500 \mathrm{ml}$ PBS

Heat-inactivated serum $\quad$ Serum was incubated at $56^{\circ} \mathrm{C}$ for $30 \mathrm{~min}$

Triiodoithyronine $\quad 5 \mathrm{mM}$ stock solution in $96 \%$ ethanol

L-Thyroxin $\quad 4 \mathrm{mM}$ stock solution in $0.25 \mathrm{M} \mathrm{NaOH}, 25 \%$ ethanol

Putrescin $\quad 10 \mathrm{mM}$ stock solution in DMEM

Preparation of Coverslips Glass coverslips were treated with concentrated $\mathrm{HCl}$ (37\%) overnight, washed with $\mathrm{dd}_{2} \mathrm{O}$ and dried on parafilm. Then, coverslips were baked at $200^{\circ} \mathrm{C}$ for $6 \mathrm{~h}$.

\subsubsection{Handling of cell-lines}

The major cell-lines used in this thesis were the OPC cell line Oli-neu (Jung et al., 1995) and the breast cancer cell line SKBR3 (Trempe, 1976).

PLL for cell-lines

$3 \mathrm{ml}$ of $50 \times$ PLL stock in $500 \mathrm{ml}$ PBS

DMEM-Medium

DMEM supplemented with 10\% Horse serum, $1 \times$

GlutaMax, and 1 x Pen/Strep

Oli-neu Sato-Medium

DMEM supplemented with $1 \%$ ITSA supplement, $1 \mathrm{x}$ GlutaMax, 1 x Pen/Strep, 5 \% Horse Serum, 500 pM Triiodo-Thyronine (TiT), 520 pM L-Thyroxine, 200 nM Progesterone, and $100 \mu \mathrm{M}$ Putrescein

Oli-neu cells were grown on PLL-coated cell culture dishes or glass coverslips. Oli-neu Sato medium was used as a growth medium. SKBR3 cells were also cultured on PLLcoated cell culture material, DMEM medium was used. Cells were transfected using the Trans-IT transfection reagent (Mirus-Bio) according to the manufacturer's guidelines. 


\subsubsection{Cryo-preservation of mammalian cell lines}

Mammalian cell lines were cryo-preserved to avoid aging, minimize genetic changes and loss by contamination.

Freezing medium

$50 \%$ FCS, $10 \%$ DMSO in DMEM

Cells were detached from culture dishes by trypsinization, pelleted by centrifugation and resuspended in freezing medium (approx. 1x10^7 cells $/ \mathrm{ml}$ ). The suspension was aliquoted into cryogenic storage vials and cooled down to $-80^{\circ} \mathrm{C}$ at a cooling rate of $1^{\circ} \mathrm{C} / \mathrm{min}$. The next day, cells were transferred to liquid nitrogen storage.

For thawing, cells were removed from the storage, thawn in $a 37^{\circ} \mathrm{C}$ water bath and transferred into a centrifugation tube with pre-warmed growth medium. After pelleting ( $5 \mathrm{~min}, 900 \times \mathrm{g}, 37^{\circ} \mathrm{C}$ ), the cells were resuspended in growth medium and plated on prepared cell-culture dishes.

\subsubsection{Glial mixed cultures}

The preparation of primary cell cultures was performed according to our previously described protocol (Trajkovic et al., 2006) with varius modifications. Primary glial mixed cultures were prepared from newborn NMRI-mice and separated into microglia; oligodendrocyte precursor cells (OPCs) and astrocytes by differential shaking.

BME growth medium

BME supplemented with $10 \%$ Horse serum, $1 x$ GlutaMax, and $1 \times$ Pen/Strep

In order to prepare the glial mixed cultures, newborn mice (P1) were decapitated; the brains were exposed by a midline incision and transferred into Hanks Buffered Saline Solution (HBSS). Under a dissection microscope, the meninges were removed and the hindbrains were discarded. A total of 5 brains were pooled and incubated with $0.25 \%$ trypsin/EDTA at $37^{\circ} \mathrm{C}$ for $10 \mathrm{~min}$. The tissues were washed twice with BME growth medium and further dissociated by trituration (10-times) using a glass pipette. The cell suspension was passed through a cell sieve and subsequently plated onto 5 PLL-coated cell culture flasks with BME growth medium. Two thirds of the growth medium was exchanged twice a week.

\subsubsection{Primary oligodendrocyte precursor cells}

Primary oligodendrocyte precursor cells were obtained from glial mixed cultures and differentiated in "Super-Sato"-medium.

"Super-Sato"-medium DMEM supplemented with $2 \%$ B27 supplement, $1 \mathrm{x}$ GlutaMax, 1 x Pen/Strep, $110 \mu \mathrm{g} / \mathrm{ml}$ Sodium pyruvate, 
$1 \%$ Horse Serum, 500 pM Tri-iodo-Thyronine (TiT), 520 pM L-Thyroxine

10 days after plating the glial mixed cultures, microglia were removed by gentle, manual shaking, leaving a culture that consisting of OPCs on top of a confluent layer of astrocytes. The next day, OPCs were shaken off by hand and pelleted by centrifugation. The OPC-pellet was re-suspended in Super Sato differentiation medium. The OPC suspension was transferred into an untreated cell culture dish and incubated at $37^{\circ} \mathrm{C}$ for $3 \mathrm{~min}$. During this time, contaminating microglia and astrocytes adhered to the culture dish, while OPCs remained in suspension. This step was repeated a second time, to yield highly pure OPC cultures. These cells were plated onto PLL-coated cell culture dishes or glass cover slips with Super Sato. The day of OPC plating was defined as DIV-0 and cells were harvested for experiments at the subsequent days.

\subsubsection{Astrocyte cultures}

DMEM growth medium

DMEM supplemented with $10 \%$ Fetal calf serum, $1 \mathrm{x}$ GlutaMax, and 1 x Pen/Strep

After shaking off the OPCs, fresh DMEM growth medium was added to the remaining astrocytes and the cells were allowed to recover for 72 hours. The astrocytes were then harvested for further experiments. The purity of these cells was determined separately by trypsinization, seeding onto PLL-coated coverslips and immuno-staining after 48 hours.

\subsubsection{Microglia cultures}

The preparation of microglia was performed as described previously (Regen et al., 2011). In brief, glial mixed cultures were treated with microglia colony stimulating factor (MCSF) to enhance microglia proliferation. After 3 days, microglia were harvested by gentle shaking and seeded onto PLL-coated cell culture dishes with DMEM growth medium (see 2.3.5!). After another 3 days, cells were used for experiments.

\subsubsection{Cortical neurons}

Cultures of cortical neuron were prepared from embryonic mice at E16.5 as described by Schneider et al., 2006 with minor modifications. Pregnant NMRI mice were euthanized by cervical dislocation and opened to reveal the embryos. The embryos were decapitated; the brains were exposed by a midline incision and transferred into HBSS. Meninges were stripped from the surface of the brain and hindbrain was discarded. 3 brains were pooled, treated with $0.25 \%$ trypsin/EDTA for $10 \mathrm{~min}$ and washed with neuronal growth medium (MEM with B27-supplement, $0.6 \%$ Glucose, $0.22 \%$ Bicarbonate, Pyruvate, Glutamax, Penicillin and Streptomycin). Cells were 
plated onto PLL-coated cell culture dishes with neuronal medium. After 16 hours, Cytosine arabinoside (AraC) was added in a final concentration of $4 \mu \mathrm{M}$. The addition was repeated the second day after plating. The third day, AraC was washed out and cells were cultivated in normal growth medium until day 5 , day 10 , and day 16 , respectively.

\subsubsection{Preparation of mouse embryonic fibroblasts}

Mouse embryonic fibroblasts (MEF) were obtained from embryonic mice (E15.5). The embryos were extracted from the pregnant mother, the head and inner organs were removed. The remaining tissue was digested with $0.25 \%$ trypsin/EDTA for $10 \mathrm{~min}$ and dissociated by tirturation. The cells were grown on untreated cell culture flasks with DMEM medium (see 2.3.5!) until the cell layer was confluent. Medium was changed twice a week to remove cell debris. After four passages, a pure MEF-cell culture was achieved.

\subsubsection{Treatment of cell cultures}

When cells were treated with drugs, the compounds were usually used as working solutions dissolved in DMSO. For treatment, approximately half of the growth medium of the cells was transferred into an Eppendorf tube, the appropriate amount of drug solution was added, mixed and the media was given back to the cells. For controls, the same volume of the drug solvent was used.

\subsubsection{Transfection of cell cultures}

Oli-neu and SKBR3 cells were transiently transfected with a pcDNA3.1 (+) plasmid with the coding sequence of murine Bcas1 with a C-terminal myc tag connected by a Gly4linker. The pmaxGFP (Lonza) was used as a control. Transfections were performed using Mirus Trans-IT according to the manufacturer's recommendations.

\subsubsection{Immunocytochemisty}

Immuno-staining of cells was performed in order to determine the purity of cell preparations and to visualize the localization of proteins with the cells. Staining was essentially performed as described in Simons et al., 2002.

Phosphate-buffered saline see 2.2.1!

4\% PFA solution see 2.2.1!

Permeabilization buffer $0.1 \%$ Triton-X-100 in PBS (v/v)

Blocking solution $5 \%$ Horse serum and $0.5 \%$ Triton-X-100 in PBS (v/v)

Cells on coverslips were washed with PBS and fixed with pre-warmed 4\% PFA in PBS for $20 \mathrm{~min}$. After washing with PBS, cells were permeabilized for $1 \mathrm{~min}$ and washed 
with PBS. Cells were incubated with blocking solution for $45 \mathrm{~min}$, followed by incubation with primary antibodies in blocking solution for $60 \mathrm{~min}$. After three washing steps, secondary antibodies in blocking solution were added. After $60 \mathrm{~min}$, cells were washed three times and mounted in Mowiol (see 2.2.3!).

The following primary antibodies were used, usually in a $1: 300$ dilution: Fluorescent and HRP-coupled antibodies were purchased from Dianova (Hamburg).

Tab. 2.3 Antibodies used in this study

\begin{tabular}{lllc}
\hline Antibody & raised in & source & cataloge number \\
\hline Actin (AC-40) & ms monoclonal IgG & Sigma & A3853 \\
A2B5 & ms IgM, monoclonal & Millipore & MAB312R \\
Col11A1 & rb polyclonal & abcam & ab64883 \\
GFAP-GA5 & ms monoclonal & Novocastra & \\
GFAP & rb polyclonal & Promega & G5601 \\
Iba 1 & rb polyclonal & Wako & $019-19741$ \\
LSAMP n-term & rb polyclonal lgG & Biozol & LSC80705/28397 \\
LSAMP (2G9) & ms IgG2a & Hybridoma & 2 G9 \\
Myc tag & rb polyclonal IgG & Upstate & $06-549$ \\
Mag Clone 513 & ms IgG1 & Millipore & MAB1567 \\
MBP & rb polyclonal & Millipore & AB5864 \\
MBP & ms IgG & Sternberger/Covance & SMI 94 \\
O4 & ms IgM & Sommer et al. 1981 & \\
O1 & ms lgM & Sommer et al. 1981 & \\
PDGF Receptor a & rb IgG & Cell Signaling (NEB) & 3174 \\
Tubulin beta (neuronal) ms monoclonal lgG1 & Sigma & T4026 \\
beta III Tubulin (5G8) & ms monoclonal IgG1 & Promega & G7121 \\
\hline
\end{tabular}

\subsubsection{Light microscopy of cell cultures}

Images were obtained using a Leica DM6000 widefield fluorescent microscope and the Leica LAS AF software package. For confocal laser scanning microscopy, a Leica TCS SP5 AOBS on a Leica DM6000 was used. Images were further processed using ImageJ, Adobe Photoshop and Adobe Illustrator. 


\subsection{Molecular biology methods}

In this thesis, mostly standard methods of molecular biology have been used. These methods were mainly performed as described by Sambrook and Russel, 2000.

\subsubsection{Isolation of genomic DNA from mouse tail tips}

Tail biopsies were taken from genetically modified mice, DNA isolation was performed using the Invisorb Spin Tissue Midi Kit (Invitek) according to the manufacturer's instructions. DNA was eluted in $100 \mu$ l elution buffer and stored at $-20^{\circ} \mathrm{C}$.

\subsubsection{Polymerase chain reaction for genotyping}

For genotyping, specific sequences were amplified by polymerase chain reaction (PCR) using the GoTaq Flexi DNA Polymerase Kit (Promega). The PCR mix consists of $1 \times$ GoTaq Green buffer, $1.25 \mathrm{mM} \mathrm{MgCl}$, 5 \% DMSO, $0.2 \mathrm{mM}$ dNTPs, $1.25 \mathrm{U}$ TaqPolymerase and $0.5 \mu \mathrm{M}$ of each primer. For every reaction, $20 \mu \mathrm{l}$ reaction mix and $1 \mu \mathrm{l}$ genomic DNA were used.

Tab. 2.4 Sequencing primers for genotyping

\begin{tabular}{|c|c|c|c|c|c|c|c|c|}
\hline \multicolumn{2}{|c|}{ PCR } & \multicolumn{4}{|c|}{ Sequence $\left(5^{\prime}-3^{\prime}\right)$} & \multicolumn{3}{|c|}{ AGCT Lab \# } \\
\hline \multirow{2}{*}{\multicolumn{2}{|c|}{ Bcas1-PCR A }} & \multirow{2}{*}{\multicolumn{4}{|c|}{$\begin{array}{l}\text { AAGAAGCGAAAGGCTCGGAAGACC } \\
\text { TGAACTGATGGCGAGCTCAGACC }\end{array}$}} & \multicolumn{3}{|c|}{24375} \\
\hline & & & & & & \multicolumn{3}{|c|}{24376} \\
\hline \multirow{3}{*}{\multicolumn{2}{|c|}{ Bcas1 - PCR B }} & \multicolumn{4}{|c|}{ TCATCTCCTAAGTGGTGAGGAAGG } & \multicolumn{3}{|c|}{24377} \\
\hline & & \multicolumn{4}{|c|}{ GAGACCCTCTGAGGCTGATGAGGC } & \multicolumn{3}{|c|}{24378} \\
\hline & & \multicolumn{4}{|c|}{ CAACGGGTTCTTCTGTTAGTCC } & \multicolumn{3}{|c|}{24379} \\
\hline \multirow{2}{*}{\multicolumn{2}{|c|}{ LacZ }} & \multicolumn{4}{|c|}{ CCCATTACGGTCAATCCGCCG } & \multicolumn{3}{|c|}{3435} \\
\hline & & & \multicolumn{3}{|c|}{3436} \\
\hline \multirow{2}{*}{\multicolumn{2}{|c|}{ E2A-Cre }} & & & & CAGGGTGTTATAAGCAATCCC & \multicolumn{3}{|c|}{4192} \\
\hline & & \multirow{2}{*}{\multicolumn{4}{|c|}{$\begin{array}{l}\text { CCTGGAAAATGCTTCTGTCCG } \\
\text { CACTGATATTGTAAGTAGTTTGC }\end{array}$}} & \multirow{2}{*}{\multicolumn{3}{|c|}{$\begin{array}{r}4193 \\
15300\end{array}$}} \\
\hline \multirow{2}{*}{\multicolumn{2}{|c|}{ FLIR-PCR 1}} & & & & & & & \\
\hline & & \multicolumn{4}{|c|}{ CTAGTGCGAAGTAGTGATCAGG } & \multicolumn{3}{|c|}{15301} \\
\hline \multirow{2}{*}{\multicolumn{2}{|c|}{ FLIR-PCR 2}} & \multicolumn{4}{|c|}{ TGTTTTGGAGGCAGGAAGCACTTG } & & 15302 & \\
\hline & & \multicolumn{4}{|c|}{ AAATACTCCGAGGCGGATCACAAG } & & 15303 & \\
\hline CNP- & & GCC & AAACT & ССАТСТC & & & 2016 & \\
\hline & & $\mathrm{CCC}$ & CCTTT & TACCAC & & & 7315 & \\
\hline & & CATA & CTGAA & ACGAGA & & & 1955 & \\
\hline Bcas & CRs & & E2A- & PCR & & LacZ & uchdow! & n PCR \\
\hline $95^{\circ} \mathrm{C}$ & $3 \min$ & & $95^{\circ} \mathrm{C}$ & $2 \min$ & & $98^{\circ} \mathrm{C}$ & $3 \min$ & \\
\hline $95^{\circ} \mathrm{C}$ & $30 \mathrm{sec}$ & & $95^{\circ} \mathrm{C}$ & $45 \mathrm{sec}$ & & $98^{\circ} \mathrm{C}$ & $30 \mathrm{sec}$ & \\
\hline $62^{\circ} \mathrm{C}$ & $30 \mathrm{sec}$ & 35 cycles & $55^{\circ} \mathrm{C}$ & $45 \mathrm{sec}$ & 40 cycles & $58^{\circ} \mathrm{C}$ & $30 \mathrm{sec}$ & 3 cycles \\
\hline $72^{\circ} \mathrm{C}$ & $30 \mathrm{sec}$ & & $72^{\circ} \mathrm{C}$ & $60 \mathrm{sec}$ & & $72^{\circ} \mathrm{C}$ & $30 \mathrm{sec}$ & \\
\hline $72^{\circ} \mathrm{C}$ & $3 \mathrm{~min}$ & & $72^{\circ} \mathrm{C}$ & $10 \mathrm{~min}$ & & $98^{\circ} \mathrm{C}$ & $30 \mathrm{sec}$ & 3 ucloce \\
\hline & & & & & & $72^{\circ} \mathrm{C}$ & $30 \mathrm{sec}$ & seycres \\
\hline FLIR & & & CNP- & PCR & & $98^{\circ} \mathrm{C}$ & $30 \mathrm{sec}$ & \\
\hline $95^{\circ} \mathrm{C}$ & $3 \min$ & & $95^{\circ} \mathrm{C}$ & $2 \min$ & & $\begin{array}{l}56^{\circ} \mathrm{C} \\
72^{\circ} \mathrm{C}\end{array}$ & $\begin{array}{l}30 \mathrm{sec} \\
30 \mathrm{sec}\end{array}$ & 3 cycles \\
\hline $95^{\circ} \mathrm{C}$ & $30 \mathrm{sec}$ & & $95^{\circ} \mathrm{C}$ & $30 \mathrm{sec}$ & & $98^{\circ} \mathrm{C}$ & $30 \mathrm{sec}$ & \\
\hline $58^{\circ} \mathrm{C}$ & $30 \mathrm{sec}$ & 35 cycles & $50^{\circ} \mathrm{C}$ & $30 \mathrm{sec}$ & 35 cycles & $55^{\circ} \mathrm{C}$ & $30 \mathrm{sec}$ & 30 cycles \\
\hline $72^{\circ} \mathrm{C}$ & $60 \mathrm{sec}$ & & $72^{\circ} \mathrm{C}$ & $90 \mathrm{sec}$ & & $72^{\circ} \mathrm{C}$ & $30 \mathrm{sec}$ & \\
\hline $72^{\circ} \mathrm{C}$ & $2 \min$ & & $72^{\circ} \mathrm{C}$ & $3 \mathrm{~min}$ & & $72^{\circ} \mathrm{C}$ & $5 \mathrm{~min}$ & \\
\hline
\end{tabular}




\subsubsection{Agarose gel electrophoresis}

PCR-products were separated by agarose gel electrophoresis and visualized using the intercalating dye SYBR-Safe.

$50 \times$ Tris/Acetate-EDTA $\quad 242 \mathrm{~g}$ Tris, $57.1 \mathrm{ml}$ glacial acetic acid, $100 \mathrm{ml} 0.5 \mathrm{M}$ EDTA (pH 8.0) to a final volumen of $1000 \mathrm{ml}$

$1 \times$ Tris/Acetate-EDTA Dilute $50 \times$ solution $1: 50$ in $\mathrm{ddH}_{2} \mathrm{O}$

$1.5 \%$ agarose in $1 \times$ TAE-buffer were heated in a microwave oven until dissolved. SYBR-Safe DNA Gel stain (Life technologies) was added and gel was cast in a homemade apparatus. $20 \mu \mathrm{l}$ of each PCR mix were added into every pocket and separation was performed at $130 \mathrm{~V}$ for $90 \mathrm{~min}$. The gel was visualized using the INTAS UVSystem and INTAS DR software,

\subsubsection{High-fidelity polymerase chain reaction for cloning}

For the amplification of DNA sequences for cloning, the Phusion High-Fidelity Master Mix (Thermo Scientific) was used according to the manufacturer's instructions. In brief, $10 \mu \mathrm{l}$ of $2 \times$ Master mix, $8 \mu \mathrm{lddH_{2 }} \mathrm{O}, 0.5 \mu \mathrm{M}$ of each primer and $1 \mu \mathrm{l}$ of a $50 \mathrm{ng} / \mu \mathrm{l}$ template DNA were used.

\subsubsection{Enzymatic digestion of PCR products and plasmids}

Restriction digestion was performed using enzymes and buffers from New England Biolabs. Every reaction consist of $1-2 \mu \mathrm{g}$ DNA, $3 \mu \mathrm{l} 10 \mathrm{x}$ restriction buffer, $0.3 \mu \mathrm{l} 100 \mathrm{x}$ BSA and $1 \mu$ of each enzyme in $30 \mu$ total volume.

\subsubsection{Ligation}

For the ligation of digested inserts and vector, the DNA T4 ligase system from Fermentas was used according to the manufacturer's recommendations.

\subsubsection{Transformation of competent E. coli and plasmid preparation}

$50 \mu \mathrm{l}$ of DH5a chemically competent E. coli (Invitrogen) were thawn on ice and $0.5 \mu \mathrm{g}$ plasmid DNA were added. The mixture was incubated on ice for $30 \mathrm{~min}$, heat-shocked at $42^{\circ} \mathrm{C}$ for $30 \mathrm{sec}$ and returned to the ice for $2 \mathrm{~min} .700 \mu \mathrm{l}$ of LB media was added, cells were shaken at $37^{\circ} \mathrm{C}$ and $200 \mathrm{rpm}$ for $60 \mathrm{~min}$. $200 \mu \mathrm{l}$ of the bacterial culture was given onto LB agar plates with appropriate antibiotic and incubated over night at $37^{\circ} \mathrm{C}$. The next day, single colonies were picked and transferred into liquid LB media with the appropriate antibiotic. Bacteria were grown over night and used for preparations using the NucleoBond Xtra Midi or Mini Kit (Macherey-Nagel) according to the manufacturer's recommendations. DNA sequencing was performed at the AGCT lab. 


\subsection{RNA methods}

RNA-isolation and -handling was generally done in a special fume hood. Surfaces were cleaned with RNase-AWAY (Roth) and all steps were performed on ice. Whenever possible, RNase-free disposable plastic-ware was used. All glassware was pre-treated either with $0.1 \%$ DEPC in $d_{d d} \mathrm{H}_{2} \mathrm{O}$ and autoclaved, or baked at $200^{\circ} \mathrm{C}$ for 6 hours.

\subsubsection{Preparation of TRIzol-Lysates}

Cultured cells were washed 3-times with sterile PBS, scraped in TRIzol reagent (Invitrogen) and incubated at room temperature for $5 \mathrm{~min}$ to dissociate complexes of nucleic acids and proteins. Lysates were stored at $-20^{\circ} \mathrm{C}$ before isolation of RNA.

Tissue samples were flash-frozen in liquid nitrogen, ground using liquid-nitrogen-cooled mortar and pestle and the powder was dissolved in TRIzol reagent.

\begin{tabular}{cc}
\hline $10 \mathrm{~cm}$ cell culture dish & $1.5 \mathrm{ml} \mathrm{TRIzol}$ reagent \\
$6 \mathrm{~cm}$ cell culture dish & $1.0 \mathrm{ml}$ TRIzol reagent \\
$3 \mathrm{~cm}$ cell culture dish & $0.5 \mathrm{ml}$ TRIzol reagent \\
$50 \mathrm{~g}$ Tissue & $1.0 \mathrm{ml}$ TRIzol reagent \\
\hline
\end{tabular}

\subsubsection{Isolation of total RNA}

Total RNA was isolated using a modified version of the Chomczynski-/Sacchi-method, as described in manual for the TRIzol reagent.

DEPC- $\mathrm{H}_{2} \mathrm{O}$

$70 \%$ Ethanol in DEPC-H2O

$5 \mathrm{M}$ Ammonium acetate

$70 \%$ Ethanol in $\mathrm{ddH}_{2} \mathrm{O}$
$0.1 \%$ Diethylpyrocarbonate and $100 \mathrm{ml}$ of Millipore- $\mathrm{H}_{2} \mathrm{O}$ are mixed, incubated over night at $37^{\circ} \mathrm{C}$ and autoclaved. $70 \mathrm{ml}$ of absolute ethanol (molecular biology grade) filled up to100 ml with DEPC- $\mathrm{H}_{2} \mathrm{O}$

$3.854 \mathrm{~g}(0.05 \mathrm{~mol})$ in $10 \mathrm{ml}$ with DEPC- $\mathrm{H}_{2} \mathrm{O}$

$70 \mathrm{ml}$ of absolute ethanol (molecular biology grade) filled up to $100 \mathrm{ml}$ with Millipore- $\mathrm{H}_{2} \mathrm{O}$

$1.0 \mathrm{ml}$ TRIzol lysate was mixed with $200 \mu \mathrm{l}$ chloroform (1/5 volume) and incubated on ice for $15 \mathrm{~min}$. Phase separation was facilitated by centrifugation $\left(15 \mathrm{~min}, 4^{\circ} \mathrm{C}\right.$, $10.000 \mathrm{xg}$ ) and upper phase was transferred into a new Eppendorf cup. An equal volume $(500 \mu \mathrm{l})$ of Isopropanol was added, mixed by inversion and incubated for another $15 \mathrm{~min}$ on ice or $60 \mathrm{~min}$ at $-20^{\circ} \mathrm{C}$. RNA was pelleted by centrifugation (15 min, $4^{\circ} \mathrm{C}, 10.000 \mathrm{xg}$ ), supernatant discarded and RNA was resuspended in $200 \mu \mathrm{LEPC}$ $\mathrm{H}_{2} \mathrm{O} .500 \mu \mathrm{l}$ of $96 \%$ Ethanol and $70 \mu \mathrm{l}$ of $5 \mathrm{M} \mathrm{Ammonium}$ acetate were added and RNA was precipitated at $-80^{\circ} \mathrm{C}$ for several hours. The precipitated RNA was harvested by centrifugation ( $30 \mathrm{~min}, 4^{\circ} \mathrm{C}, 10.000 \times \mathrm{xg}$ ), washed with $500 \mu \mathrm{l}$ of $70 \%$ Ethanol (in Millipore- $\mathrm{H}_{2} \mathrm{O}$, not DEPC-treated) and centrifuged again $\left(10 \mathrm{~min}, 4^{\circ} \mathrm{C}, 10.000 \mathrm{xg}\right)$. Supernatant was aspirated, RNA pellet air-dried for $5 \mathrm{~min}$ and resuspended in $25 \mu \mathrm{l}$ of 
sterile Millipore- $\mathrm{H}_{2} \mathrm{O}$. The concentration and purity of RNA was determined spectrophotometrically (A260/A280) in a 1: 100 dilution and RNA was stored at $-80^{\circ} \mathrm{C}$.

\subsubsection{Denaturating agarose electrophoresis}

As a quality control, RNA was checked by denaturating agarose gel electrophoresis.

De-ionized formamide A glass beaker with magnetic stir-bar was was baked at $200^{\circ} \mathrm{C}$ for 6 hours. $100 \mathrm{ml}$ of formamide and $10 \mathrm{~g}$ of Amberlite ion-exchange resign were added and stirred for $30 \mathrm{~min}$. This de-ionized formamide was sterile-filtered and stored at $-20^{\circ} \mathrm{C}$ in RNase-free tubes.

Agarose-runing buffer (10x) $20.93 \mathrm{~g}$ MOPS (0.1 mol), $2.05 \mathrm{~g}$ Sodium acetate (25 mmol), $1.46 \mathrm{~g}$ EDTA and $2.0 \mathrm{~g} \mathrm{NaOH}$ were dissolved in approx. $300 \mathrm{ml}$ of DEPC- $\mathrm{H}_{2} \mathrm{O}$. pH was adjusted to 7.0 with $1 \mathrm{M} \mathrm{NaOH}$, made up to $500 \mathrm{ml}$ with DEPC- $\mathrm{H}_{2} \mathrm{O}$ and autoclaved.

Agarose-runing buffer (1x) $100 \mathrm{ml}$ of $10 \mathrm{x}$ buffer were combined with $20 \mathrm{ml} 37 \%$ formaldehyde and $880 \mathrm{ml}$ of DEPC- $\mathrm{H}_{2} \mathrm{O}$.

Bromophenol blue solution Saturated solution in DEPC- $\mathrm{H}_{2} \mathrm{O}$

RNA loading dye (5x) $\quad 100 \mu \mathrm{l}$ Bromophenol blue, $80 \mu \mathrm{l} 0.5 \mathrm{M}$ EDTA (pH 8.0), $720 \mu \mathrm{l} 37 \%$ formaldehyde, $2.0 \mathrm{ml}$ Glycerol, $3.0 \mathrm{ml}$ deionized formamide and $4.0 \mathrm{ml}$ of $10 \mathrm{x}$ agarose running buffer were combined and filled to $10 \mathrm{ml}$ with DEPC- $\mathrm{H}_{2} \mathrm{O}$.

For casting of the gels, $1.2 \mathrm{~g}$ low-melting Agarose, $10 \mathrm{ml}$ Agarose-runing buffer (10x) and $90 \mathrm{ml}$ of DEPC- $\mathrm{H}_{2} \mathrm{O}$ were combined and heated in a microwave-oven. The gel was allowed to cool down to $65^{\circ} \mathrm{C}$ in a water bath, $1.8 \mathrm{ml}$ of $37 \%$ Formaldehyde and $1.0 \mu \mathrm{g}$ of $10 \mathrm{mg} / \mathrm{ml} \mathrm{EtBr-stock}$ were added. The gel was cast and allowed to polymerize for 60 $\min$. The gel was equilibrated with Agarose-runing buffer (1x) for at least 30 min before gel running.

1 volume of RNA loading dye (5x) was combined with 4 volumes of RNA-sample $(2 \mu \mathrm{g})$, incubated at $65^{\circ} \mathrm{C}$ for $5 \mathrm{~min}$, chilled on ice and loaded onto the equilibrated gel. Gel-run was performed under for $60 \mathrm{~min}$ at $60 \mathrm{~V}(5-7 \mathrm{~V} / \mathrm{cm})$. 


\subsubsection{Reverse-transcription quantitative real-time PCR}

Expression of different target genes was analyzed using quantitative real-time PCR using the SYBR Green method. For this analysis, total RNA is reverse transcribed into CDNA and quantitative real-time PCR is performed on a Roche Light Cycler.

\section{Reverse Transcription}

Reverse Transcription of RNA into cDNA was performed using the SuperScript III FirstStrand Synthesis System (Invitrogen) according to the manufacturer's instructions.

In brief, $2 \mu \mathrm{g}$ of total RNA, $1 \mu \mathrm{l} 50 \mu \mathrm{M}$ oligo(dT) $)_{20}$-Primer and $1 \mu \mathrm{l} 10 \mathrm{mM}$ dNTP mix were combined and filled up to a final volume of $10 \mu \mathrm{l}$ with $\mathrm{H}_{2} \mathrm{O}$. The mix was incubated at $65^{\circ} \mathrm{C}$ for $5 \mathrm{~min}$ and cooled down to $4^{\circ} \mathrm{C}$. $10 \mu \mathrm{l}$ of RT-mix $(2 \mu \mathrm{l} 10 \mathrm{x}$ buffer, $4 \mu \mathrm{l} 25 \mathrm{mM}$ $\mathrm{MgCl}_{2}, 2 \mu \mathrm{l} 0.1 \mathrm{M}$ DTT, $1 \mu \mathrm{l}$ RNaseOUT[40 U], $1 \mu \mathrm{l}$ SuperScript-III-RT) were added and incubated at $50^{\circ} \mathrm{C}$ for $50 \mathrm{~min}$. The reaction was terminated at $85^{\circ} \mathrm{C}$ for $5 \mathrm{~min}$. After RNaseH-treatment, cDNA was diluted $1: 20$ with $\mathrm{H}_{2} \mathrm{O}$ and stored at $-20^{\circ} \mathrm{C}$.

\section{Real-time quantitative PCR (qPCR)}

The expression of target genes was quantified by quantitative realtime-PCR and correlated to the expression level of housekeeper genes. PCR was performed using the Power SYBR Green PCR Master Mix (Roche) according to the manufacturer's guidelines. Gene specific, exon-spanning primers were designed using the Universal Probe-Library Assay Design Center Software (Roche) and synthesized in the AGCTLab (Facility of the MPI-EM).

Tab. 2.5 Primers for quantitative real-time PCR

\begin{tabular}{llc}
\hline Primer & Sequence $\left(\right.$ ( $^{\prime}$-3 $^{\prime}$ ) & AGCT Lab \# \\
\hline GAPDH (Fw) & CAATGAATACGGCTACAGCAAC & 14539 \\
GAPDH (Rev) & TTACTCCTTGGAGGCCATGT & 14540 \\
Adamts4 (Fw) & CTTCCTGGACAATGGTTATGG & 21297 \\
Adamts4 (Rev) & GAAAAGTCGCTGGTAGATGGA & 21298 \\
Bcas1 (Fw) & AAAGACTCCAGCTGCCAAAC & 19022 \\
Bcas1 (Rev) & CTTGTCCACTGATTTCTTGTCCT & 19023 \\
Col11a1 (Fw) & CAGATTGTGACTTAACATCCAAGG & 33002 \\
Col11a1 (Rev) & CTCGATTATATCCTCAGGTGCAT & 33003 \\
Enpp6 (Fw) & GAGGATGGCACGGATATGAC & 20224 \\
Enpp6 (Rev) & GCAGCTCTGAAGTTGGACTTG & 20225 \\
II1rap (Fw) & CATCCATCTGGTCGCTGTC & 33004 \\
II1rap (Rev) & AAATACCACAGAAGTCCCATCC & 33005 \\
Plp1 (Fw) & GGCTAGGACATCCCGACAAGT & 11292 \\
Plp1 (Rev) & GGCAAACACCAGGAGCCATA & 11293 \\
\hline
\end{tabular}




\subsubsection{RNA-extraction, generation of the cDNA libraries and Illumina RNA- Sequencing}

Cell cultures were washed three times with PBS, approximately 1 million cells were lysed in $750 \mu \mathrm{l}$ of RLT buffer (Quiagen) and passed through a 27G needle. Samples were stored at $-80^{\circ} \mathrm{C}$ until RAN-preparation. The RNA preparation and CDNA library synthesis was performed by Dr. Elena Ciirdaeva.

Total RNA was isolated using the RNeasy Mini Kit (Quiagen) according to the manufacturer's guidelines. RNA concentration was determined using a NanoDrop ND1000 spectrophotometer and RNA integrity was assessed with an Agilent 2100 Bioanalyzer.

For the first round of amplification, cDNA synthesis was performed using $300 \mathrm{ng}$ of RNA and the Superscript III first strand synthesis kit (Invitrogen). A mixture of T7-B primers was used in this reaction. Afterwards, second strand synthesis was performed using DNA Polymerase I and $2^{\text {nd }}$-strand buffer (Invitrogen). The double-stranded cDNA was purified using a CyScribe GFX Purification kit (GE Healthcare) and used for invitro-transcription (MEGAscript T7 Kit, Ambion). The resulting aRNA was purified using a RNeasy Micro column kit (Quiagen).

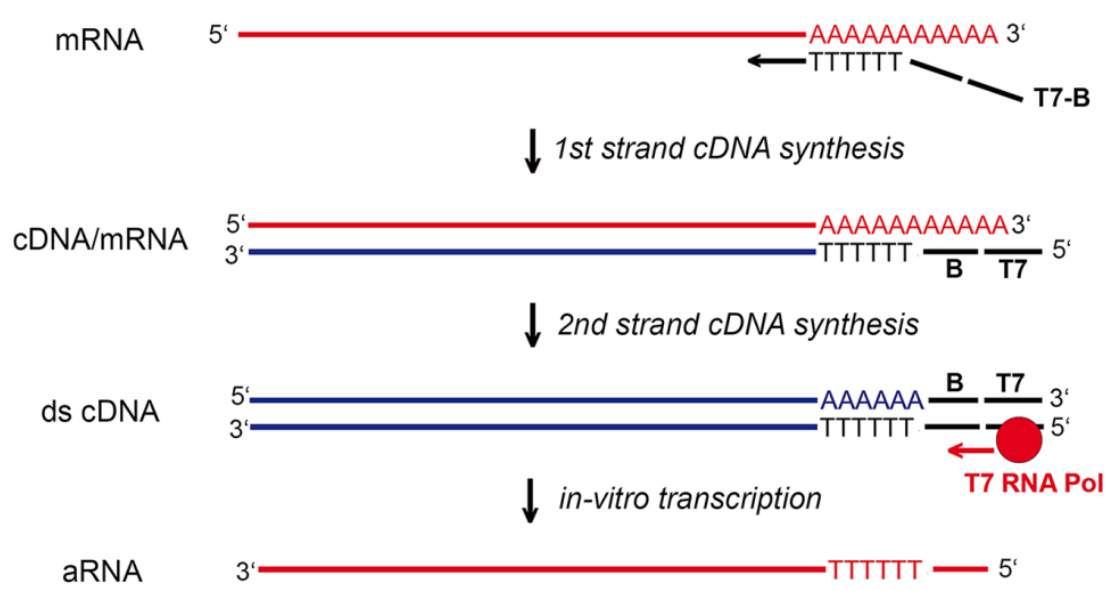

Fig. 2.1: Schematic overview of the first round of amplification. In this step, adaptor $B$ and the T7 polymerase sequence are added. Then, anti-sense RNA (aRNA) is generated by in-vitro transcription.

For the second round of amplification, between 300 and $800 \mathrm{ng}$ aRNA were mixed with a Dec1-hairpin-N9 primer and first strand synthesis was performed using the Superscript III first strand synthesis kit (Invitrogen). $2^{\text {nd }}$ strand synthesis was done with a B-short primer and Taq-Polymerase. cDNA was purified with the NuleoSpin Extract II Kit (Macherey \& Nagl). 


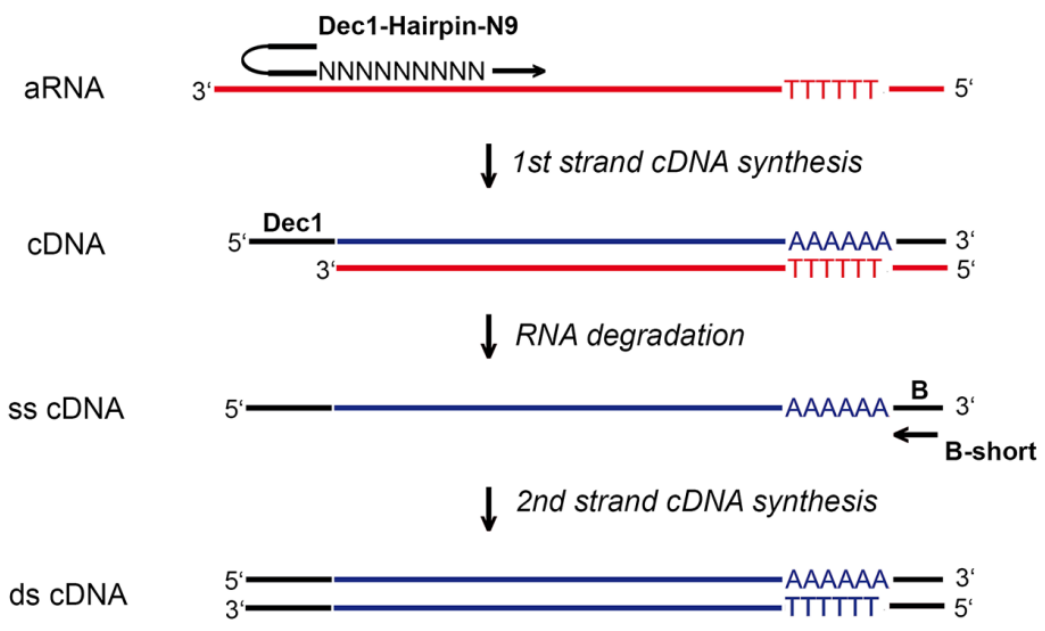

Fig. 2.2: Schematic overview of the second round of amplification. In this step, the Dec1 adaptor is introduced.

Sequencing codes were introduced by step-out PCR. Therefore, cDNA was mixed with the appropriate Code_Cis40 primers and amplified by PCR using the PWO Master Mix (Roche). The Illumina sequencing adaptors were introduced in a second PCR using the appropriate primers.

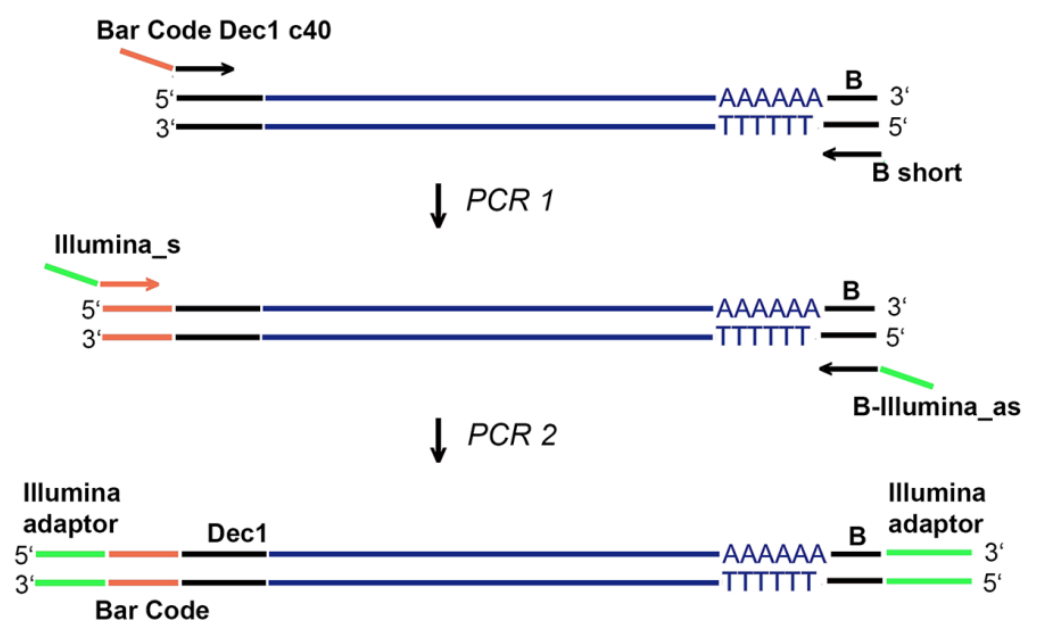

Fig. 2.3: Schematic overview of the third round of amplification. In the first $P C R$ reactions, sample-specific bar codes are introduced to allow for simultaneous sequencing of several samples. In the second PCR, Illumina adaptors are introduced.

Samples were sent to Dr. Richard Reinhardt at the Max Planck Genome Center in Cologne for Illumina2000 sequencing. Sven Wiechert performed BLAST analysis of the sequencing data in order to identify the nucleotides. Nirmal Kannaiyan analyzed and normalized the datasets. 


\subsection{Protein biochemistry methods}

\subsubsection{Preparation of lysates for SDS-PAGE}

Lysis buffer

$2 \%$ Nonidet P-40, $0.2 \%$ SDS, 0.5 mM EDTA in

PBS, supplemented with Boehringer complete and

PMSF

Frozen tissue samples were homogenized in Lysis buffer using an Ultra-turrax and centrifuged for $5 \mathrm{~min}$ at $10.000 \times \mathrm{g}$. Protein concentration was determined using a Pierce BCA assay kit according to the manufacturers guidelines. Protein concentration was adjusted to $1.0 \mu \mathrm{g} / \mu \mathrm{l}$. Samples were combined with the appropriate amount of $5 \mathrm{x}$ samples buffer (see 2.6.2), heated for $10 \mathrm{~min}$ to $95^{\circ} \mathrm{C}$ and stored at $-20^{\circ} \mathrm{C}$.

\subsubsection{SDS-PAGE}

Proteins of tissue and cell lysates were separated on sodium dodecyl sulfate polyacrylamide gel electrophoreses (SDS-PAGE), transferred onto nitrocellulose membranes (Western Blot) and detected with the approriate antibodies. The here described method is based on the protocol from Eckert and Kartenbeck, 1996.

Stacking gel buffer

Resolving gel buffer

Electrophoresis buffer (10x)

Sample buffer $(5 \mathrm{x})$
$125 \mathrm{mM}$ Tris/HCl, pH 6.8

$375 \mathrm{mM}$ Tris $/ \mathrm{HCl}, \mathrm{pH} 8.8$

25 mM Tris, 192 mM Glycine, $0.1 \%$ SDS

$50 \% \quad$ Glycerol, $\quad 10 \% \quad$ SDS, $\quad 0.5 \%$ b-Mercaptoethanol, $625 \mathrm{mM}$ Tris (pH 6.8), $5 \mathrm{mM}$ EDTA (pH 8.0) $0.05 \%$ Bromophenolblue

$10 \%$ APS
$10 \%(\mathrm{w} / \mathrm{v})$ Ammoniumperoxodisulfate in $\mathrm{ddH} 2 \mathrm{O}$

The BioRad Mini-Protean 3 system was used to cast poly-acrylamide gels. The composition of the resolving and stacking gels are described in the lower table. The resolving gel was cast between the glass plates and covered by a layer of isopropanol. After polymerization (45 min), isopropanol was removed and the stacking gel was cast.

\begin{tabular}{lrrrrll}
\hline Resolving gel & & & & & Stacking gel \\
& $\mathbf{7 . 5} \%$ & $\mathbf{8 . 7 5} \%$ & $\mathbf{1 0} \%$ & $\mathbf{1 2 . 5 \%}$ & & \\
\hline Aqua dest & $5.0 \mathrm{ml}$ & $4.5 \mathrm{ml}$ & $4.0 \mathrm{ml}$ & $3.0 \mathrm{ml}$ & Aqua dest & $2.0 \mathrm{ml}$ \\
Tris/HCl $(1.5 \mathrm{M}, \mathrm{pH} 8.8)$ & $3.0 \mathrm{ml}$ & $3.0 \mathrm{ml}$ & $3.0 \mathrm{ml}$ & $3.0 \mathrm{ml}$ & Tris/HCl $(0.5 \mathrm{M}, \mathrm{pH} 6.8)$ & $0.8 \mathrm{ml}$ \\
AA/BA & $3.0 \mathrm{ml}$ & $3.5 \mathrm{ml}$ & $4.0 \mathrm{ml}$ & $5.0 \mathrm{ml}$ & AA/BA & $0.5 \mathrm{ml}$ \\
APS (10\%) & $60 \mu \mathrm{l}$ & $60 \mu \mathrm{l}$ & $60 \mu \mathrm{l}$ & $60 \mu \mathrm{l}$ & APS $(10 \%)$ & $30 \mu \mathrm{l}$ \\
TEMED & $30 \mu \mathrm{l}$ & $30 \mu \mathrm{l}$ & $30 \mu \mathrm{l}$ & $30 \mu \mathrm{l}$ & TEMED & $15 \mu \mathrm{l}$ \\
\hline
\end{tabular}

Samples were loaded onto the gel and SDS-PAGE was performed for $90 \mathrm{~min}$ at $100 \mathrm{~V}$. 


\subsubsection{Western Blot Analysis}

Transfer buffer (1x)

Ponceau S solution

TRIS-buffered saline (TBS) TBS with Tween 20 (TBS-T)

Blocking solution
25 mM TRIS base, 192 mM Glycine, $20 \%$ methanol

$1 \%(w / v)$ in $3 \%$ Chloroacetic acid

10 mM TRIS-base, 150 mM NaCl, pH 7.4

$0.1 \%$ Tween 20 in TBS, pH 7.4

$4 \%$ non-fat milk powder in TBS

After SDS-PAGE, the proteins were transferred onto a nitrocellulose membrane. The gel was removed from the glass plates and incubated for 5 min in transfer buffer to wash out SDS. Then, the gel was assembled in the blotting cassette with the membrane and Whatman filters. The blotting system was filled with transfer buffer, cooled with an ice pack and transfer was performed at $100 \mathrm{~V}$ for $60 \mathrm{~min}$.

To check successful transfer, the membrane was stained with Ponceau S for 5 min and rinsed with $\mathrm{dd}_{2} \mathrm{O}$. Then, membranes were de-stained with TBS-T and blocked with Blocking solution for $60 \mathrm{~min}$. Incubation with the first antibodies (in blocking solution) was performed over night at $4^{\circ} \mathrm{C}$. The next day, membranes were washed three times with TBS and incubated with the appropriate secondary antibodies for $60 \mathrm{~min}$ at room temperature. After three consecutive washing steps, Pierce ECL solution was added and light emission was detected using X-ray-films.

\subsection{Proteomic analysis and data processing}

Lysis buffer

$4 \%$ SDS, 100 mM DTT, 100 mM TRIS/HCl, pH 7.6

Proteomic analysis was essentially performed as described previously (Nagaraj et al., 2011). For brain and liver proteomics, mice were perfused with TBS, tissues were extracted and snap-frozen in liquid nitrogen. Cell cultures were washed three times with TBS, flash-frozen on dry ice and stored at $-80^{\circ} \mathrm{C}$ before sample preparation. Cells were lysed in lysis buffer at $99^{\circ} \mathrm{C}$ for $5 \mathrm{~min}$. These lysates were cooled down to room temperature, sonicated using a Branson type sonicator and clarified by centrifugation. Protein concentration was adjusted to $2 \mu \mathrm{g} / \mu \mathrm{l}$ and a total of $100 \mu \mathrm{g}$ total protein was subjected to chloroform-methanol-precipitation. Proteins were digested with LysC and trypsin (Shevchenko et al., 2006) and desalted using StageTips (Rappsilber et al., 2007). $25 \mu \mathrm{g}$ of the digested peptides were separated into six fractions using strong ionic exchange according to the previously described pipette tip protocol (Wiśniewski et al., 2009). 
Eluted peptides were separated during a $4 \mathrm{~h}$ run using a $50 \mathrm{~cm}$ long reverse phase C18 column on an Easy-nLC-system (Thermo Fisher Scientific), directly coupled to a Q-Exactive Hybrid Quadrupole-Orbitrap mass spectrometer (Thermo Fisher Scientific). Mass spectra were processed using MaxQuant software (Cox and Mann, 2008) and analysed by the Andromeda search engine against the Uniprot mouse sequence database. Peptides with a minimum of seven amino acids were considered and the required FDR was set to $1 \%$ at a peptide and protein level. Protein identification required at least one unique or razor peptide. Quantification was performed using the label-free quantification (LFQ) algorithm of MaxQuant. Bioinformatic analysis was performed in the Perseus software environment. All of these steps were prepared by Kitri Sharma (Max-Planck-Institute for Biochemistry, Martinsried).

\subsubsection{Fc-fusion protein generation and purification}

Binding buffer

$20 \mathrm{mM}$ sodium phosphate, $\mathrm{pH} 7.0$

Elution buffer

$0.1 \mathrm{M}$ glycine, $\mathrm{pH} 2.7$

Neutralization buffer

$1 \mathrm{M} \mathrm{TRIS} / \mathrm{HCl}, \mathrm{pH} 9.0$

Necl1-Fc and Necl4-Fc plasmids were provided by Elior Peles (Weizmann Institute, Israel). The Fc fragment was amplified and inserted into a pcDNA3.1(+) plasmid using the primers 5'-AAAAGAGCTCGGAGGAGGAGGAGATCCCCGTCGTGCATCTATC-3' and 5'-AAAAGGGCCCTCTAGATCATTTACCC-3'. The extracellular domain from Lsamp, Ntm, Opcml and MCAM were amplified and inserted into the Fc plasmid using Nhel restriction sites. Soluble Fc-fusion proteins were purified using Protein A HP Spin Trap columns (GE Healthcare), following manufacturer's instructions. In brief, HEK cells were transfected, after 2-3 days, the supernatant was collected and centrifuged for $15 \mathrm{~min}$ at $4.000 \mathrm{~g}$ at $4^{\circ} \mathrm{C}$. $1 \times$ Complete Protease Inhibitor Cocktail (Roche) was added to the supernatant and then concentrated using Amicon Ultra-15 Centrifugal Filter Units (Millipore) according to manufacturer's recommendations. The final volume of $2 \mathrm{~mL}$ was diluted in equal volume of binding buffer. The storage solution from the column was removed by centrifugation for $30 \mathrm{~s}$ at $100 \mathrm{~g}$. The column was equilibrated adding $600 \mu \mathrm{L}$ of binding buffer, centrifuged for $30 \mathrm{~s}$ at $100 \mathrm{~g}$. Then, 600 $\mu \mathrm{L}$ of the antibody solution were added, incubated for 4 min while gently mixing and then centrifuged for $30 \mathrm{~s}$ at $100 \mathrm{~g}$. This procedure was repeated until all the volume was loaded on the column. Then the column was washed twice adding $600 \mu \mathrm{L}$ binding buffer and centrifuging for $30 \mathrm{~s}$ at $100 \mathrm{~g}$. Two collection tubes per sample were prepared for eluted fractions, each one containing $30 \mu \mathrm{L}$ of neutralizing buffer. The proteins were eluted twice by adding $400 \mu \mathrm{L}$ of elution buffer, mixing by inversion, 
placing the column in a $2 \mathrm{~mL}$ microcentrifuge tube containing $30 \mu \mathrm{L}$ neutralizing buffer and centrifuged for $1 \mathrm{~min}$ at $50 \mathrm{~g}$. The proteins were aliquoted and kept at $-20^{\circ} \mathrm{C}$. All fusion proteins were prepared by Natalia Manrique-Hoyos.

\subsubsection{Binding assay}

For binding assays, supernatant from transfected HEK cells was centrifuged for 10 min at $5000 \mathrm{rpm}$. Per each $18 \mathrm{~mm}$ coverslip of neuronal or oligodendroglial culture, $150 \mu \mathrm{L}$ of media were mixed with $1.5 \mu \mathrm{L}$ of Cy3-conjugated anti-human Fc antibody (Dianova) and incubated for $30 \mathrm{~min}$ at RT. Then, the mix was added to each coverslip and incubated for $20 \mathrm{~min}$ at RT in a humid chamber. Finally, the coverslips were washed 3 times with PBS and the cells were fixed with 4\% PFA for 15 min at RT.

\subsubsection{Adhesion assay}

Glass coverslips in a 24-well plate were coated with $500 \mu \mathrm{L}$ of a solution with $10 \mu \mathrm{g} / \mathrm{mL}$ of donkey anti-human Fc antibody (Dianova) in $50 \mathrm{mM}$ Tris- $\mathrm{HCl}(\mathrm{pH} \mathrm{9.0)}$ and left overnight at $4^{\circ} \mathrm{C}$. Then, the coverslips were washed 3 times with supplement-free DMEM and $500 \mu \mathrm{L}$ of a solution containing $10 \mu \mathrm{g} / \mathrm{mL}$ of Fc-fusion protein in $0.2 \%$ BSA/PBS. After $1 \mathrm{~h}$ of incubation at $37^{\circ} \mathrm{C}$, the coverslips were washed 3 times with DMEM and fresh Super SATO media was added. PLL coating $(100 \mu \mathrm{g} / \mathrm{mL}$ was used as a positive control to verify the quality of the primary oligodendrocyte preparation. After washing and placing new media, 25000 OPC were plated and allowed to grow for four days, and fixed with 4\% PFA. Binding and adhesion assays were performed by Natalia Manrique-Hoyos and Caroline Bergner. 


\section{Chapter III: Results}

\subsection{Generation of highly pure primary cell cultures}

In this study, we performed transcriptomics and proteomics of cultured neuronal and glial cells, as well as a proteomic analysis of mouse brain. A pre-requisite for this was to obtain sufficient amounts of highly pure cell cultures. Therefore, we optimized our protocol for cell preparation: We harvested OPCs from glial mixed cultures by differential shaking. For a removal of contaminating cells, the cell suspension was incubated in uncoated cell-culture dishes, where contaminating cells adhered. The supernatant of pure OPCs was transferred to PLL-coated cell culture dishes with differentiation medium.
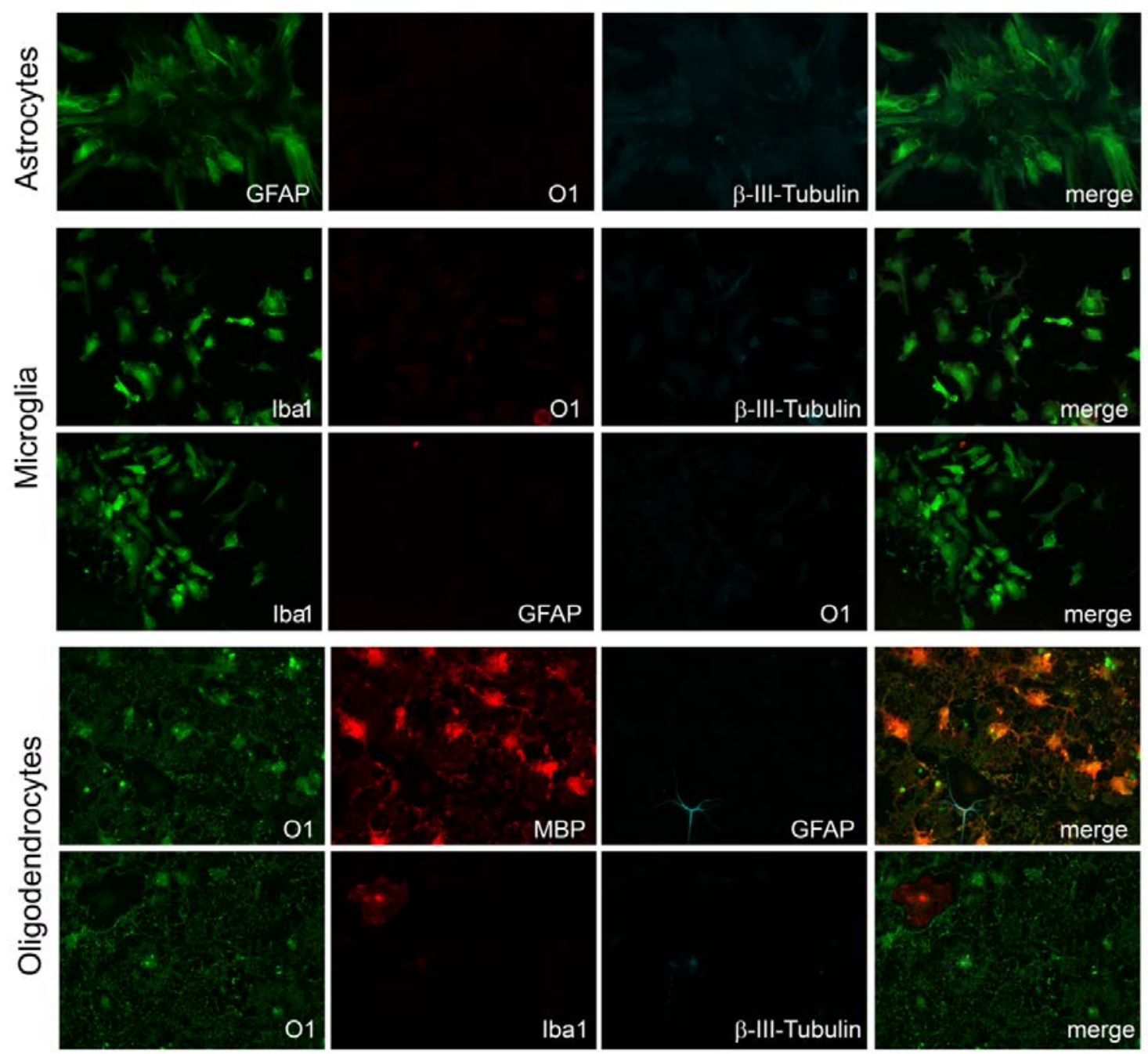

Fig. 3.1: Quality controls of primary cell cultures. Immuno-staining of every sample was performed using markers of oligodendrocytes (O1, MBP), microglia (Iba1), astrocytes (GFAP) and neurons ( $\beta$-III-tubulin). Samples with a purity $>95 \%$ were included in the further analyses.

With this method we obtained highly pure oligodendrocyte cultures. Purity of every preparation was confirmed by immuno-staining (Fig. 3.1). We used antibodies against 
$\mathrm{O} 1$ and MBP to stain oligodendrocytes, GFAP was used as a marker for astrocytes, Iba1 for microglia and beta-III-tubulin for neurons. Only cells with a purity $>95 \%$ were included into the further analysis. Cortical neurons were prepared from embryonic day 16.5 mice and treated with Arabinosyl-Cytosine (AraC) on DIV-1 and DIV-2 to eliminate proliferating cells. Medium was changed and cells were allowed to grow at least for another 2 days. That way, the effect of AraC treatment on the proteome and transcriptome should be minimized. We hardly observed any glial cell in these neuronal preparations (purity $>97 \%$ ).

\subsection{Workflow for proteomic and transcriptomic analysis}

Mouse brains and cell culture samples were lysed and pre-cleaned using the filteraided sample preparation protocol (Wiśniewski et al., 2009). After enzymatic digestion, peptides were separated into six fractions using anion exchange in a StageTip format. LC-MS/MS was performed using an EASY nLC system coupled to a Q-Exactive Orbitrap mass spectrometer. Raw data were transferred into the MaxQuant software and the abundance of proteins was determined by label-free quantification (LFQ).

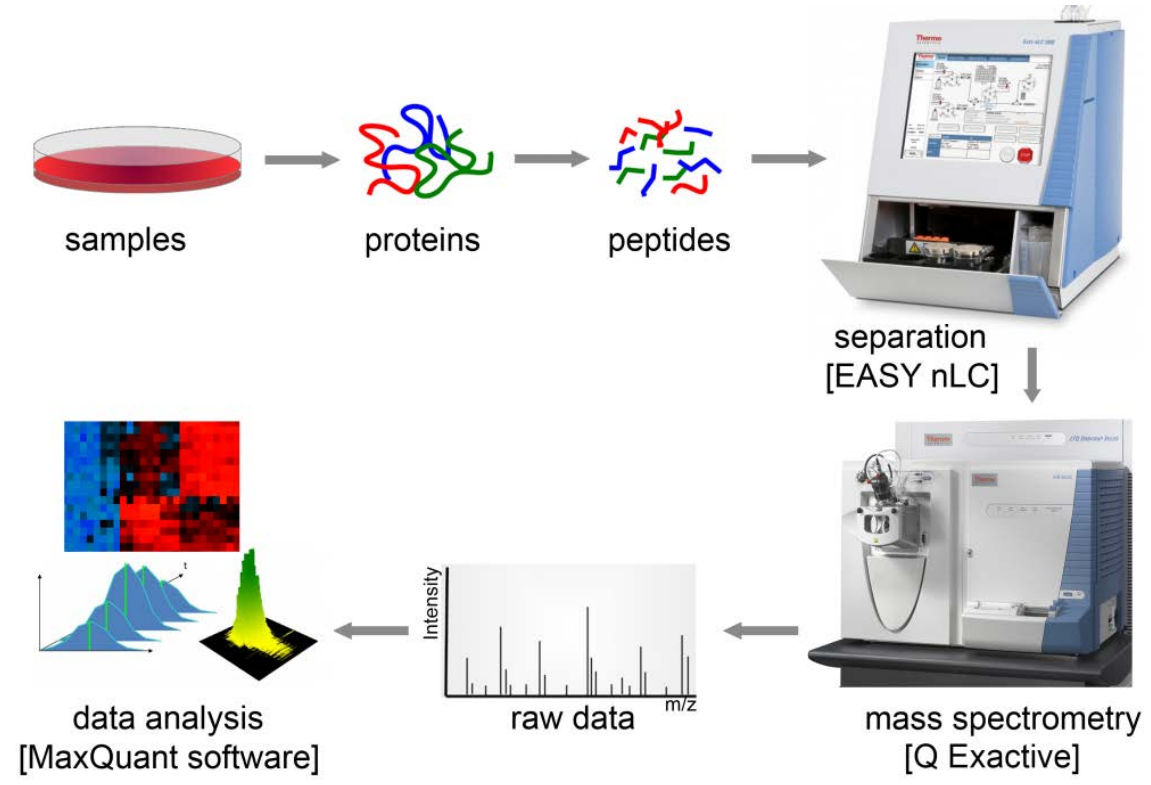

Fig. 3.2: Workflow of the proteomic analysis. After purity of cells samples was confirmed, cells were lysed and filter-aided sample preparation was done. Proteins were digested with LysC and trypsin, and analyzed by LC-MS/MS using a Q-Exactive mass spectrometer. MaxQuant software was used to analyze raw data and for label-free quantification. 
In order to determine the coverage of the proteomic analysis, we wanted to compare the proteome with the transcriptome of cultured CNS cells (Fig. 3.3). Therefore, mRNA was isolated and cDNA was amplified as described in the Materials and Methods section. During the amplification steps, bar code sequences and Illumina adaptors were introduced. The resulting cDNA libraries were subjected to Illumina next generation sequencing.
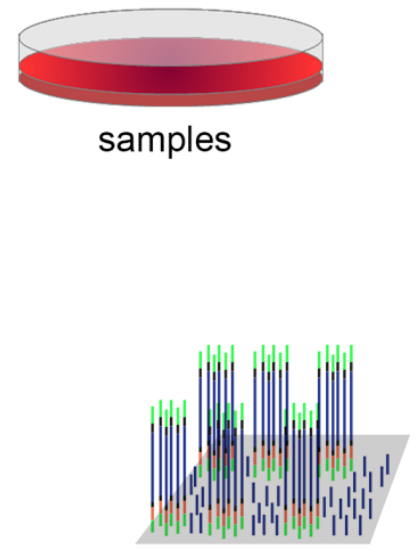

Illumina Sequencing and bioinformatic analysis
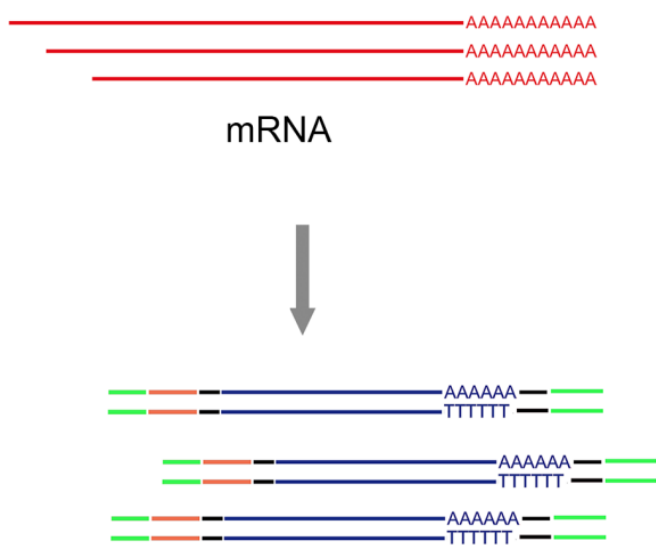

Library with adaptors

Fig. 3.3: Workflow of the transcriptomic analysis. mRNA was isolated from cell culture samples, cDNA libraries with the appropriate adaptors and Barcode sequences were introduced to enable simultaneous Illumina sequencing of different samples.

\subsection{Adult mouse brain proteome}

In a first step of the proteomic analysis, brains from adult mice were lysed, enzymatically digested and subjected to proteomic analysis. We could identify and quantify 11,328 proteins. We found that 147 proteins are $>10$-fold enriched in the brain as compared to the expression in the liver.

We then plotted the amount of protein in the brain (normalized protein intensity) against the enrichment in the brain as compared to liver (fold abundance over liver). Within the top 40 most abundant and enriched proteins we found components of the myelin sheath (CNP1, MBP and PLP1), the cytoskeleton (Actb, GFAP, Map1a, Map2, Map6, Nefh, Nefl, Sptan1, Tuba1b, Tubb3), synapses (Bsn, Camk2a, Camk2b, Dnm1, Snap25, Stx1b, Syn1, Syn2, Syt1), as well as glycolysis and energy pathways (Aldoa, Eno2, Ldhb) (Fig. 3.4). GO-based enrichment analysis further revealed that cell surface proteins are highly overrepresented within the brain-enriched proteins (data not shown). 

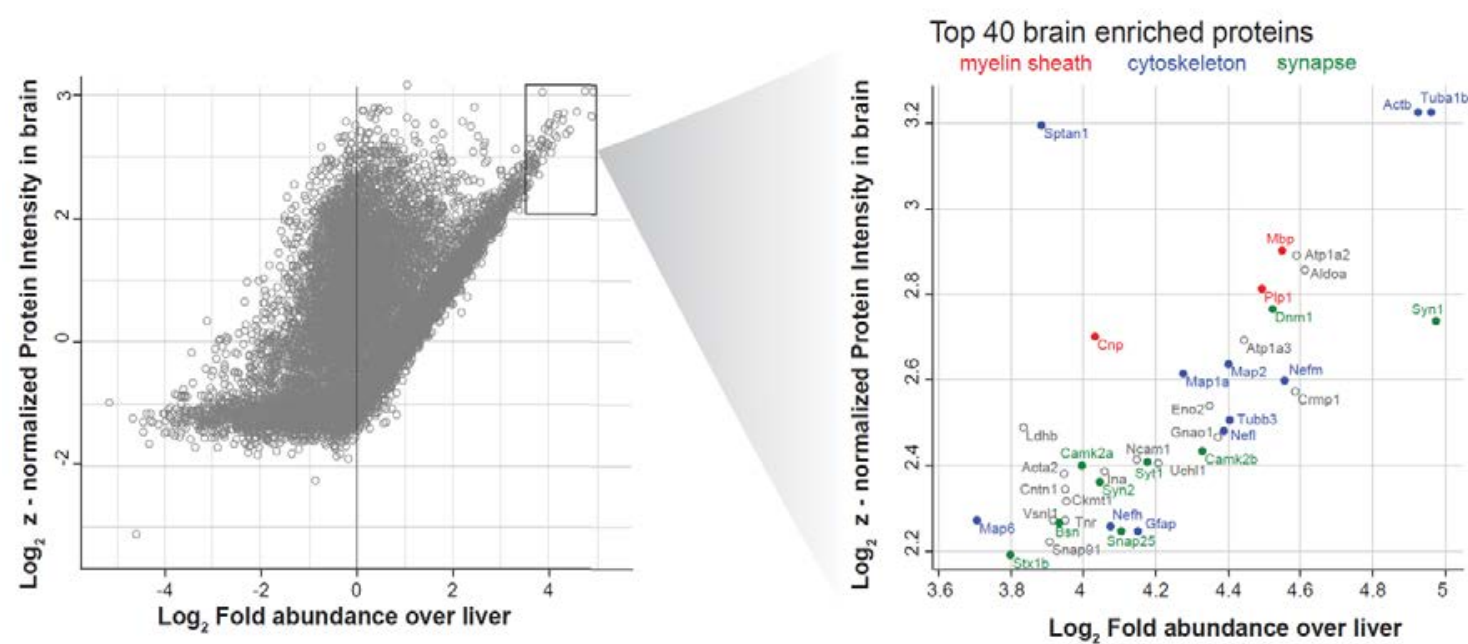

Fig. 3.4: Proteins enriched in the brain as compared to the liver proteome. Scatter plot of log2fold expression versus log2 LFQ intensity in the mouse brain as compared to the liver proteome. Among the top 40 most abundant proteins were components of the myelin sheath (red), the cytoskeleton (blue) and synapses (green).

\subsection{CNS Cell type proteomics}

Similar to the results of the mouse brain proteomics, we identified more than 11,000 proteins in the different CNS cell types (Fig. 3.5 a). Taken together, a total of 12,278 proteins could be identified. Out of these, 10,287 proteins were found in all of these samples (Fig. 3.5 b). Initial NGS data covered a total of 25,658 protein coding transcripts, however, but included ultra-low abundant gene products, with abundance lower than one RPKM. Such gene products result from rare stochastic transcription events and are thought to result in non-functional mRNAs. Therefore, we excluded these transcripts and obtained a number of 12,933 protein-coding gene products (Fig. 3.5 c).

a

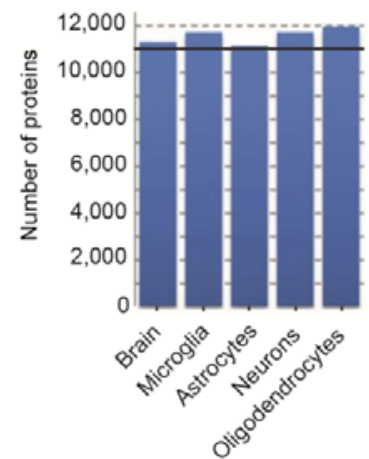

b

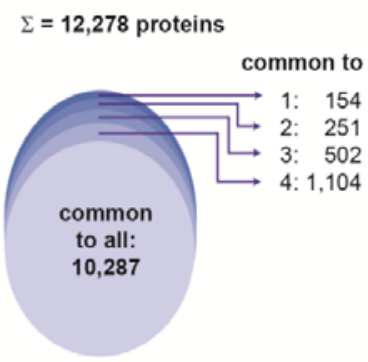

C

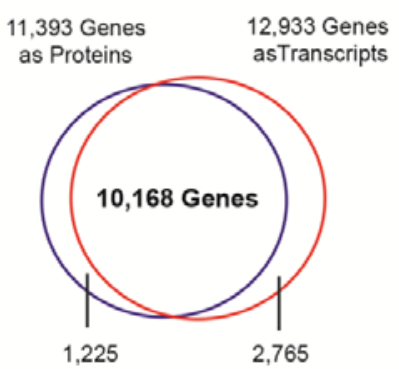

Fig. 3.5: Number of identified proteins and comparison to RNAseq data. (a) In the proteomic analysis, more than 11,000 proteins were identified in each sample. (b) A total of 10,287 proteins could be identified and quantified in all samples. (c) Venn-diagram of gene products found in proteomic and transcriptomic analysis. 
These results show that we identified approximately 10,000 proteins and almost 13,000 transcripts. For the transcripts, were no protein could be detected, we performed a Gene Ontology (GO) analysis. We found mainly G-protein coupled receptors, including olfactory receptors (data not shown). Such gene products are very unlikely to be functional in glia and cortical neurons. Therefore, we assume that these gene products are not actually translated and that our proteomic analysis is almost complete, which means that we found almost all proteins in neurons and glia.

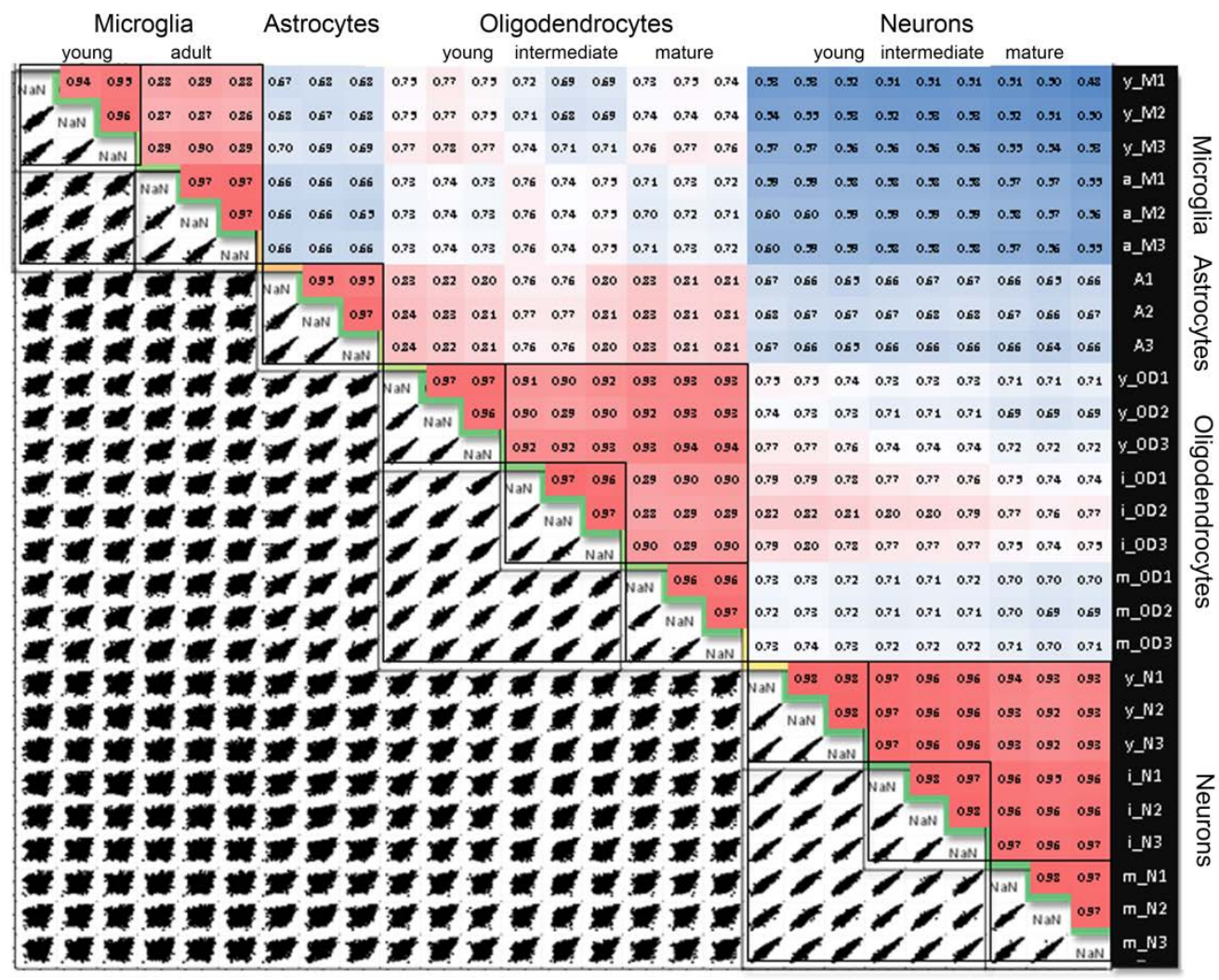

Fig. 3.6: High correlation between proteomes of similar cell types. Replicates of the same samples show high correlation (usually $>95 \%$, colored in red), while there is a lower correlation between different cell types (colored blue).

Next, we wanted to validate the quality of our proteomic datasets. The first step was to check the correlation between the different replicates of every cell type. Pearson's correlation coefficient was high between the different replicates, usually above $95 \%$, indicating that the same proteins could be identified in the different replicates. Furthermore, the correlation between related proteomes was very high, in young and mature oligodendrocytes, more than $90 \%$ identical proteins were found. The correlation between oligodendrocytes and astrocytes, both originating from the same precursors, was still 80\% (Fig. 3.6). 


\subsection{Proteins can be clustered according to their expression in cell types}

We clustered the proteins according to their expression level in the certain cell types (Fig. 3.7). As expected, proteome profiles are closest between similar cell types, oligodendrocytes and astrocytes derive from the same precursors and have related proteomes. Microglia are less related and show higher difference in the proteome. Neurons differ more from glial cells.

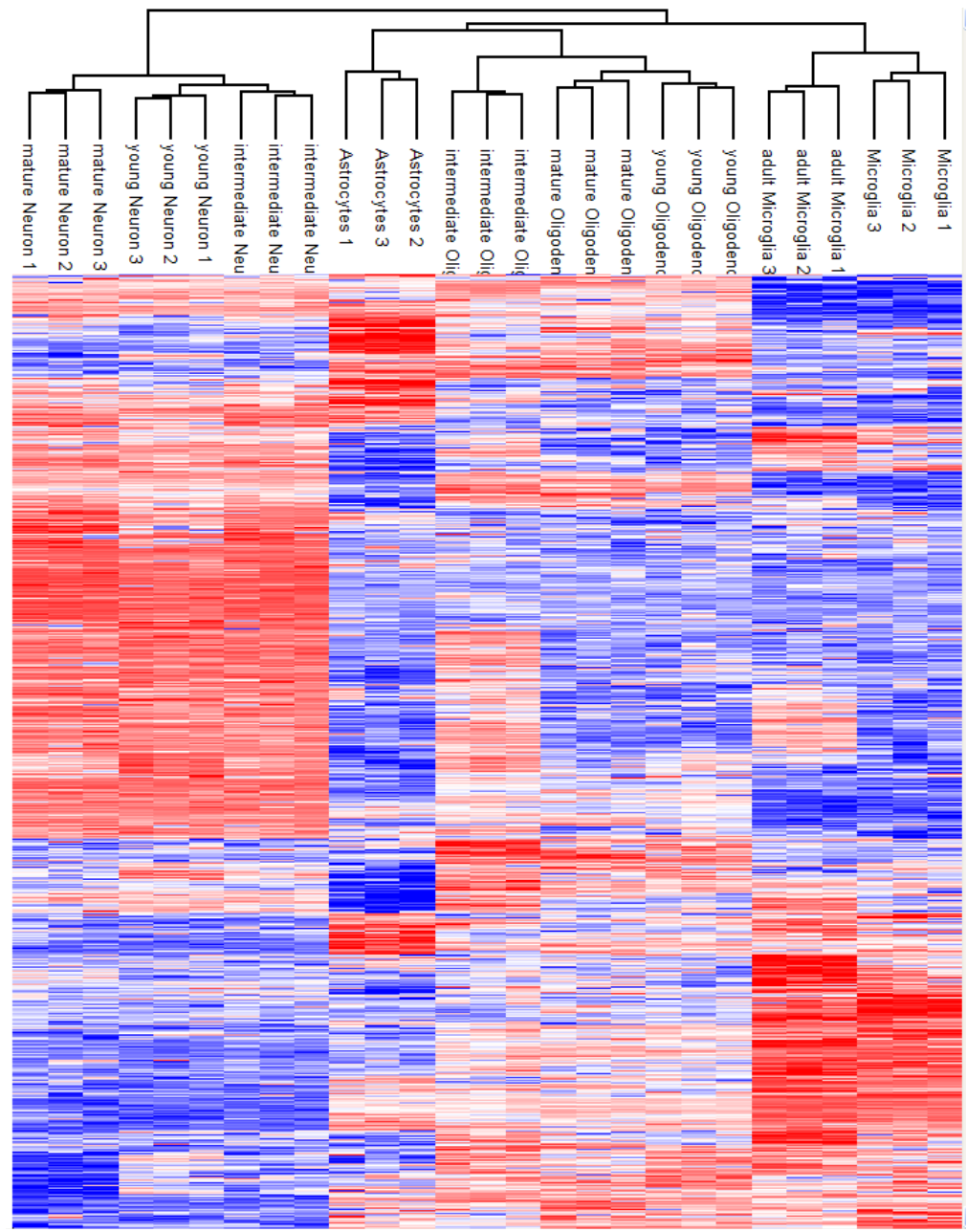

Fig. 3.7: Clustering of proteins according to their expression. Proteins with a low expression level are shown in blue, highly expressed proteins in red. The analysis clearly shows that certain clusters are mainly expressed in distinct cell types. 


\subsection{Pathways highly enriched in specific cell types}

For a quantitative analysis of the proteins in different cell types, we used the iBAQ algorithm. This tool normalizes the summed peptide identities by the number of theoretically observable peptides of the protein and, thereby, enables copy number estimation for every protein of the proteome. Based on these data, we clustered proteins that are at least 10-fold enriched in a particular cell type and performed a gene ontology analysis. Since the different cell types have distinct functions, this analysis should result in pathways that are important for the specific cell functions.

We found astrocytes to be highly enriched in pathways that are involved in metabolic function, such as amino acid metabolism and fatty acid metabolism. Furthermore, cytoskeleton related pathways were enriched and, surprisingly, the cilium (Tab. 3.1).

Tab. 3.1 Pathways enriched in astrocytes

\begin{tabular}{llcc}
\hline Type & Name & P-value & Enrichment \\
\hline GOCC name & mitochondrion & $4,48 \mathrm{E}-17$ & 1,85 \\
GOBP name & oxoacid metabolic process & $3,09 \mathrm{E}-14$ & 2,08 \\
GOBP name & organic acid metabolic process & $4,87 \mathrm{E}-14$ & 2,06 \\
GOBP name & carboxylic acid metabolic process & $3,09 \mathrm{E}-14$ & 2,08 \\
GOBP name & cellular ketone metabolic process & $1,96 \mathrm{E}-14$ & 2,07 \\
GOCC name & mitochondrial part & $8,54 \mathrm{E}-13$ & 1,90 \\
GOMF name & cofactor binding & $3,42 \mathrm{E}-12$ & 2,53 \\
GOBP name & small molecule metabolic process & $2,87 \mathrm{E}-11$ & 1,58 \\
GOCC name & mitochondrial matrix & $1,48 \mathrm{E}-10$ & 2,99 \\
GOMF name & oxidoreductase activity & $5,74 \mathrm{E}-11$ & 1,88 \\
GOCC name & contractile fiber part & $3,49 \mathrm{E}-10$ & 3,14 \\
GOBP name & organic acid catabolic process & $4,54 \mathrm{E}-10$ & 2,94 \\
GOBP name & carboxylic acid catabolic process & $4,54 \mathrm{E}-10$ & 2,94 \\
GOBP name & cellular amine metabolic process & $7,83 \mathrm{E}-10$ & 2,15 \\
GOMF name & coenzyme binding & $1,82 \mathrm{E}-09$ & 2,57 \\
GOBP name & cellular amino acid metabolic process & $1,34 \mathrm{E}-09$ & 2,25 \\
GOCC name & cilium & $4,48 \mathrm{E}-08$ & 2,77 \\
GOBP name & fatty acid oxidation & $1,28 \mathrm{E}-08$ & 3,85 \\
KEGG name & Valine, leucine and isoleucine degradation & $4,61 \mathrm{E}-08$ & 3,51 \\
GOBP name & fatty acid beta-oxidation & $2,21 \mathrm{E}-08$ & 4,09 \\
\hline
\end{tabular}

In microglia, we found different pathways that are connected to their function as immune cells, for example "immune response", "immune effector process" and "regulation of cytokine production" (Tab. 3.2). The proteins enriched in neurons (Tab. 3.3) were mainly grouped in pathways such as "neurological system process", "synapse" and "axon guidance". Moreover, it also contained pathways that are correlated with neuronal diseases, such as Alzheimer's disease and Parkinson's disease. Interestingly, also the pathway of "homophilic cell adhesion" was highly enriched. 
Tab. 3.2 Pathways enriched in microglia

\begin{tabular}{llcc}
\hline Type & Name & P-value & Enrichment \\
\hline GOBP name & immune system process & $9,24 \mathrm{E}-43$ & 2,17 \\
GOBP name & defense response & $3,54 \mathrm{E}-32$ & 2,24 \\
GOBP name & immune response & $8,64 \mathrm{E}-31$ & 2,47 \\
GOBP name & response to biotic stimulus & $1,12 \mathrm{E}-27$ & 2,14 \\
GOBP name & response to other organism & $1,97 \mathrm{E}-27$ & 2,42 \\
GOBP name & innate immune response & $4,49 \mathrm{E}-26$ & 2,71 \\
GOBP name & immune effector process & $1,06 \mathrm{E}-25$ & 2,51 \\
GOBP name & regulation of immune system process & $8,07 \mathrm{E}-22$ & 1,90 \\
GOBP name & multi-organism process & $2,26 \mathrm{E}-20$ & 2,00 \\
GOBP name & regulation of immune response & $2,69 \mathrm{E}-20$ & 2,18 \\
KEGG name & Lysosome & $2,78 \mathrm{E}-19$ & 2,60 \\
GOBP name & positive regulation of immune system process & $7,33 \mathrm{E}-19$ & 2,10 \\
GOCC name & lytic vacuole & $9,24 \mathrm{E}-19$ & 2,23 \\
GOCC name & lysosome & $2,11 \mathrm{E}-18$ & 2,22 \\
GOCC name & vacuole & $3,16 \mathrm{E}-17$ & 2,14 \\
GOBP name & defense response to virus & $3,33 \mathrm{E}-16$ & 2,78 \\
GOBP name & positive regulation of immune response & $4,39 \mathrm{E}-15$ & 2,24 \\
GOBP name & regulation of cytokine production & $1,43 \mathrm{E}-14$ & 2,15 \\
KEGG name & Ribosome & $1,95 \mathrm{E}-13$ & 2,79 \\
GOBP name & response to bacterium & $2,11 \mathrm{E}-13$ & 2,55 \\
\hline
\end{tabular}

Tab. 3.3 Pathways enriched in neurons

\begin{tabular}{llcc}
\hline Type & Name & P-value & Enrichment \\
\hline GOCC name & synapse part & $1,33 \mathrm{E}-27$ & 1,92 \\
GOCC name & neuron projection & $4,44 \mathrm{E}-22$ & 1,71 \\
GOCC name & synaptic membrane & $5,02 \mathrm{E}-21$ & 2,04 \\
GOBP name & neurological system process & $1,14 \mathrm{E}-17$ & 1,76 \\
GOBP name & regulation of transmission of nerve impulse & $3,75 \mathrm{E}-15$ & 1,93 \\
GOBP name & regulation of neurological system process & $3,75 \mathrm{E}-15$ & 1,93 \\
GOCC name & postsynaptic membrane & $3,94 \mathrm{E}-14$ & 1,96 \\
GOBP name & regulation of synaptic transmission & $1,88 \mathrm{E}-14$ & 1,93 \\
GOBP name & behavior & $2,09 \mathrm{E}-14$ & 1,67 \\
GOCC name & synapse & $2,61 \mathrm{E}-13$ & 1,78 \\
GOBP name & axon guidance & $1,06 \mathrm{E}-13$ & 2,14 \\
KEGG name & Huntington's disease & $2,70 \mathrm{E}-13$ & 1,90 \\
GOBP name & learning or memory & $3,08 \mathrm{E}-13$ & 1,95 \\
GOBP name & cognition & $3,58 \mathrm{E}-13$ & 1,92 \\
GOCC name & dendrite & $4,72 \mathrm{E}-12$ & 1,82 \\
GOBP name & homophilic cell adhesion & $2,00 \mathrm{E}-12$ & 2,27 \\
GOBP name & regulation of system process & $1,79 \mathrm{E}-12$ & 1,67 \\
KEGG name & Alzheimer's disease & $1,61 \mathrm{E}-11$ & 1,81 \\
KEGG name & Parkinson's disease & $1,51 \mathrm{E}-11$ & 1,94 \\
GOBP name & learning & $1,01 \mathrm{E}-11$ & 2,14 \\
\hline
\end{tabular}

The analysis of pathways in oligodendrocytes was more diverse (Tab. 3.4). Besides the most obvious function, "myelin sheath", also RNA metabolism is highly enriched in these cells. We further found that RNA metabolism pathways are enriched in young oligodendrocytes, while mature oligodendrocytes are enriched in membrane proteins. 
Tab. 3.4 Pathways enriched in oligodendrocytes

\begin{tabular}{llrc}
\hline Type & Name & P-value & Enrichment \\
\hline GOCC name & nuclear part & $2,67 \mathrm{E}-12$ & 1,79 \\
KEGG name & Spliceosome & $1,52 \mathrm{E}-11$ & 5,00 \\
GOMF name & nucleic acid binding & $1,75 \mathrm{E}-10$ & 1,71 \\
GOBP name & mRNA processing & $2,19 \mathrm{E}-10$ & 3,41 \\
GOBP name & RNA processing & $2,16 \mathrm{E}-10$ & 2,74 \\
GOBP name & RNA metabolic process & $1,73 \mathrm{E}-09$ & 1,78 \\
GOBP name & RNA splicing & $3,89 \mathrm{E}-09$ & 3,69 \\
GOBP name & mRNA metabolic process & $3,28 \mathrm{E}-09$ & 2,91 \\
GOBP name & nucleic acid metabolic process & $2,82 \mathrm{E}-09$ & 1,68 \\
GOCC name & spliceosomal complex & $8,33 \mathrm{E}-08$ & 4,00 \\
GOBP name & nucleobase-containing compound & & \\
& metabolic process & $5,61 \mathrm{E}-07$ & 1,47 \\
GOBP name & nitrogen compound metabolic process & $5,60 \mathrm{E}-07$ & 1,41 \\
GOCC name & catalytic step 2 spliceosome & $3,55 \mathrm{E}-06$ & 4,79 \\
GOCC name & ribonucleoprotein complex & $8,33 \mathrm{E}-06$ & 1,98 \\
GOMF name & DNA binding & $1,64 \mathrm{E}-06$ & 1,75 \\
GOCC name & nucleoplasm part & $2,32 \mathrm{E}-05$ & 1,90 \\
GOBP name & cellular nitrogen compound metabolic process $3,78 \mathrm{E}-06$ & 1,38 \\
GOMF name & RNA binding & $6,88 \mathrm{E}-06$ & 1,76 \\
GOCC name & myelin sheath & 0,0001672 & 7,15 \\
KEGG name & RNA transport & 0,00016147 & 2,73 \\
\hline
\end{tabular}

Taken together, the pathway analysis did not reveal any completely unknown pathways in these cells. However, it clearly showed that pathways known to be important in the biology of these cells are indeed upregulated. This demonstrates that our analysis also identified pathways enriched in cultured cells that are similar to their in-vivo functions.

\subsection{Determination of new, cell-type specific marker proteins}

So far, our analysis focused on pathways that are enriched in the particular cell types. Next, we wanted to identify the individual proteins that are enriched. In contrast to the pathway analysis, we applied less stringent criteria and sorted for proteins that are enriched by a factor of at least four and, at the same time, significantly different between cell types.

The top 20 proteins enriched in astrocytes (Tab. 3.5) included different cytoskeleton regulators such as Plekha7, Tppp3 and Advillin, intermediate filament proteins such as Synemin, but also metabolic enzymes such as Oxoprolinase and Mono-amine-oxidase. These data generally fit to the metabolic function of astrocytes. In microglia (Tab. 3.6), we found various proteins of immunological functions, including the macrophage mannose receptor, arachidonate lipoxygenases and CD180. Finding these proteins is consistent with the role of microglia as immune cells in the central nervous system. 
Tab. 3.5 Proteins highly enriched in astrocytes

\begin{tabular}{lllll}
\hline Gene & Protein name & $\begin{array}{c}\text { log2 } \\
\text { Intensity }\end{array}$ & $\begin{array}{c}\text {-log10 } \\
\text { ANOVA } \\
\text { P-value }\end{array}$ & $\begin{array}{c}\text { max } \\
\text { fold } \\
\text { change }\end{array}$ \\
\hline Plekha7 & Pleckstrin homology domain-containing & & & \\
& family A member 7 & 34,64 & 8,98 & 7,60 \\
Synm & Synemin & 35,14 & 9,83 & 7,37 \\
Lama5 & Laminin subunit alpha-5 & 35,96 & 9,45 & 7,18 \\
Dysf & Dysferlin & 36,55 & 14,97 & 6,56 \\
Fbn1 & Fibrillin-1 & 35,47 & 9,54 & 6,40 \\
Oplah & 5-oxoprolinase & 35,35 & 7,33 & 6,27 \\
Ptrf & Polymerase I and transcript release factor & 36,43 & 11,51 & 6,14 \\
Maob & Amine oxidase [flavin-containing] B & 34,37 & 8,91 & 6,08 \\
Shroom3 & Protein Shroom3 & 33,95 & 9,92 & 6,05 \\
Lrp2 & Low-density lipoprotein receptor-related & & & \\
& protein 2 & 32,84 & 6,00 & 5,82 \\
Cp & Ceruloplasmin & 35,31 & 10,96 & 5,81 \\
Folr1 & Folate receptor alpha & 32,98 & 9,55 & 5,77 \\
Zfp185 & Zinc finger protein 185 & 32,46 & 7,99 & 5,68 \\
Cryab & Alpha-crystallin B chain & 35,04 & 12,64 & 5,50 \\
Slc25a18 & Mitochondrial glutamate carrier 2 & 35,93 & 6,64 & 5,43 \\
Tppp3 & Tubulin polymerization-promoting protein & & & \\
& family member 3 & 36,22 & 11,11 & 5,39 \\
Avil & Advillin & 32,10 & 6,36 & 5,39 \\
Pawr & PRKC apoptosis WT1 regulator protein & 34,90 & 12,19 & 5,29 \\
Rin1 & Ras and Rab interactor 1 & 33,17 & 9,53 & 5,25 \\
Trip6 & Thyroid receptor-interacting protein 6 & 33,36 & 5,99 & 5,19 \\
\hline
\end{tabular}

Tab. 3.6 Proteins highly enriched in microglia

\begin{tabular}{llccc}
\hline Gene & Protein name & $\begin{array}{c}\text { log2 } \\
\text { Intensity }\end{array}$ & $\begin{array}{c}\text {-log10 } \\
\text { ANOVA } \\
\text { P-value }\end{array}$ & $\begin{array}{c}\text { max } \\
\text { fold } \\
\text { change }\end{array}$ \\
\hline F13a1 & Coagulation factor XIII A chain & 37,20 & 12,45 & 8,19 \\
Alox12| & Arachidonate 12-lipoxygenase, leukocyte-type 36,61 & 11,89 & 7,47 \\
Mrc1 & Macrophage mannose receptor 1 & 37,58 & 13,22 & 7,47 \\
Gm5483 & & 38,78 & 6,42 & 7,37 \\
Irg1 & Immune-responsive gene 1 protein & 37,89 & 9,60 & 7,15 \\
Stab1 & Stabilin-1 & 37,84 & 9,35 & 6,80 \\
Gvin1 & Interferon-induced very large GTPase 1 & 37,11 & 17,90 & 6,67 \\
Siglec1 & Sialoadhesin & 39,41 & 14,73 & 6,64 \\
Lyz2 & Lysozyme C-2 & 37,12 & 5,22 & 6,61 \\
Ptgs1 & Prostaglandin G/H synthase 1 & 36,77 & 6,89 & 6,49 \\
Syk & Tyrosine-protein kinase SYK & 36,71 & 12,93 & 6,15 \\
Msr1 & Macrophage scavenger receptor types I and II & 37,59 & 14,32 & 6,00 \\
Itgb2 & Integrin beta;Integrin beta-2 & 39,08 & 17,53 & 5,87 \\
Alox5 & Arachidonate 5-lipoxygenase & 35,68 & 10,78 & 5,56 \\
Cd180 & CD180 antigen & 36,80 & 7,33 & 5,44 \\
Cd36 & Platelet glycoprotein 4 & 37,27 & 9,21 & 5,39 \\
Creg1 & Protein CREG1 & 34,88 & 7,05 & 5,33 \\
Apobr & Apolipoprotein B receptor & 35,19 & 11,60 & 5,33 \\
Gpnmb & Transmembrane glycoprotein NMB & 36,38 & 10,33 & 5,30 \\
Adam8 & Disintegrin and metalloproteinase & & & \\
& domain-containing protein 8 & 34,36 & 8,11 & 5,29 \\
\hline & & & & \\
\hline
\end{tabular}


Tab. 3.7 Proteins highly enriched in neurons

\begin{tabular}{|c|c|c|c|c|}
\hline Gene & Protein name & $\begin{array}{c}\log 2 \\
\text { Intensity }\end{array}$ & $\begin{array}{l}\text {-log10 } \\
\text { ANOVA } \\
\text { P-value }\end{array}$ & $\begin{array}{c}\text { max } \\
\text { fold } \\
\text { change }\end{array}$ \\
\hline Stx1a & Syntaxin-1A & 36,71 & 14,65 & 7,76 \\
\hline Ppfia2 & Liprin-alpha-2 & 36,22 & 12,31 & 6,97 \\
\hline \multirow[t]{2}{*}{ Kiaa1239 } & Leucine-rich repeat and WD repeat-containing & & & \\
\hline & protein KIAA1239 & 34,59 & 8,39 & 6,56 \\
\hline Odz2 & Teneurin-2 & 36,17 & 14,11 & 6,53 \\
\hline Camkv & CaM kinase-like vesicle-associated protein & 36,53 & 15,82 & 6,51 \\
\hline $\mathrm{Napb}$ & Beta-soluble NSF attachment protein & 36,63 & 12,28 & 6,36 \\
\hline Plxna2 & Plexin-A2 & 36,22 & 14,39 & 6,36 \\
\hline L1cam & Neural cell adhesion molecule L1 & 37,02 & 13,72 & 6,31 \\
\hline lgsf3 & Immunoglobulin superfamily member 3 & 36,63 & 9,94 & 6,07 \\
\hline Add2 & Beta-adducin & 37,01 & 10,66 & 5,95 \\
\hline \multirow[t]{2}{*}{ Cxadr } & Coxsackievirus and adenovirus & & & \\
\hline & receptor homolog & 37,92 & 16,85 & 5,95 \\
\hline Pclo & Protein piccolo & 34,50 & 14,28 & 5,90 \\
\hline \multirow[t]{2}{*}{ Cacna2d1 } & Voltage-dependent calcium channel ubunit & & & \\
\hline & alpha-2/delta-1 & 36,44 & 16,10 & 5,86 \\
\hline Syt 1 & Synaptotagmin-1 & 36,81 & 14,06 & 5,74 \\
\hline Gucy1b3 & Guanylate cyclase soluble subunit beta-1 & 35,75 & 16,47 & 5,55 \\
\hline Slc32a1 & Vesicular inhibitory amino acid transporter & 34,99 & 14,98 & 5,51 \\
\hline Snap25 & Synaptosomal-associated protein 25 & 36,91 & 12,46 & 5,51 \\
\hline Lppr3 & $\begin{array}{l}\text { Lipid phosphate phosphatase-related } \\
\text { protein type } 3\end{array}$ & 35,56 & 11,90 & 5,46 \\
\hline \multirow[t]{2}{*}{ Atp2b2 } & Plasma membrane calcium-transporting & & & \\
\hline & ATPase 2 & 35,98 & 14,26 & 5,36 \\
\hline Dclk1 & Serine/threonine-protein kinase DCLK1 & 39,48 & 12,58 & 5,32 \\
\hline
\end{tabular}

Tab. 3.8 Proteins highly enriched in oligodendrocytes

\begin{tabular}{llllc}
\hline Gene & Protein name & $\begin{array}{c}\text { log2 } \\
\text { Intensity }\end{array}$ & $\begin{array}{c}\text {-log10 } \\
\text { ANOVA } \\
\text { P-value }\end{array}$ & $\begin{array}{c}\text { max } \\
\text { fold } \\
\text { change }\end{array}$ \\
\hline Bcas1 & Breast carcinoma-amplified sequence 1 & 39,19 & 15,78 & 8,63 \\
Plp1 & Myelin proteolipid protein & 38,38 & 12,05 & 6,96 \\
Col11a1 & Collagen alpha-1(XI) chain & 36,32 & 11,25 & 6,67 \\
Mbp & Myelin basic protein & 39,54 & 11,42 & 6,60 \\
Mag & Myelin-associated glycoprotein & 35,85 & 7,38 & 6,03 \\
Sox10 & Transcription factor SOX-10 & 35,12 & 9,87 & 4,81 \\
Adamts4 & A disintegrin and metalloproteinase & & & \\
& with thrombospondin motifs 4 & 35,06 & 6,43 & 4,79 \\
Ugt8 & 2-hydroxyacylsphingosine 1-beta- & & & \\
& galactosyltransferase & 36,94 & 12,28 & 4,61 \\
II1rap & Interleukin-1 receptor accessory protein & 35,18 & 8,74 & 4,47 \\
Enpp6 & Ectonucleotide pyrophosphatase/ & & & \\
& phosphodiesterase family member 6 & 36,21 & 12,47 & 4,37 \\
Tnr & Tenascin-R & 37,01 & 10,59 & 4,01 \\
Tmem88b & Transmembrane protein 88B & 32,87 & 11,53 & 3,99 \\
Psip1 & & 34,80 & 5,11 & 4,73 \\
Tppp & Tubulin polymerization-promoting protein & 36,51 & 6,83 & 3,93 \\
Cnp & 2,3-cyclic-nucleotide 3-phosphodiesterase & 40,36 & 17,86 & 3,83 \\
Slc44a1 & Choline transporter-like protein 1 & 34,29 & 8,74 & 3,78 \\
Vcan & Versican core protein & 35,58 & 9,44 & 3,66 \\
Cspg4 & Chondroitin sulfate proteoglycan 4 & 35,92 & 12,33 & 3,51 \\
Clca1;Clca2 & Calcium activated chloride channel regulator1 & 34,53 & 11,18 & 3,44 \\
Afap112 & Actin filament-associated protein 1-like 2 & 35,51 & 9,58 & 4,04 \\
\hline & & & &
\end{tabular}


The highly enriched proteins of neurons (Tab.3.7) included known synaptic proteins such as Syntaxin 1A, Snap25, Synaptotagmin and Piccolo: Furthermore, cell adhesion molecules such as L1 and Igsf3 were found. Among the oligodendrocyte-specific proteins (Tab. 3.8) are known myelin proteins such as Plp1, Mag, Cnp and Mbp. Other proteins have not been described or thoroughly analyzed in oligodendrocytes so far, this included Bcas1, Col11a1, Adamts4, Il1rap and Enppp6. 
To confirm that these gene products are indeed expressed in oligodendrocytes, we performed RT-qPCR on cDNA prepared from oligodendrocytes, astrocytes, microglia, neurons and fibroblasts. Plp1 served as a positive control. Our data show that all of these gene products are indeed expressed in oligodendrocytes (Fig. 3.8). Since Bcas1 and Col11a1 are the proteins of highest expression level and specificity (Tab. 3.8), we chose those proteins for further biological analysis.
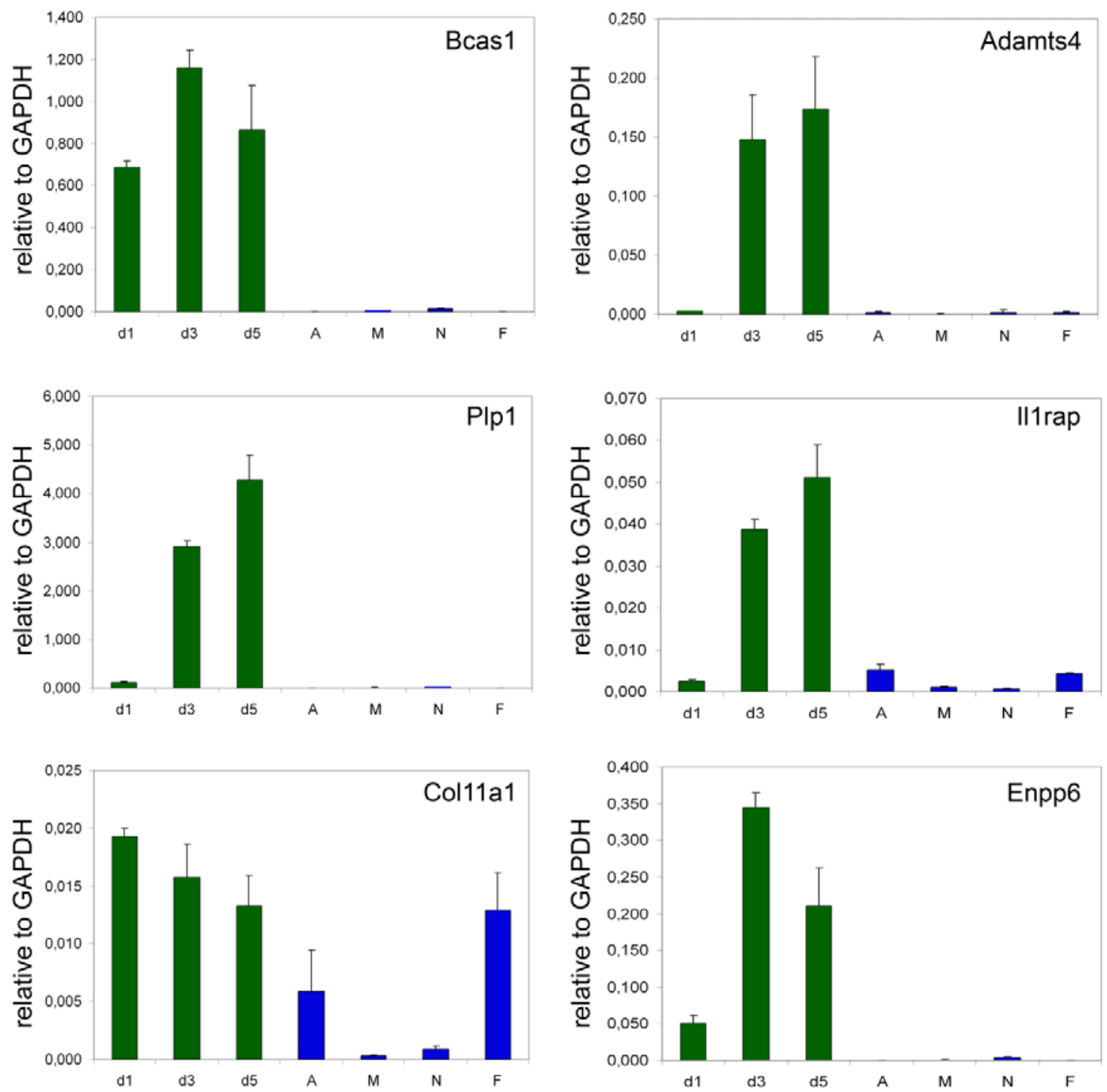

Fig. 3.8: RT-qPCR analysis confirms expression of highly enriched gene products. RT-qPCR analysis of primary cell cultures was performed and expression was calculated relative to GAPDH. Expression of the different gene products in oligodendrocytes could be confirmed in all cases. Note that Bcas1 is early expressed and stays upregulated. In contrast, Col11a1 is high in young cells and decreases over time. Like Plp1, Adamts4, Il1rap and Enpp6 are upregulated in more mature oligodendrocytes (d1: OPCs on DIV-1, d3: OPCs on DIV-3, d5: OPCs on DIV-5, A: Astrocytes, M: Microglia, N: Neurons, F: Fibroblasts, Bars show mean \pm SD, $\mathrm{n}=3-4$ technical replicates). 


\subsection{Col11a1 as a new marker for immature oligodendrocytes}

A first candidate that we chose from the proteomic analysis was Col11a1. We wanted to confirm that the protein is indeed expressed in oligodendrocytes and performed immuno-cytochemistry of cultured brain cells. Col11a1 is expressed in very young oligodendrocytes, but not in mature cells. An expression in astrocytes and microglia was not detected, fibroblasts, however, showed a faint staining (Fig. 3.9).
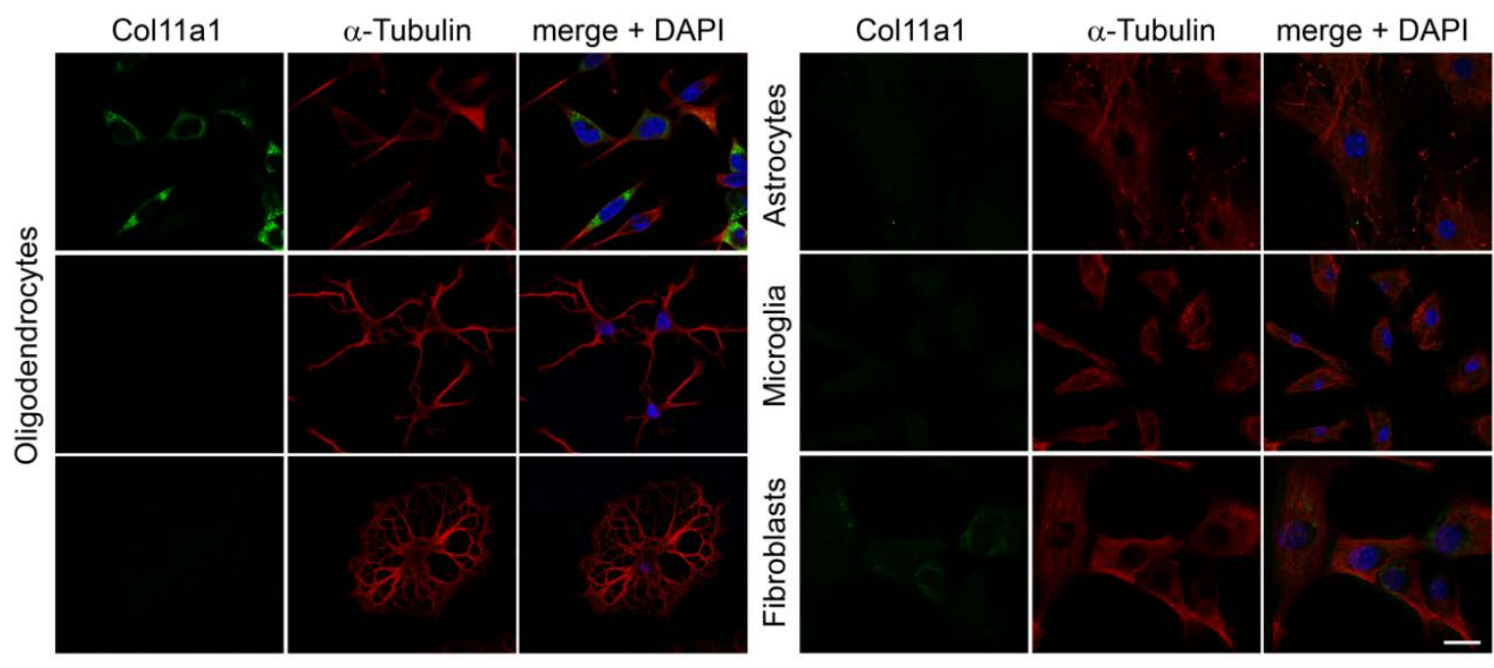

Fig. 3.9: Immunocytochemistry shows Col11a1 expression in young oligodendrocytes. Oligodendrocytes were fixed with 4\% PFA after 14 hours, $2 \frac{1}{2}$ and 4 days in culture) and immuno-stained for Col11a1 and $\alpha$-Tubulin. Astrocytes, Microglia and Fibroblasts served as controls. Col11a1 is mainly expressed in young oligodendrocytes and, to lower extend, in fibroblasts (Scale bar: $20 \mu \mathrm{m}$ ).

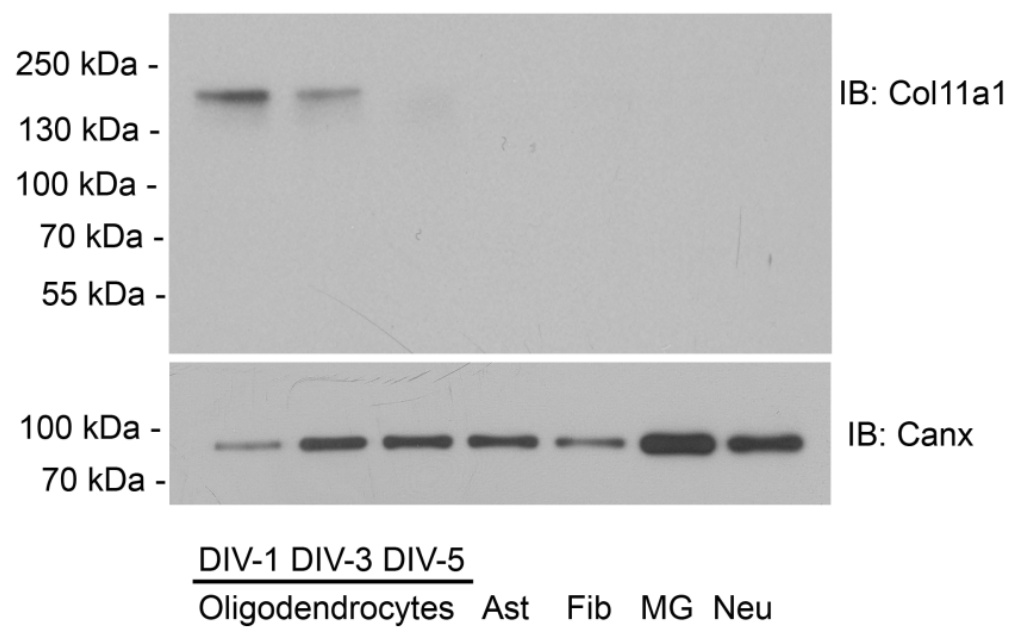

Fig. 3.10: Western Blot analysis confirms expression of Col11a1 in young oligodendrocytes. Cell lysates were separated in SDS-PAGE, blotted onto nitrocellulose membranes and probed with antibodies against Col11a1 and Calnexin. Western blot shows that Col11a1 is expressed in young OPCs; no expression was observed in other cell types (Ast: Astrocytes, Fib: Fibroblasts, MG: Microglia, Neu: Neurons). 
We also performed a Western Blot analysis of cell lysates and observed a similar expression pattern: Col11a1 was found in OPCs on DIV-1, and, at a lower level, in more mature OPCs on DIV-3. The protein was not detected in lysates of mature oligodendrocytes, astrocytes, fibroblasts, microglia or neurons (Fig. 3.10).

Besides cultured oligodendrocytes, we wanted to visualize the localization of Col11a1 in the brain. Even if the protein is further processed and secreted, we expected localization within myelinating areas of the brain. When we performed an immunostaining of the brain of a three-week old mouse, we observed a staining in the striatum, in areas where myelination was already ongoing, as shown by MBP-staining (Fig. 3.11).

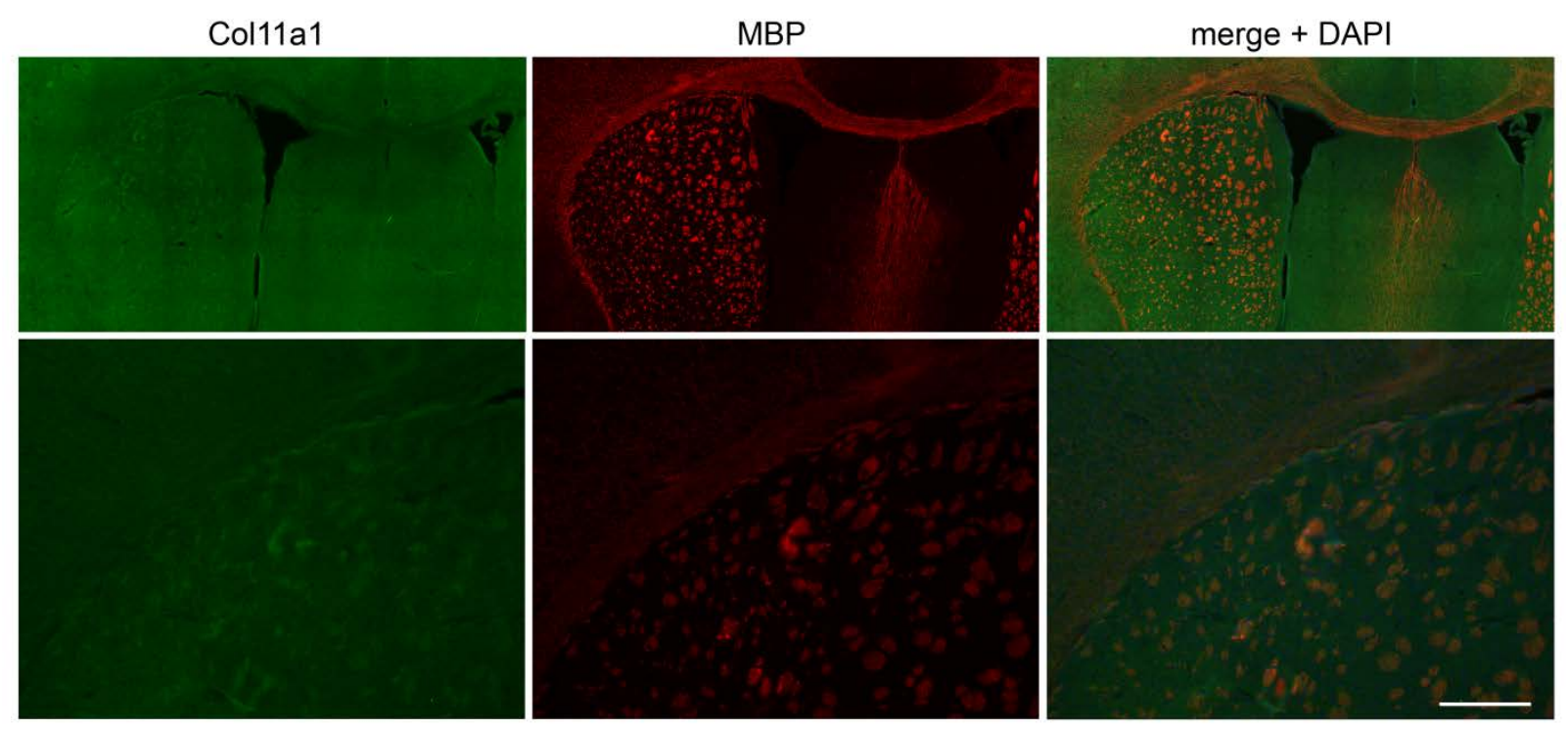

Fig. 3.11: Expression of Col11a1 in the striatum of a young mouse. Immunostaining on brain slices of a three-week old mouse shows localization in myelinating areas (Scale bar: 50 $\mu \mathrm{m})$.

These data show that Col11a1 is indeed expressed by cultured oligodendrocytes and can be found in myelinated areas within the brain. This finding demonstrates that our proteomic analysis successfully identified a novel protein in young oligodendrocytes. 


\subsection{Bcas1 as a new marker for oligodendrocytes}

A second protein that we found highly expressed and highly specific in oligodendrocytes was the Breast carcinoma amplified sequence 1 (Bcas1). As shown above, Bcas1 expression in oligodendrocytes was confirmed by RT-qPCR (Fig. 3.8).

We wanted to find out if this gene product is also expressed in other tissues apart from the brain. Therefore, we performed RT-qPCR analysis of tissues from adult mice and found Bcas1 clearly expressed in brain, stomach and testis (Fig. 3.12).

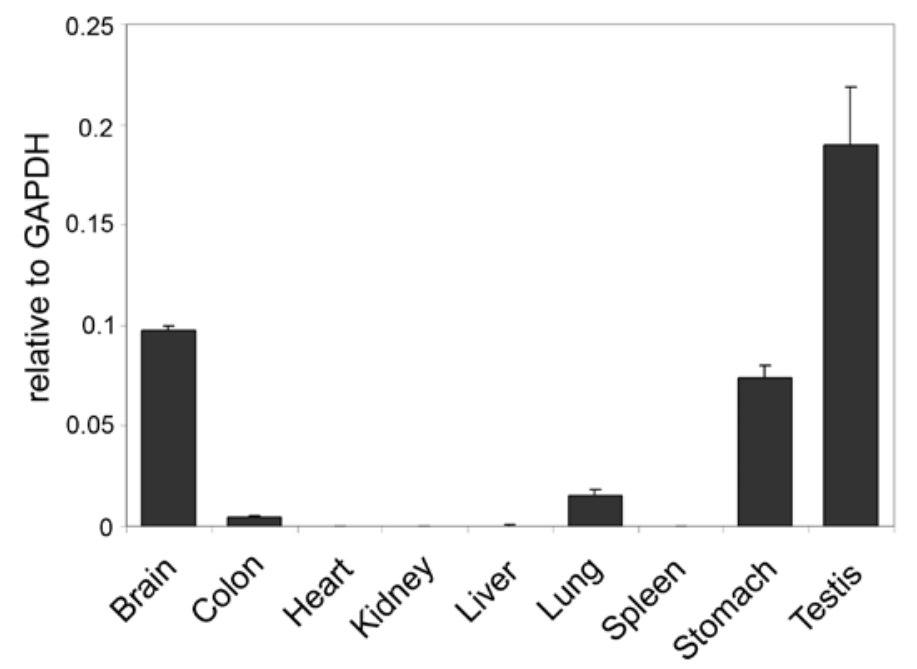

Fig. 3.12: Bcas1 is expressed in brain, stomach and testis. Expression of Bcas 1 in different tissues of adult mice was determined by quantitative real-time PCR. Expression was highest in testis, stomach and brain. A certain level of Bcas1 is also detectable in the lung (Bars show mean $\pm S D, n=3-4$ technical replicates).

Besides a potential function Bcas1 in oligodendrocytes, these results indicate that Bcas1 might play a role in cells outside of the brain. This finding was important for us for the generation of Bcas1-deficient mice. As described later, we started generating conditional knockout mice, since it was not clear if conventional knockout mice are fertile and viable.

\section{Bcas1 localizes to the cell cortex and actin-rich structures}

In order to find out more about the potential function of Bcas1, we wanted to determine the subcellular localization of Bcas1. During this study, we found that commercially available Bcas1 antibodies were not specific in Western blot and immuno-staining (data not shown). As the generation of a specific antibody is still ongoing, we wanted to determine subcellular localization of Bcas1 using a tagged expression construct. Therefore, we generated an plasmid with the murine Bcas1 cDNA sequence and a C- 
terminal myc-tag. This plasmid was used to transfect the oligodendrocyte-precursor cell line Olineu. As Bcas1 was first described in breast cancer cells, we also transfected the human breast cancer cell line SKBR3 with this construct. A plasmid encoding for the cytoplasmic fluorescent protein maxGFP was used as a control. As expected, GPF showed general cytoplasmic localization in both cell types. Interestingly, we found Bcas1 at the cell cortex together with actin filaments (Fig. 3.13).

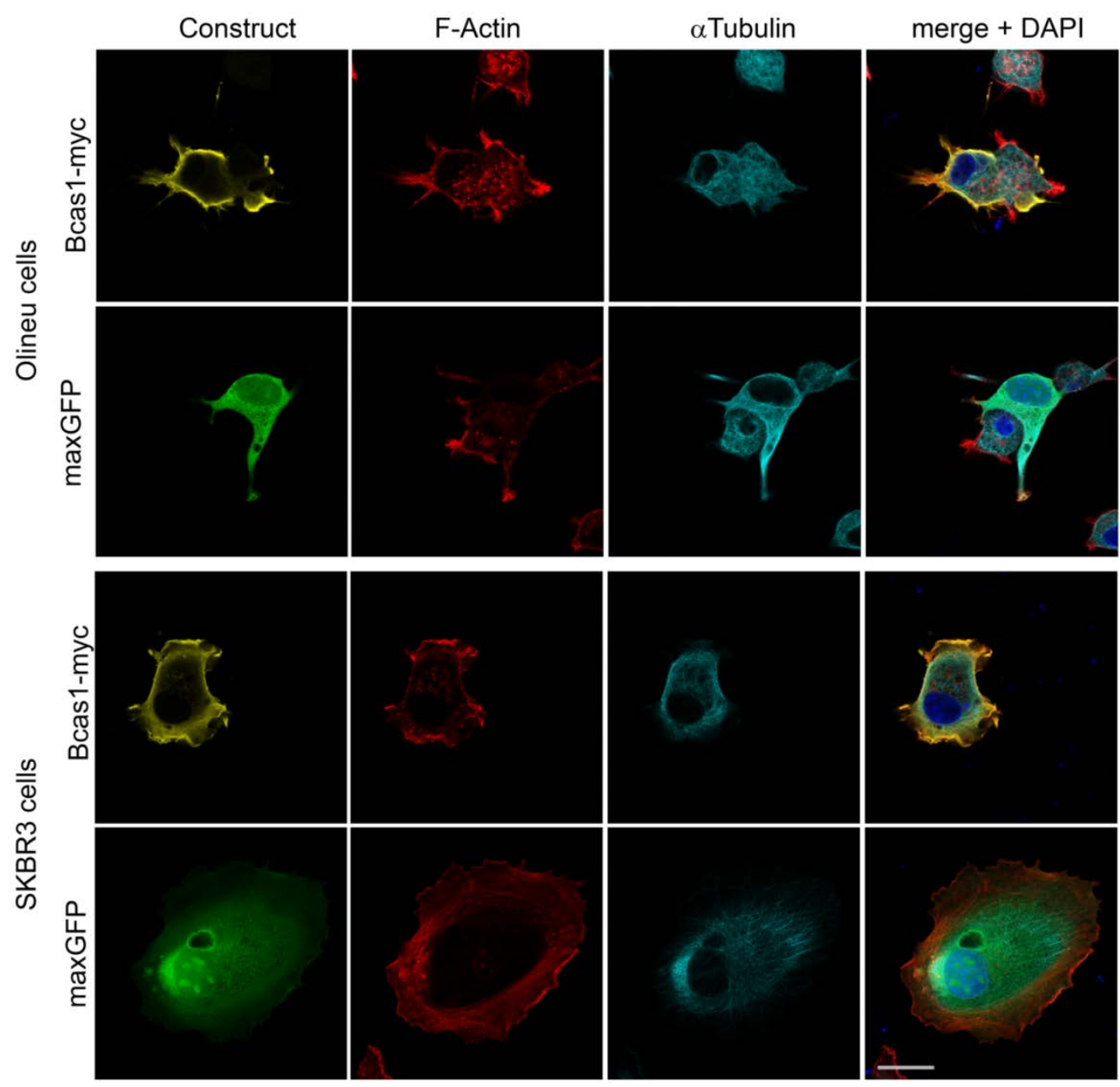

Fig. 3.13: Bcas1 localizes at actin-rich structures. Oli-neu cells and SKBR3 cells were transfected with plasmids encoding myc-tagged Bcas1 or maxGPF and fixed with 4\% PFA after 18 hours. Subsequently, cells were stained using antibodies against the myc-tag and $\alpha$-Tubulin, actin-filaments were visualized using fluorescently labeled Phalloidin. Images show a clear localization of Bcas1 at the cortex of the cells and localization to actin-rich structures (Scale bar: $20 \mu \mathrm{m})$.

The localization at the cell cortex together with actin filaments could indicate that Bcas1 binds to biological membranes and/or actin filaments. One the specific antibody has been generated and evaluated, further experiments will be performed to confirm localization of Bcas1. As nothing was known about the function of Bcas1, we generated targeted Bcas1 mice and, eventually, knockout mice. 


\section{Generation of Bcas1 targeted mice}

So far, we showed that Bcas1 is expressed in the brain and highly enriched in young and mature oligodendrocyte. In order to find out more about the function of Bcas1 we wanted to generate Bcas1-deficient mice. Since RT-qPCR showed that Bcas1 is also expressed in testis, stomach and lung, we could not exclude lethality or infertility of conventional knockout mice. As a consequence, we decided to generate targeted Bcas1 mice to allow a conditional, oligodendrocyte specific ablation of Bas1.

We obtained commercially available ES-cells for Bcas1 targeting. These cells contained $\beta$-galactosidase- and neomycin resistance-cassettes between FRTsequences. Furthermore, exon 3 was flanked by loxP sites and a third loxP-sequence was localized between the $\beta$-galactosidase- and neomycin resistance-cassettes (Fig. 3.14).

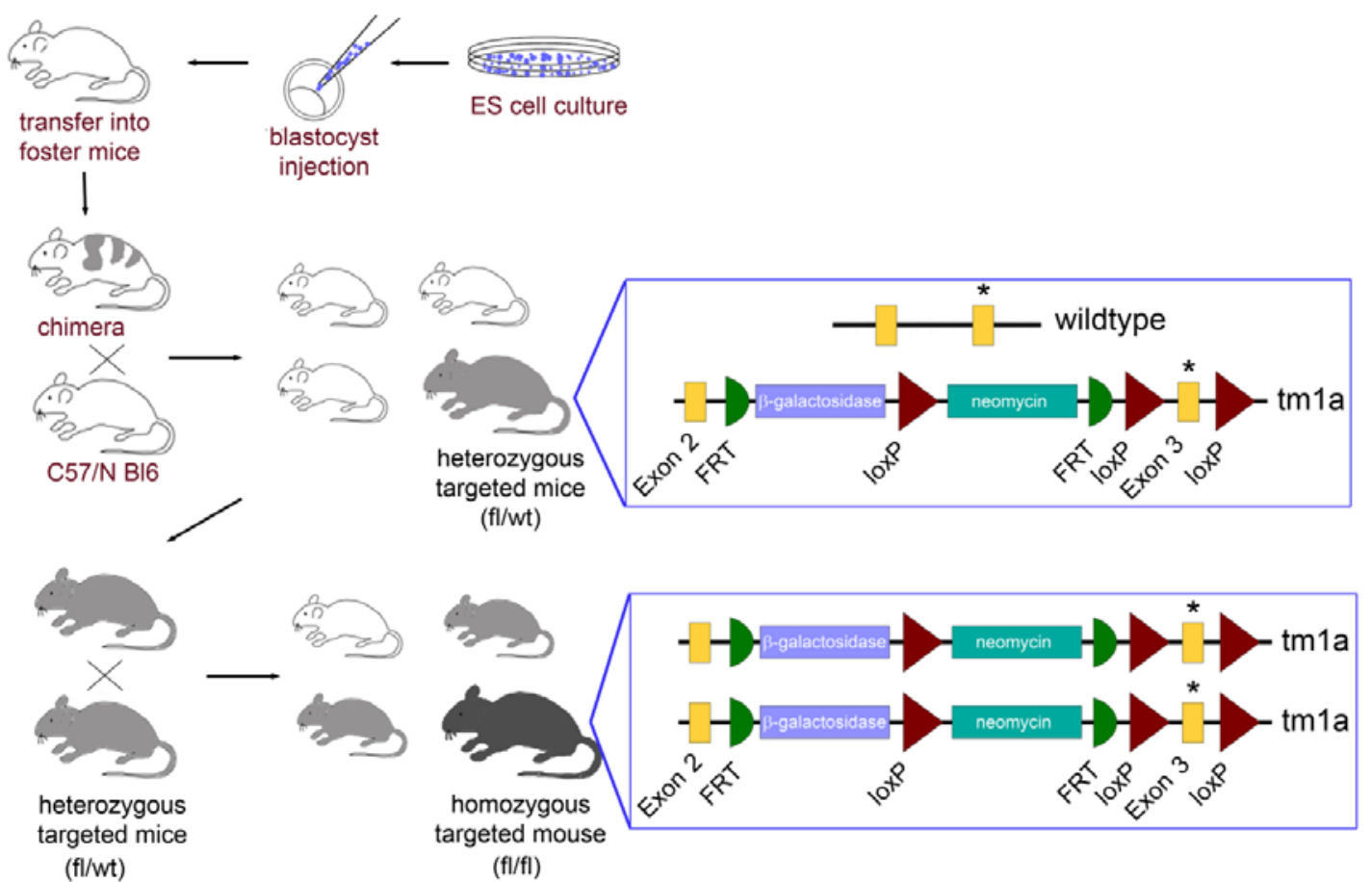

Fig. 3.14: Strategy to generate Bcas1 targeted mice (BCASFX). Bcas1 targeted mice were prepared from commercially available ES cells. These cells were injected into blastocysts to obtain chimeric founder animals. The resulting animals were bred with C57/N BI6 wildtype mice to obtain heterozygous mice. These mice were further bred to gain homozygous targeted mice (Bcas1<tm1aMsi>).

We injected these ES cells into mouse blastocysts and obtained five chimeric mice with an overall chimerism between $5 \%$ and $80 \%$. Two male mice with a chimerism of $80 \%$ were bred with C57N/BI6 wildtype mice to check germ-line transmission and to obtain heterozygous transgenic mice. Breeding of the first chimera resulted in a total of 17 
pups, all of which were wildtype. Breeding of the second chimera also resulted in 17 pups, out of which five mice were heterozygous targeted mice. These animals were used bred among each other to obtain homozygous targeted mice. Systematically, this mouse line were termed "Bcas $1<\operatorname{tm} 1 a M s i>$ ", in our lab it carries the name "BCASFX" (Fig. 3.10). These animals did not exhibit any obvious clinical symptoms, were viable and fertile.

Floxed Bcas $1<\mathrm{tm} 1 \mathrm{aMsi}>$ mice contained $\beta$-galactosidase- and neomycin resistancecassettes flanked by FRT-sites. We removed these cassettes by crossing with FLPrecombinase mice; offspring was subsequently crossbred with C57/BL6 wildtype mice to remove the FLP-recombinase. The short lab name of these mice is "FLIR_Rec", according to official nomenclature, these mice are called "Bcas $1<$ tm1cMsi>" (Fig. 3.15).

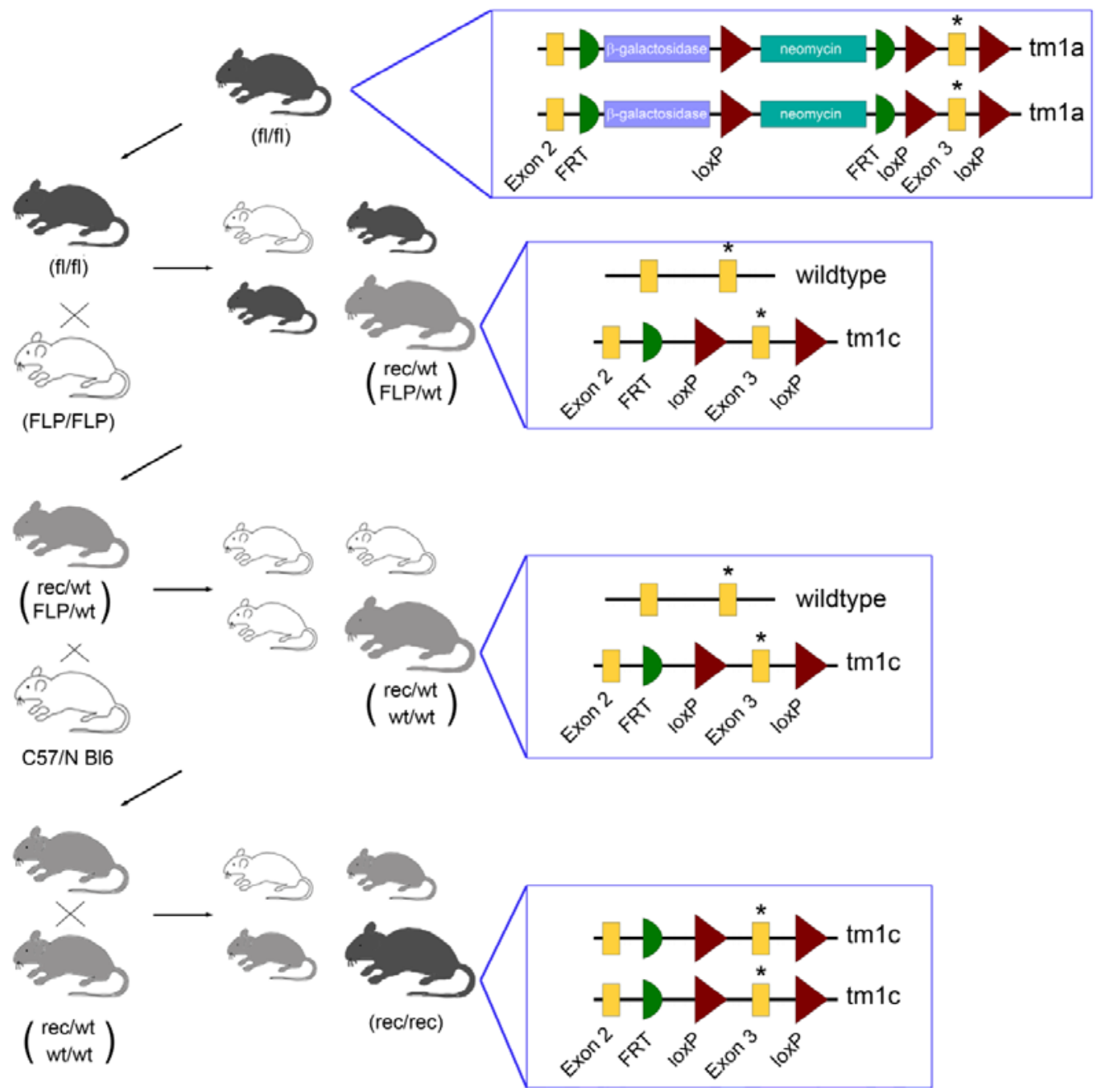

Fig. 3.15: Strategy for the removal of resistance and reporter cassettes. Floxed Bcas $1<\mathrm{tm} 1 \mathrm{aMsi}>$ were bred with FLP recombinase mice. The offspring was heterozygous for FLP recombinase and recombined, targeted Bcas1. Breeding of these animals with C57/N BI6 
wildtype mice was performed to remove the FLP recombinase and, in a second step, obtain homozygous recombined animals. The strain was termed "FLIR-Rec" or "Bcas1<tm1c-Msi>".

The genotypes of the animals were determined using at least three different PCRs: The PCR-A was designed to specifically identify transgenic mice. One primer binds to a sequence in exon 3, the other in a transgene-specific sequence. Genomic DNA of wildtype mice cannot be amplified with this reaction, while targeted mice give a $347 \mathrm{bp}$ PCR product. PCR-B was performed with three primers; the first binds to a part of the 5' homology arm, the second to the $\beta$-galactosidase cassette, the third in the 3 ' homology arm. These primers amplify a $647 \mathrm{bp}$ product for wildtype animals and a $534 \mathrm{bp}$ product for the transgenic animals with $\beta$-galactosidase cassette. Upon FLPrecombination, these primers give a 750 bp product. Furthermore, we used primers to detect the LacZ/ $\beta$-galactosidase cassette (Fig. 3.16).
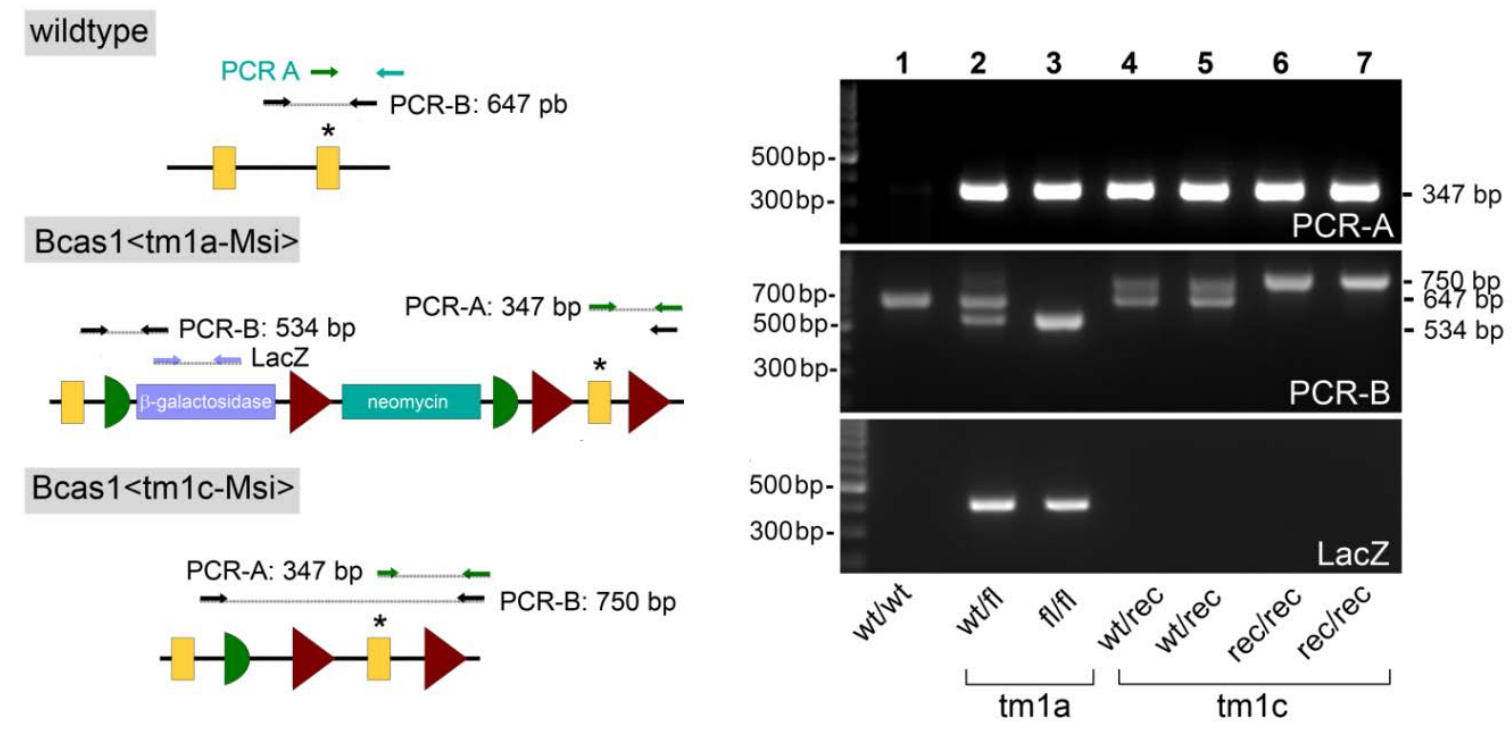

Fig. 3.16: Generation of Bcas1 targeted mice. Genomic DNA of mice was analyzed by three different PCRs to distinguish between wildtype mice and mutant animals before and after FLPrecombination. PCR-A gives a $347 \mathrm{bp}$ product for genetically modified animals, as long as the targeted exon is still there. PCR-B gives a $647 \mathrm{bp}$ product for wildtype, $534 \mathrm{bp}$ for mutant mice before and $750 \mathrm{bp}$ after FLP-recombination. The LacZ PCR amplifies a part of the $\beta$ galactosidase cassette. 


\section{Specific ablation of Bcas1 in oligodendrocytes}

To study a potential role of Bcas1 in oligodendrocytes, floxed Bcas1 mice after FLPrecombination ("Bcas1<tm1c-Msi>") were cross-bred with homozygous CNP1-Crerecombinase mice. CNP1 is expressed in young oligodendrocytes and Schwann cells and is therefore used to for the ablation of Bcas1 in these cells (Fig. $\mathbf{3 . 1 7} \mathrm{a}$ ).

a

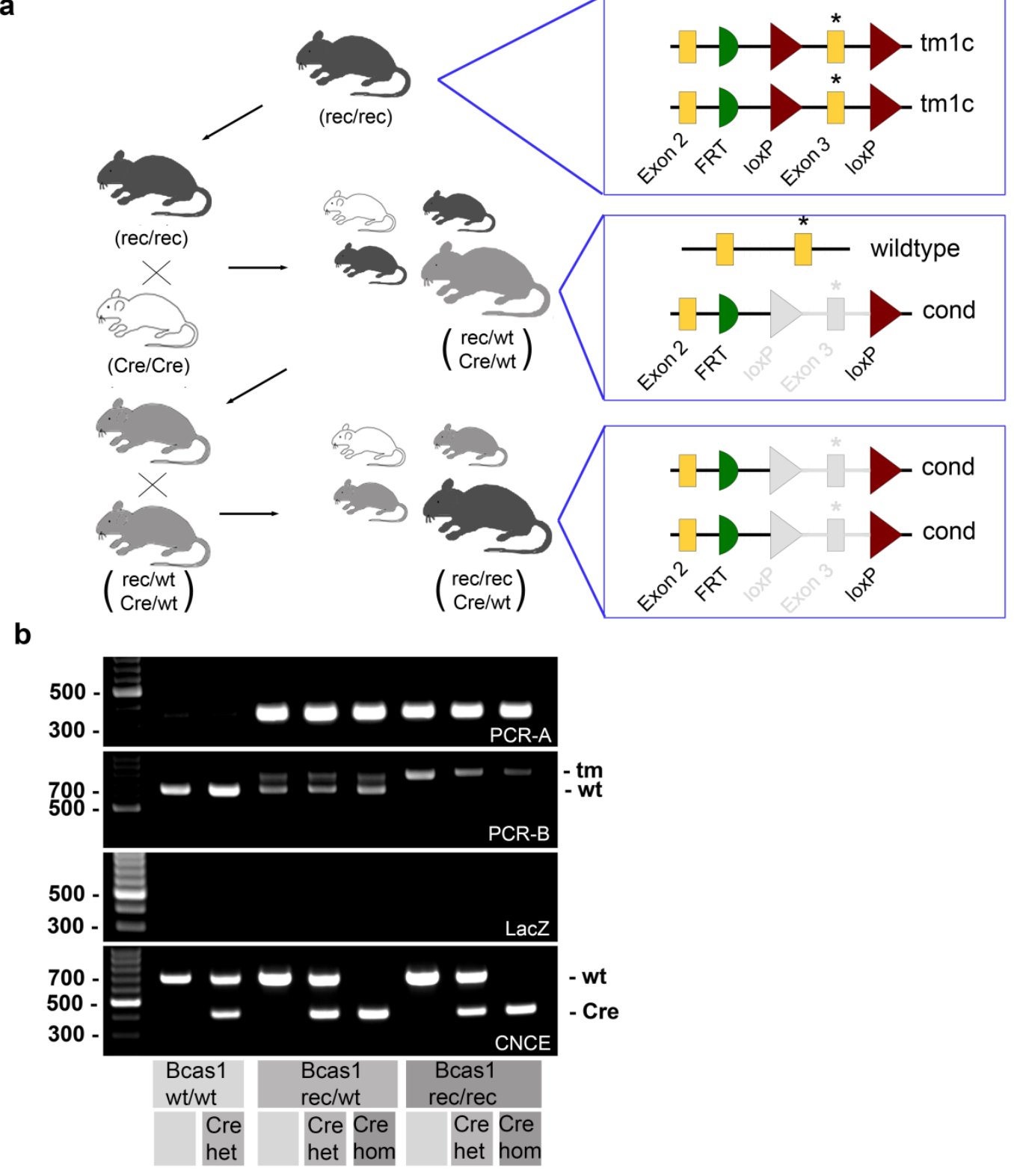

Fig. 3.17: Generation of conditional Bcas1 knockout mice. (a) Homozygous floxed Bcas1<tm1c-Msi> mice after FL recombination were bred with CNP1-Cre recombinase mice. The offspring was further bred to obtain homozygous floxed mice with heterozygous CNP1-Cre. (b) Genomic DNA was analyzed as mentioned above. Sample 1 represents wildtype, while sample 2 is heterozygous CNP1-Cre. Samples 3 - 5 are from heterozygous Bcas1 targeted mice, samples 6 - 8 from homozygous targeted mice. 
After breeding FLR-recombined, targeted Bcas1 mice with CNP-Cre mice and subsequent breeding of the offspring, we obtained homozygous floxed Bcas1 mice with CNP-Cre (Fig. 3.17, b). These mice were viable, fertile and did not show obvious clinical symptoms.

\section{Analysis of Bcas1 conditional knockout mice reveals myelin abnormalities}

We were interested if myelination might be disturbed in the conditional knockout mice. Therefore, we prepared optic nerves of four months and 12 months old animals for electron microscopy (Fig. 3.18 a). The ratio between the axonal diameter and the diameter of the myelinated axon, the g-ratio, was determined for all samples. In the four months old animals, we did not observe a difference in myelin thickness between the conditional knockout animals and the floxed Bcas1 controls. In the 12 months old animals, however, we found an increased g-ratio in the knockout animals, indicating thinner myelin (Fig. 3.18 b).

a

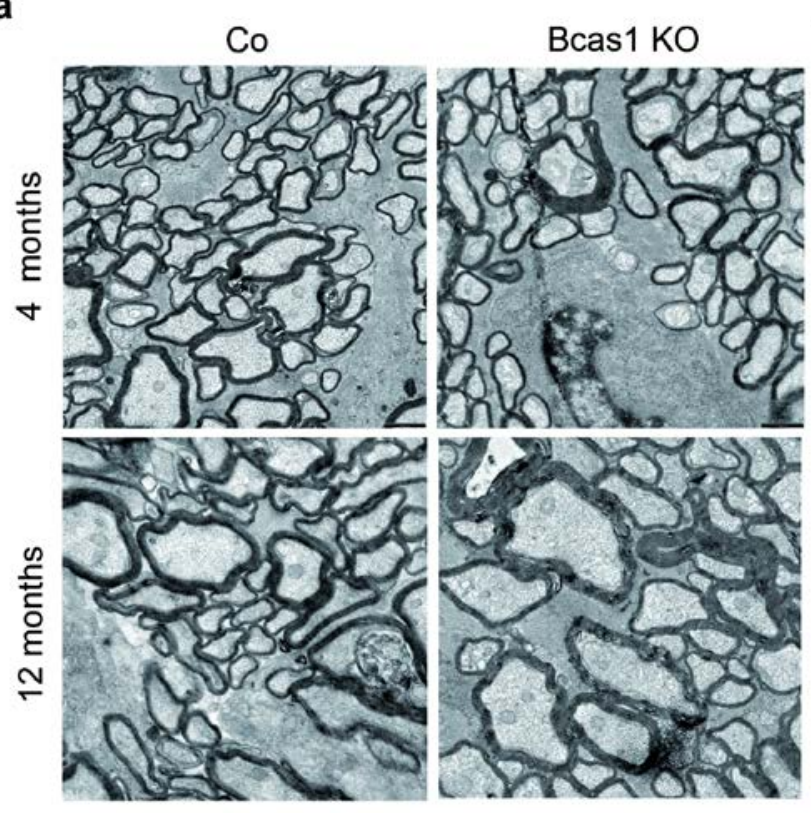

b
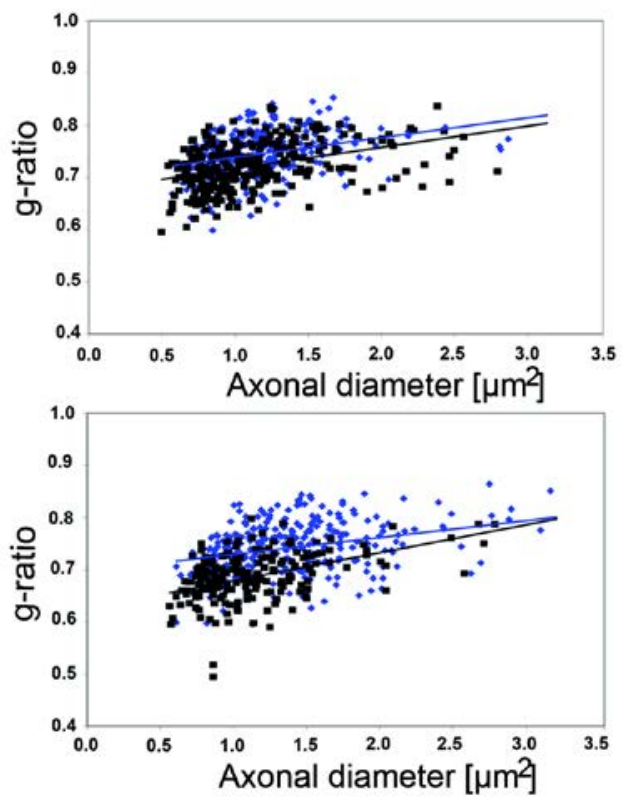

Fig. 3.18: Myelin is disturbed in conditional Bcas1 knockout mice. (a) EM images of ultrathin section of optic nerve from conditional Bcas1 knockout mice and floxed control animals at 4 months and 12 months of age. (b) Scatter plots of g-ratios from individual fibers of optic nerves from floxed controls (black) and Bcas1 conditional knockout mice (blue) The g-ratio in one year old mice is increased in conditional knockout mice, indicating that myelin is thinner in the knockout as compared to control animals. 


\section{Conventional knockout of Bcas1}

Besides the effect of Bcas1-loss in myelinating cells, we were further interested in the function of Bcas1 in other brain cells and further tissues. Therefore, Bcas1<tm1cMsi> mice were bred with E2A-Cre mice, that should have a ubiquitous expression of Crerecombinase.

The F1 generation was further crossed with C57/N Bl6 wildtype mice, to ensure a full loss of the exon 3 and to remove the Cre-transgene. The resulting offspring was further bred to obtain homozygous Bcas1 knockout mice. This mouse line was termed "NBCAS".

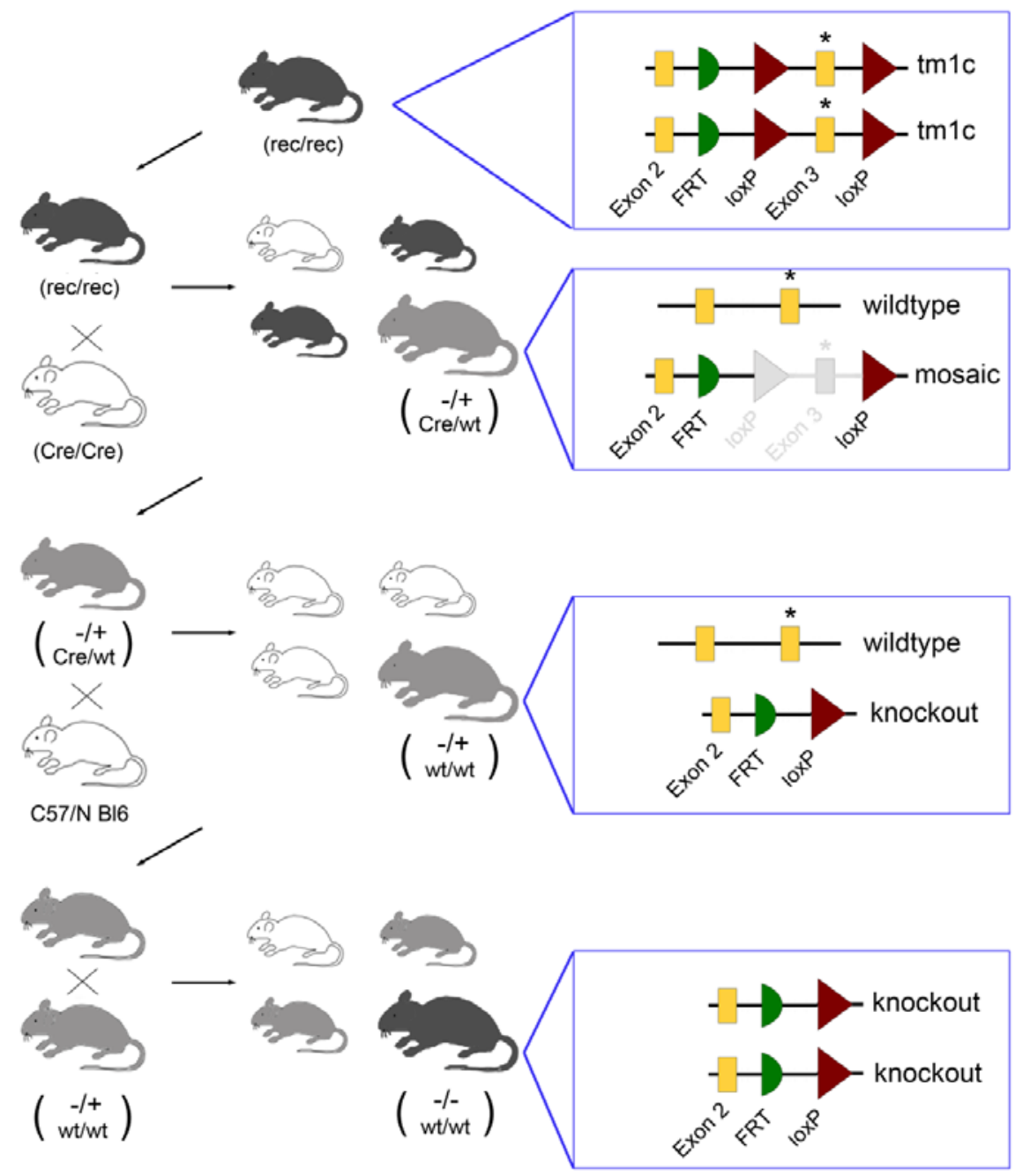

Fig. 3.19: Generation of conventional Bcas1 knockout mice. Homozygous floxed Bcas1<tm1C-Msi> mice were bred with E2A-Cre recombinase mice. The offspring was further bred with wildtype to ensure germ line transmission and remove Cre recombinase. Heterozygous offspring was further bred to obtain homozygous knockout mice. 
Bcas1 (-/-) mice were obtained in the expected Mendelian ratio; these animals were viable and indistinguishable from heterozygous or wildtype mice. Furthermore, Bcas1 (-/-) mice were fertile and produced litters of the same size as wildtype mice.

Since the conditional knockout mice of Bcas1 already showed alterations in the myelin, it is interesting to know if myelin in conventional Bcas1 (-/-) mice is also disturbed. The electron microscopy analysis of these animals has, however, not been done so far. When we prepared primary oligodendrocyte cultures from Bcas1 (-/-) mice, we found that these cells develop normal and form myelin-like membrane sheets (data not shown).

Taken together, we found Bcas1 as a protein highly enriched in oligodendrocytes. We could confirm expression of Bcas1 by RT-qPCR and generated conditional Bcas1 knockout mice. These animals show outfoldings of the myelin membrane and, upon aging, reduced myelin thickness. While the function of Bcas1 still needs to be elucidated, localization of myc-tagged Bcas1 to the cell cortex indicates a potential role of Bcas1 in membrane and/or cytoskeleton function. 


\subsection{Identification of new cell-adhesion molecules}

So far, we performed a proteomic analysis of cultured glial and neuronal cells and showed that the data can be used to identify novel oligodendrocyte proteins. We went on and wanted to find out if we can identify pathways that are shared or coupled between different cell types.

Therefore, we looked for the relative enrichment of certain KEGG pathways in different cell types. We found that proteins for terpenoid backbone biosynthesis and cell adhesion molecules are enriched in both neurons and oligodendrocytes (Fig. 3.20).

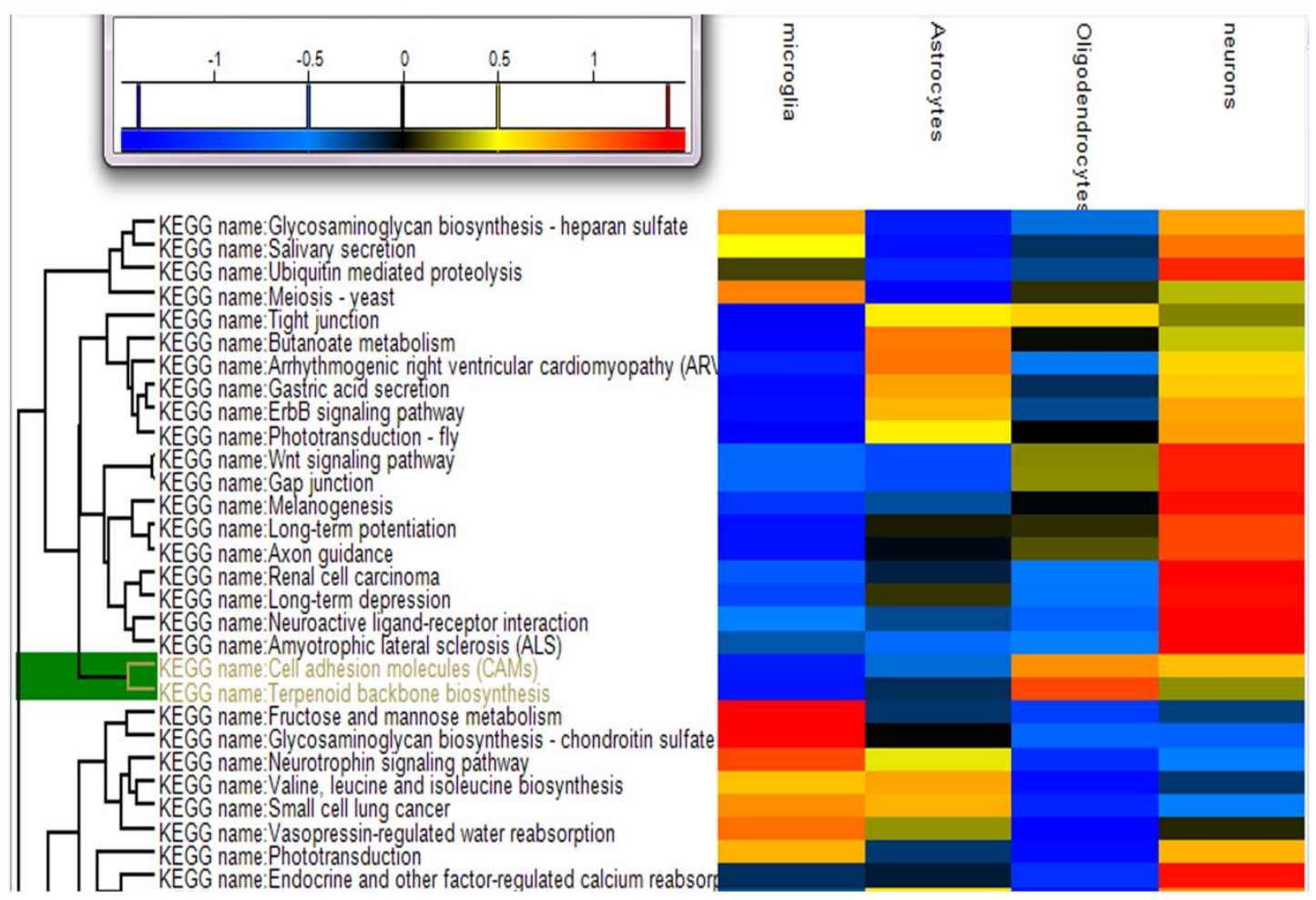

Fig. 3.20: Pathways enriched in different cell types. Expression data were sorted for an enrichment of different pathways in cell types. In both neurons and oligodendrocyes, terpenoid backbone synthesis and cell adhesion molecules were enriched.

When we looked into the cell adhesion molecules enriched in both neurons and oligodendrocytes, we found the IgLON family of cell adhesion molecules. This family consists of four GPI anchored glycoproteins with three Ig domains; the limbic systemassociated membrane protein (Lsamp), Neurotrimin ( $\mathrm{Ntm}$ ), the Opioid binding cell adhesion molecule (Opcml) and the Neuronal growth regulator 1 (Negr1). Strikingly, the three proteins Lsamp, Opcml and Negr1 are xpressed on both neurons and oligodendrocytes, and Ntm, the fourth family member, is also expressed on neurons. 
Since the IgLON family was found on neurons and oligodendrocytes, we wanted to find out if these proteins could be involved in the interaction between those cell types. Proteins of the IgLON family can promote cell-cell-adhesion by homo- and heterophilic interactions. In order to show binding of IgLON proteins, we generated soluble forms of these proteins by fusing the extracellular domain to a human Fc fragment. The purified extracellular domains were added to cultured oligodendrocytes and neurons to determine binding. As it is known that Necl1 and Necl4 bind to oligodendrocytes and axons, respectively, soluble Necl1-Fc and Necl4-Fc constructs were used as positive controls. MCAM-Fc served as a negative control.

As expected, the soluble Necl4-Fc-fusion protein bound to neuronal cultures, while soluble Necl1 bound to oligodendrocytes. The Lsamp-Fc-fusion protein, however, was able to bind to both cell types (Fig. 3.21).
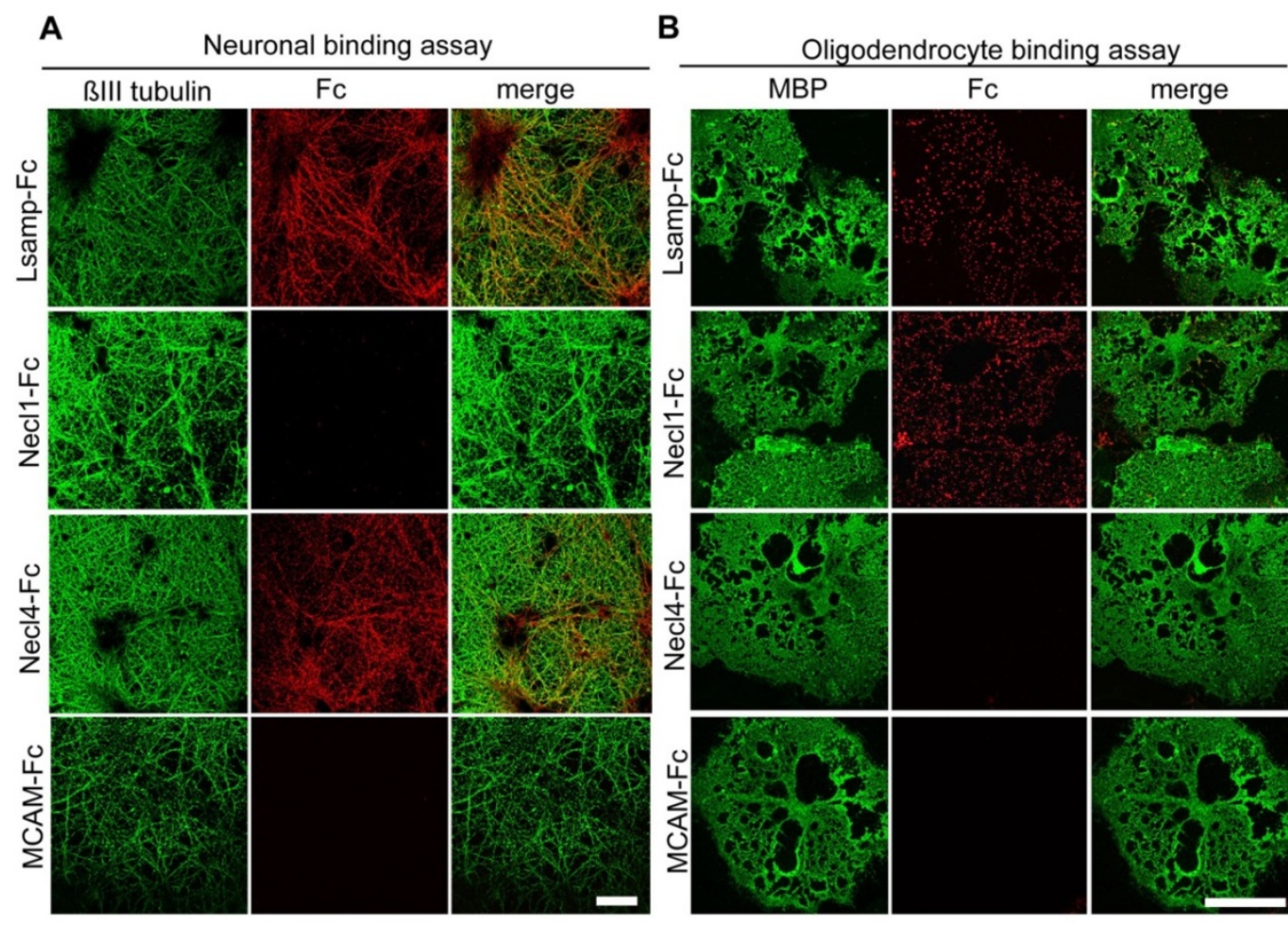

Fig. 3.21: Binding of soluble Lsamp construct to neurons and oligodendrocytes. Cells were incubated with soluble Fc-fusion proteins and visualized by immuno-staining. Images show a binding of Lsamp-Fc to both neurons (A) and oligodendrocytes (B). This figure was provided by Dr. Natalia Manrique Hoyos.

Having shown that Lsamp can bind to both neurons and oligodendrocytes, we next wanted to determine the expression pattern of this protein in the brain. Therefore, brains from mice at different age were fixed by perfusion, cryo-sections were prepared and stained with an antibody against Lsamp (Fig. 3.22). 

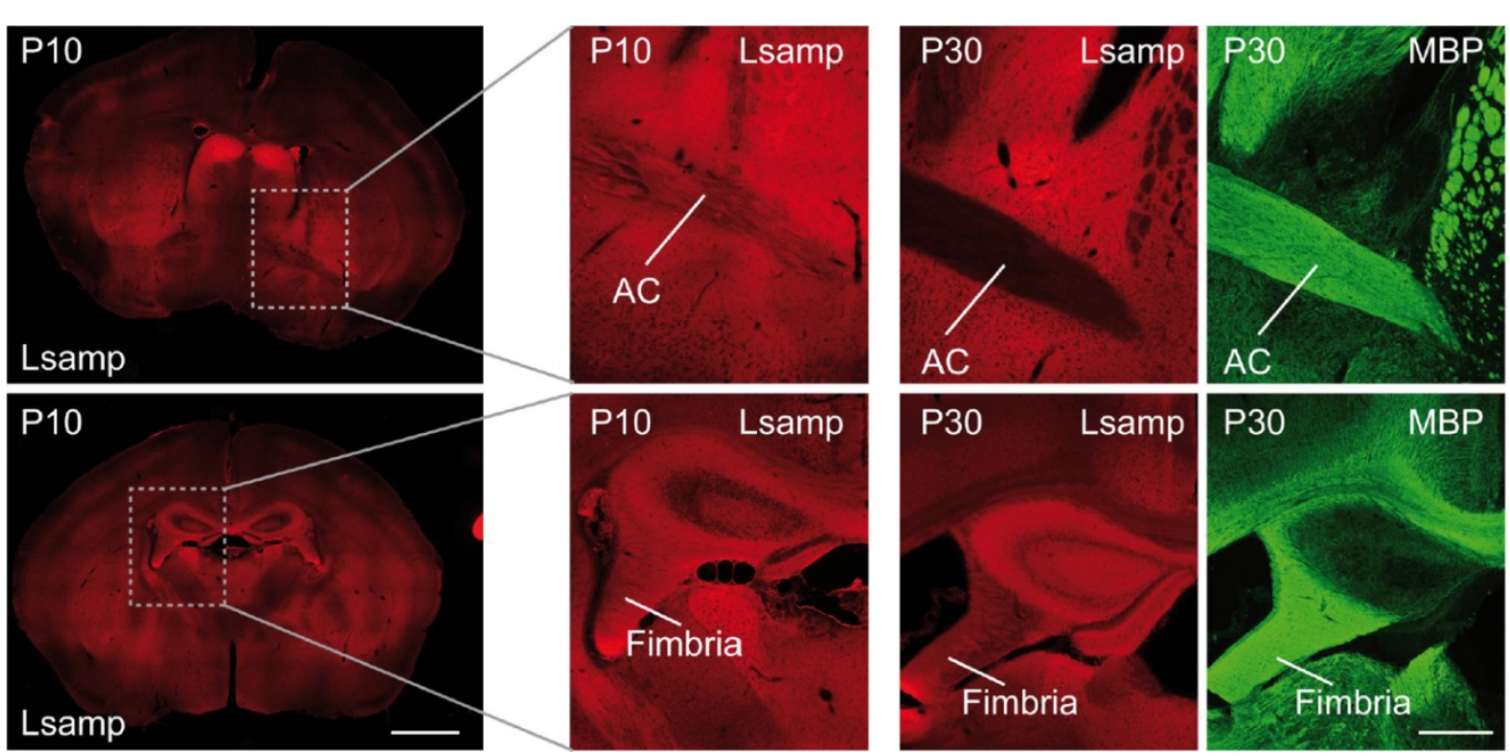

Fig. 3.22: Lsamp is enriched in fiber tracts before myelination. Immunostaining of brain slices for Lsamp and MBP shows that Lsamp is expressed in fiber tracts of the anterior commissure and fimbria of P10 mice. At a later time-point (P30), when myelination is ongoing, Lsamp staining is reduced. This figure was provided by Dr. Caroline Bergner.

We found that Lsamp is expressed in young (P10) mice in long fiber tracts connecting different areas of the limbic system, for example the anterior commissure and the fimbria of the hippocampus. In older mice (P30), when myelination is ongoing, the staining for Lsamp of these areas was reduced (Fig. 3.22).

Having shown that Lsamp is expressed in areas that can be myelinated before the onset of myelination, we wanted to find out if the protein is indeed required for proper myelination.

Since Lsamp-deficient mice are available (Innos et al., 2011), we performed electron microscopy analysis on brains from these. Given the fact that Lsamp is mainly found in the fimbria and the limbic system, we wanted to assess myelination in this area. Lsamp-expression was relatively low in the corpus callosum. Therefore, this brain region was used as a control.

Vibratome sections of wildtype and KO mouse brains at an age of P20, P30 and P60 were prepared; fimbria and corpus callosum were cut out, embedded in Epon and processed for electron microscopy. We determine the diameter of the myelinated axon in dependence to the axonal diameter (g-ratio). As expected, analysis of myelination in the corpus callosum showed no difference between wildtype and Lsamp KO mice (Fig. 3.23). 
a

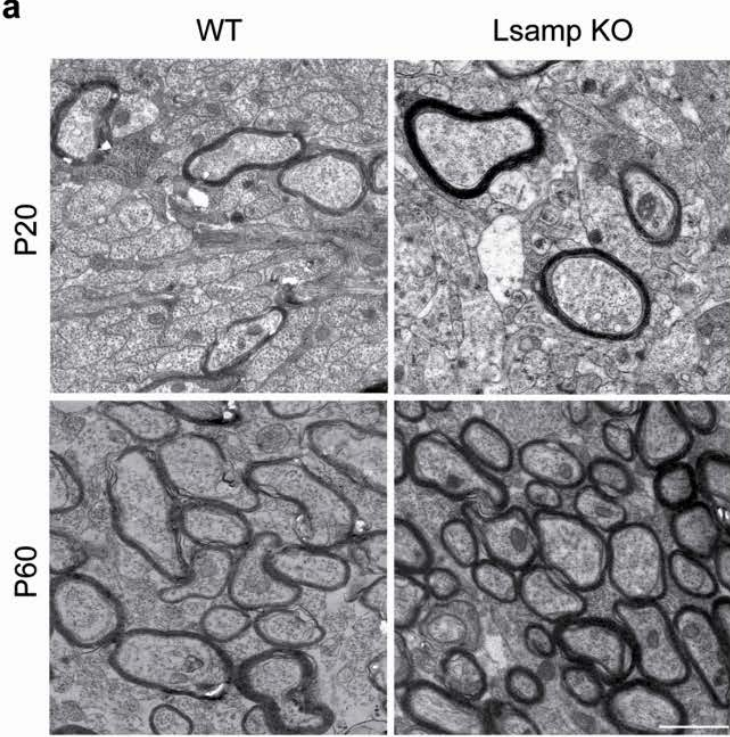

b
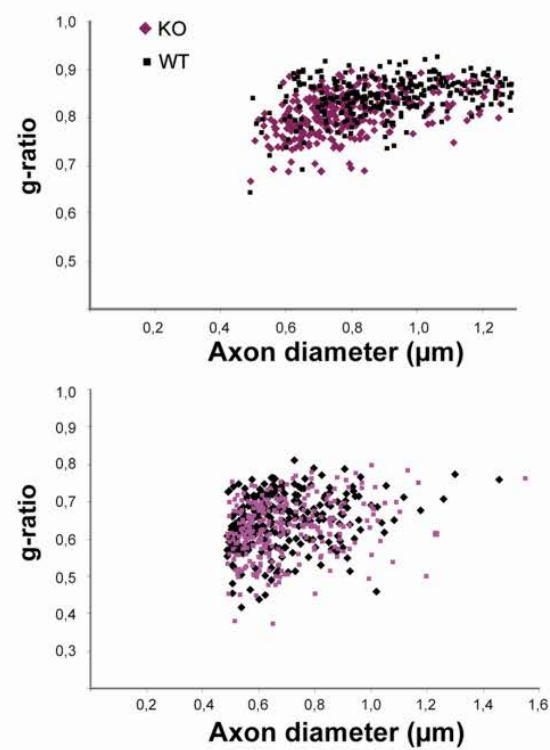

$\mathrm{P} 60$
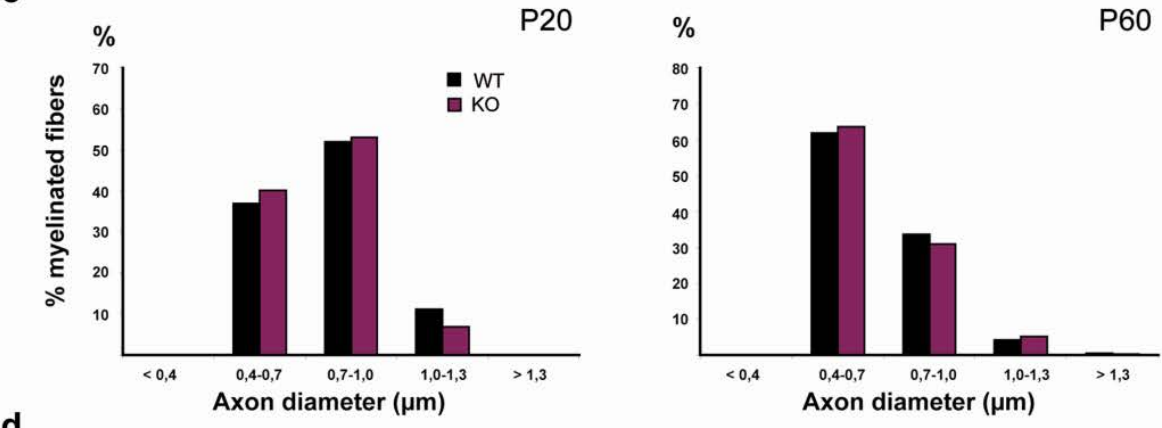

d

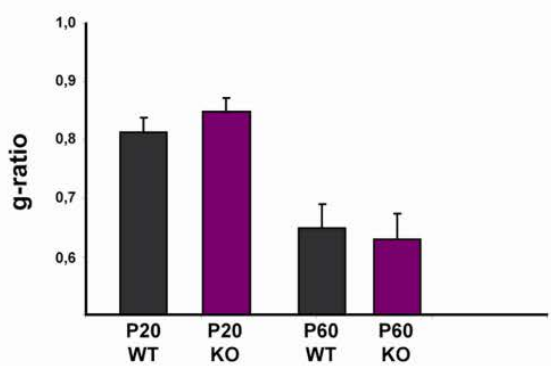

Fig. 3.23: Myelination in not altered in the corpus callosum of Lsamp-deficient mice. (a) EM images of corpus callosum at P20 and P60 (Scale bar: $1 \mu \mathrm{m}$ ). (b) Scatter plots of g-ratio from individual fibers of the corpus callosum from wildtype (black) and Lsamp KO mice (pink) at P20 ( $N=3$ animals, wt: $n=382$ axons, KO: $n=340$ axons) and P60 ( $N=3$ animals, wt: $n=250$ axons, KO: $n=309$ axons). (c) The histogram shows the percentage of myelinated axons with respect to axon diameter in $0.3 \mu \mathrm{m}$ intervals. (d) Average g-ratio at P20 and P60 for wildtype and knockout mice (Bars show mean $\pm S D, n=3-4$ animals).

However, when we analyzed myelination in fimbria of wildtype and Lsamp KO mice, we found that small caliber axons are prematurely myelinated in Lsamp KO mice at P2O. At the same time point, no axons with a diameter $<0.7 \mu \mathrm{m}$ was myelinated in the wildtype condition. This difference was not found at P30 or P60 (Fig. 3.24 a - c). 


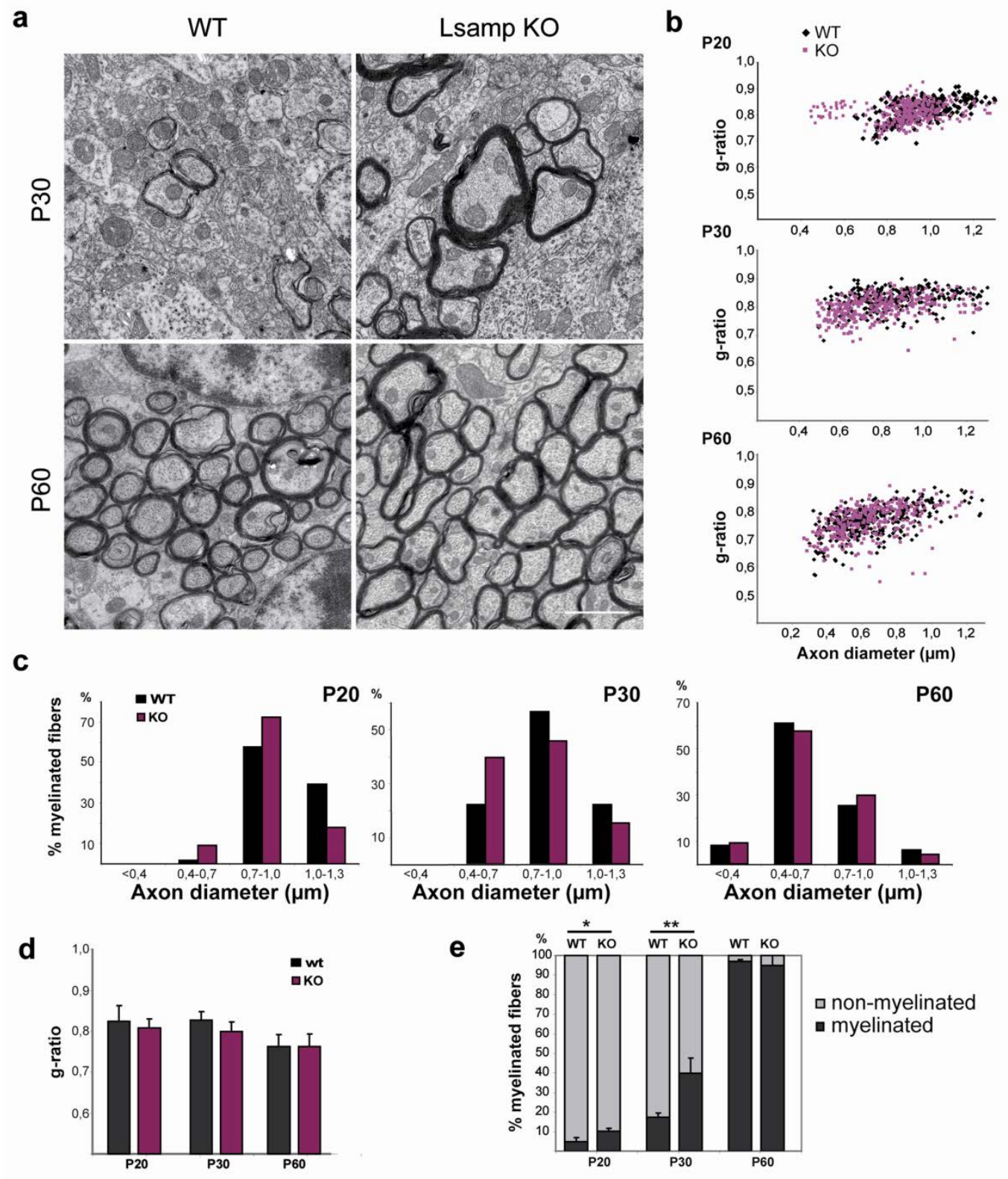

Fig. 3.24: Lsamp is a negative regulator for myelination in the fiber tracts of the fimbriafornix. (a) EM images of fimbria at P30 and P60 (Scale bar: $1 \mu \mathrm{m}$ ). (b) Scatter plots of g-ratio from individual fibers of the corpus callosum from wildtype (black) and Lsamp KO mice (pink) at P20 ( $N=3$, wt: $n=245$ axons, KO: $n=355$ axons), P30 (wt: $n=276$ axons, KO: $n=399$ axons) and P60 ( $N=3$, wt: $n=369$ axons, KO: $n=328$ axons). (c) The histogram shows the percentage of myelinated axons with respect to axon diameter in $0.3 \mu \mathrm{m}$ intervals. There is a shift towards myelination of small caliber axons in Lsamp KO mice. (d) Average g-ratio at P20 and P60 for wildtype and Lsamp KO mice (Bars show mean $\pm S D, n=3-4$ animals). (e). Counting of myelinated and non-myelinated fibers revealed that during development more axonal segments are myelinated in Lsamp KO mice.

As the g-ratio analysis obviously takes only myelinated axons into consideration, we also determined the number of myelinated and non-myelinated axons. There, we found 
a considerably higher number of myelinated axons in the Lsamp KO as compared to the wildtype condition (Fig. $3.25 \mathrm{e}$ ).

Taken together, we analyzed our datasets for adhesion molecules that are expressed by both neurons and oligodendrocytes. In our lists, we found all members of the IgLON family of adhesion molecules. We confirmed that a soluble construct of Lsamp, one member of this family, can bind to both neurons and oligodendrocytes. Immunohistochemistry showed that Lsamp is expressed in certain areas that can be myelinated, but the protein level is high before the onset of myelination and later reduced. When we analyzed axons of Lsamp-deficient mice, we found that myelination occurs comparably early and faster in these animals. These results indicate that Lsamp is a negative regulator of myelination in fimbria and, perhaps, in the entire limbic system.

Apart from the biological importance of Lsamp, these findings show that our proteomic datasets can not only be used to find novel proteins within a cell type, but that it can also help to understand functional coupling, in this case adhesion, between different cell types. Therefore, the proteomic analysis that we performed can serve as a valuable tool for neurobiological research. 


\section{Chapter IV: Discussion and future directions}

\subsection{Proteomic analyses}

Myelin is an important component of the nervous system of higher organisms; it enables fast nerve cell conduction and provides trophic support to neuronal axons. Disturbances of myelin result in severe diseases, such as Multiple Sclerosis and Leukodystrophies. Understanding the molecular aspects of myelin biogenesis is, therefore, a prerequisite for the pharmacological intervention in such diseases.

Certain groups have already performed proteomic studies on oligodendrocytes and myelin. A study performed by Dumont et al. (2007) identified approximately 200 different proteins in cultured oligodendrocytes; Ishii et al. (2009) analyzed biochemically purified myelin and identified 300 proteins. These numbers seem extremely small, if we take into consideration that the human genome contains at least 25,000 protein-coding genes (Pennisi, 2001). The relatively low coverage of the proteome can be explained by the fact, that membrane proteins are difficult to analyze using classical biochemical approaches such as 2D gel electrophoresis. Moreover, mass spectrometers that were previously used for proteomic analyses were not that sensitive and accurate. In any case, improved analyses are needed to cover the majority of expressed proteins.

Within the last years Orbitrap mass spectrometers became widely available for proteomic analyses. These instruments offer high sensitivity and mass accuracy, which allows in-depth proteomic analysis. Another important factor in the advances of proteomic analyses was the development of new software for the interpretation of data produced by mass spectrometers. MaxQuant is such a software package; it uses specific algorithms for an efficient analysis of data obtained by mass spectrometry and, thereby, increases the number of identified peptides (Cox and Mann, 2008). Even before an analysis is performed, the sample preparation is an important aspect that determines the outcome of the proteomic study. One example is the filter-aided sample-preparation (FASP) protocol, which results in a clean protein preparation and greatly improves proteomic studies (Wisniewski et al., 2009).

Using the FASP protocol, together with liquid-chromatography, Orbitrap mass spectrometry and analysis by MaxQuant, Luber at al. (2010) identified and quantified more than 5,000 proteins in dendritic cells. In similar experiments, Wisniewski et al. (2013) quantified more than 10,000 proteins from paraffin-embedded samples.

We used a similar proteomic approach to analyze adult mouse brains and primary cultures of murine brain cells. Were able to identify and quantify approximately 10,000 proteins. 


\subsection{Samples used in this study}

As mentioned above, some groups have already performed proteomic analyses on cultured oligodendrocytes. Other groups, however, focused on the analysis of biochemically purified myelin. One example is the quantitative proteomic analysis performed by Jahn et al. (2009), which showed that the classical myelin proteins MBP, PLP1, CNP, MAG and MOG contribute to only approximately $30 \%$ to all myelin proteins. It is important to keep the advantages and disadvantages of both approaches in mind. While the proteomic analysis of biochemically purified myelin is the best approach to unravel the molecular composition of myelin sheaths, there are certain limitations:

First, contamination of myelin proteins with other brain proteins during the purification process cannot be excluded. Indeed, the analysis by Jahn et al. also identified astrocyte proteins such as the Glial fibrillary acidic protein (GFAP), which is unlikely to be a component of myelin sheaths. Second, regulators of myelination such as transcription factors, kinases and E3 ligases are not necessarily found in the myelin sheath, but rather in the cell bodies. Third, myelin can only be analyzed once it has been formed. Myelin proteomics can, therefore, not be used to identify regulators of OPC differentiation and myelin initiation. Fourth, it is not possible to distinguish if a protein is expressed by neurons or oligodendrocytes. This is particularly important when th comes to adhesion molecules and their binding partners on different cell types.

One major advantage of primary cultures is that these cells can be obtained at a very high purity; we used only cells with a purity of $>95 \%$. However, cultured cells do not resemble the myelin proteome in its full complexity. Oligodendrocyte differentiation invitro differs from differentiation in a living organism. Even if oligodendrocyte cultures have been widely used as model systems, this limitation should always kept in consideration. Therefore, it was important to validate the data that we obtained in a biological context. Among the most enriched oligodendrocyte proteins, we found classical myelin proteins such as Plp1, Mbp and Cnp1. As expected, we did not only find structural components of myelin, but also known regulators of oligodendrocyte differentiation, such as Sox10. As discussed below, we validated the relevance of selected hits for oligodendrocyte differentiation in-vivo. Taken together, we can conclude that the proteomic analysis of cultured oligodendrocytes is an equally powerful approach as the analysis of purified myelin. Both of these approaches have their advantages and limitations for certain biological questions. Hence, they should be seen as complementary approaches that can help to solve distinct questions in oligodendrocyte biology. 


\subsection{Highly enriched proteins in oligodendrocytes}

Among the 20 proteins highly expressed and significantly enriched in oligodendrocytes was a broad spectrum of proteins: We found classical myelin proteins such as Mbp, Plp1 and Cnp, as well as the transcription factor Sox10 and the extracellular matrix proteins Versican and Chondroitin sulfate proteoglycan 4.

Not much is known about other proteins. This is particularly true for Bcas1 and Col11a1. Bcas1 has been predominantly described in cancer biology (Collins et al., 1998; Correa et al., 2000; Beardsley et al., 2003), but nothing is known about the detailed molecular function of this protein or its role in oligodendrocytes. The identification of Bcas1 in oligodendrocytes in the current study is consistent with other data obtained from our lab and others. When we compared transcriptomic profiles of oligodendrocytes and astrocytes using microarray technology, Bcas1 was among the top 50 oligodendrocyte-enriched transcripts (Budde et al., 2010). Furthermore, it was also enriched in Oli-neu cells treated with neuron-conditioned medium (Kippert et al., 2008). Interestingly, Bcas1 was also found in a proteomic analysis of purified myelin (Jahn et al., 2009). This protein will be further discussed in 4.4 .

Collagen 11a1 (Col11a1) was also extraordinarily high and specific expressed in oligodendrocytes. This transcript is also among the top 50 candidates in a transcriptomic analysis performed by Cahoy et al. (2008). Mutations in the Col11a1 gene are associated with Stickler syndrome type 2, a disease with craniofacial changes, vitreous and retinal abnormalities (Richards et al., 1996), as well as Marshall syndrome (Griffith et al., 1998). In this study, we demonstrated that Col11a1 is expressed in OPCs and can be found in myelinated areas of the brain.

Another highly enriched protein was Adamts4, an enzyme that can cleave agrrecan and, thereby, alter the extracellular matrix (Westling et al., 2004; Fushimi et al., 2008). Enpp6 is another enzyme; it cleaves certain lipids such as sphingosylphosphorylcholine (Sakagami et al., 2005). The detailed role of these enzymes in oligodendrocytes has not yet been studied. We also found the Interleukin-1 receptor accessory protein (IIrap), which is involved in IL-1-signaling (Chen et al., 2012). It has been shown, that IL-1 signaling regulates the proliferation and differentiation of OPCs (Vela et al., 2002). Thus, it is likely that IL1rap is needed for IL1-mediated regulation of OPC proliferation and differentiation.

The Calcium activated chloride channel regulator 1 (Clca1) has been mainly studied in the context of cystic fibrosis and cancer. A recent paper shows that Clca1 is involved in the switch between proliferation and differentiation in colorectal cells: When Yang et al. (2013) differentiated Caco-2 cells with sodium butyrate, the observed upregulation of 
Clca1. RNAi-mediated downregulation of Clca1 inhibited differentiation of these cells and resulted in enhanced proliferation. Therefore, Clca1 might also play a role in cell cycle exit and differentiation of OPCs.

Yet another protein that we found was Afap12. This protein is an adapter for signal transduction processes. Overexpression of the protein in COS-7 cell resulted in an activation of the c-Src tyrosine kinase. Downregulation of Afap1/2, in contrast, resulted in reduced c-Src activity and phosphorylation of Akt and GSK3beta (Xu et al., 2007). Moreover, the protein is involved in PI3-kinase activation (Lodyga et al., 2009). This is interesting, since PI3-kinase and Akt-signaling are important regulators of myelination (Flores et al., 2008).

In this work, we focused on Bcas1 and Col11a1, since these proteins are most specific and highly expressed in oligodendrocytes. However, proteins such as Adamts4, IIrap, Enpp6, Clca1 and Afap1/2 are clearly interesting candidates for further biological experiments.

\subsection{Bcas1 as a novel oligodendrocyte-protein}

When we overexpressed myc-tagged Bcas1 in Oli-neu and SKBR3 cells, we observed a localization of the construct at the cell cortex and at certain actin-rich structures. This observation is not completely congruent with results published by Beardsley et al., 2003. They performed immuno-staining on the breast carcinoma cell lines BT-474 and SKBR3 with an antibody against Bcas1 and observed cytoplasmic puncta. When we used commercially available antibodies, we observed the same staining patterns in both SKBR3 cells and oligodendrocytes (data not shon). However, when we used cells and lysates derived from our Bcas1-deficient mice, we found that the antibody staining was unspecific (data not shown). Therefore, we are currently generating a new antibody against Bcas1.

In our RT-qPCR analysis, we also found Bcas1 expression in tissues apart from the brain, such as lung, stomach and testis. Similar expression patterns have been reported on human tissues using Northern blot analysis (Beardsley et al., 2003). Taken together, these data indicate that Bcas1 could also have a function in these tissues.

\subsubsection{Myelin abnormalities in conditional Bcas1 knockout mice}

In order to understand the role of Bcas1 in oligodendrocytes, we generated conditional knockout mice, in which exon 3 is flanked by loxP sites. The LacZ and Neomycinresistance cassettes were removed by recombination using the FLIR-recombinase. 
These mice were further crossed with CNP-Cre mice to allow an oligodendrocytespecific ablation of Bcas1.

We obtained mice that are heterozygous for CNP-Cre and homozygous for the floxed Bcas1 allele. These animals looked healthy and were devoid of any obvious neurological symptoms. However, when we performed electron microscopy on the optic nerves, we found that myelin thickness is altered upon aging, as shown by g-ratio analysis of one-year old mice.

A part of this phenotype is also observed in other knockout mice. Mice lacking the myelin protein CNP1 develop normal and have proper myelination. After some time, however, axons of these mice show a progressive degeneration and the animals die at an age of about one year (Lappe-Siefke et al.; 2003; Rasband et al.; 2005; Edgar et al., 2009). A similar phenotype was has been observed in mice lacking PLP1 (Edgar et al., 2004).

Even though conditional Bcas1 knockout mice do not show obvious clinical symptoms, it might still be interesting to assess motor function using behavioral tests such as a rotarod test or a beam balance test in order to reveal more subtle behavioral changes. Furthermore, it will be interesting to perform histological examination of these animals and check for activated microglia, astrogliosis and axonal degeneration.

One limitation of the conditional knockout mice is that recombination occurs not before oligodendrocyte differentiation. A function of Bcas1 in early steps of precursor cell migration and differentiation can, therefore, not be studied in these mice. It might still be interesting to induce demyelination in these animals, for instance by cuprizone feeding, and assess their capability of remyelination. Alternatively, myelination can be studied in the conventional Bcas1 knockout mice that were generated during this study.

\subsubsection{The role of Bcas1 in cancer}

In this study, we were mainly interested in the role of Bcas1 in oligodendrocytes and myelination. When generating knockout mice, we found the alteration in left-rightpatterning. However, we should not forget that Bcas1 has been identified originally in the context of breast cancer. These early studies only showed that Bcas1 is differently regulated in certain cancer cells. What is not known so far is, if the level of Bcas1 influences the proliferation and survival of breast cancer cells. This question could be addressed my RNAi-mediated knockdown of Bcas1 in breast cancer cells.

Another, probably even more important question is, if Bcas1 influences cancer induction and propagation. Such a question cannot be answered using cell culture systems, but requires an in-vivo approach. One way of breast cancer induction in mice 
is to apply medroxyprogesterone acetate (MPA) together with dimetylbenz[a]anthracene (DMBA) (Aldaz et al., 1996). Administration of both substances can be used as a model for hormone induced breast carcinoma induction and has been used in different studies already (e.g. Becks et al., 2010). As conventional Bcas1 knockout mice are viable, they could be treated with MPA and DMBA, and thereby serve as an interesting model system to study the effect of Bcas1 on the initiation and progression of hormone-induced breast cancer.

\subsection{Proteomic analysis identifies the IgLON cluster of cell adhesion molecules}

Apart from identifying proteins specifically expressed by one cell type, we were also interested in finding functional coupling between different cell types. When we searched for pathways that are highly enriched in both oligodendrocytes and neurons, we found the pathway "Cell adhesion molecules". Within this cluster, there were more than 280 proteins. The IgLON family of cell adhesion molecules was expressed by both cell types. We generated soluble constructs of the extracellular domains and showed that these constructs bind to both neurons and oligodendrocytes.

The IgLON protein Lsamp is highly expressed in the limbic system and Lsamp-deficient mice show alterations in anxiety-related behavior (Innos et al., 2011; Innos et al., 2012). Therefore, we analyzed if myelination is altered in this brain region. Indeed, we found that Lsamp-knockout mice show premature myelination in the fimbria, while myelination in the corpus callosum is not affected. This is a fascinating finding, because several psychiatric disorders might be associated with altered myelination in some brain areas, rather than general myelination problems. Little is known about such regulators that influence regional myelination. Therefore, Lsamp is an interesting protein for further studies. Moreover, the identification of the IgLON family of cell adhesion molecules also showed that our proteomic database can be used to study interactions between different cell types.

\subsection{Outlook on proteomic studies}

We performed the first in-depth proteomic study on cultured glial and neuronal cells. In total, more than 10,000 proteins could be identified. This means, we found ten times more proteins than any other proteomic study of brain cells or myelin could ever identify. This sensitivity shows the enormous potential of proteomics and transcriptomics for biomedical research 
As a proof of concept, we analyzed Bcas1 and Col11a1 as two novel marker proteins for oligodendrocytes. Furthermore, we looked into cell-adhesion molecules and identified the IgLON cluster of cell adhesion molecules. We could show that even a complex biological question, such as interaction partners on two different cell types, can be addressed using our datasets. A next step will be to check for potential regulators of oligodendrocyte differentiation. For instance, it would be interesting to search the database for all transcription factors, protein kinases and E3-ligases. Another option is to extend the analysis to gene products differently regulated in neurons of different time points. This could help to find further potential regulators of neuronal differentiation.

Regardless the impressive numbers of identified proteins, we should keep in mind that all expression profiling experiments eventually just result in lists. These lists will only be meaningful in the biological context. Thus, promising candidates resulting from expression profiling experiments need to be further characterized in additional biological experiments. This includes the confirmation of expression, determination of subcellular localization, as well as loss-of-function and gain of function experiments.

A clear bottleneck of such analysis will, then, be the generation of mouse models to study the in-vivo function.

Recently developed mouse genetics methods such as the CRISP/Cas9 genome editing system might help to overcome such limitations. This system is based on the nuclease Cas9 and single guide RNAs (sgRNAs), which target the nuclease to specific DNA sequences. By co-injecting Cas9 mRNA, sgRNAs and DNA-fragments into zygotes, Yang et al. (2013) generated targeted mice within a few weeks. Using the same approach, Wang et al. (2013) generated mice with simultaneous deletions of up to five genes with an efficiency of $80 \%$. The use of such systems could, therefore, enable rapid generation of knockout mice for various candidate genes. Our proteomic database can serve as a valuable resource to identify appropriate candidate proteins for such studies. 


\section{Chapter V: Additional experiments}

In addition to the experiments described and discussed in the main parts of this thesis, I further worked on other projects. One project was to generate knockout mice to study the function of actin dynamics in oligodendrocytes in-vivo.

\section{Oligodendrocyte differentiation is accompanied by actin depolymerization}

When studying the in-vitro differentiation of oligodendrocytes, we observed that mature oligodendrocytes showed a marked decrease in filamentous actin as visualized by fluorescently labeled phalloidin (Fig. 5.1 a). We could further confirm this finding using biochemical fractionation of oligodendrocyte cultures at different time-points in-vitro (Fig. 5.1 b).

a

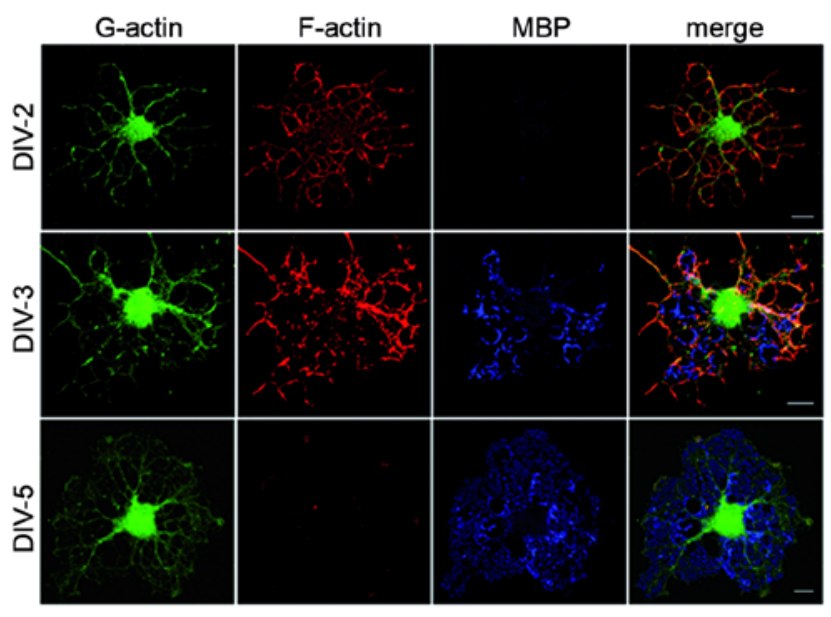

b
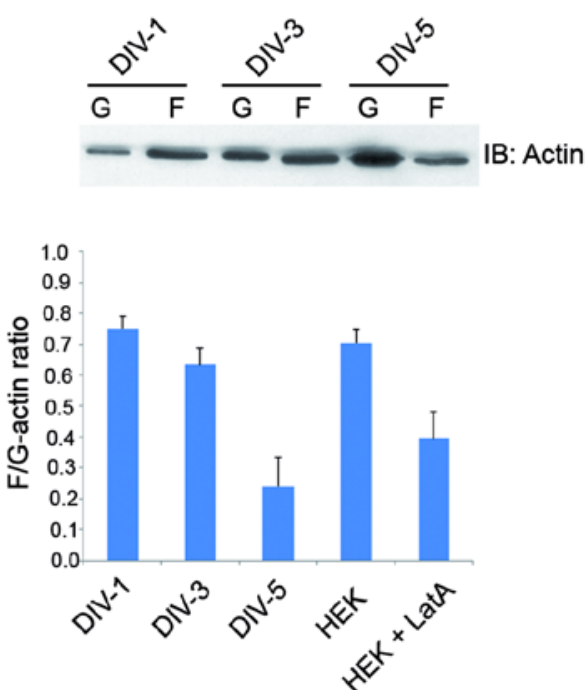

Fig. 5.1: Actin depolymerization during oligodendrocyte differentiation. (a) Staining of invitro differentiated oligodendrocytes for monomeric, globular actin (G-actin, green), filamentous acin (F-actin, red) and maturation marker MBP (cyan) shows decrease in filamentous actin upon maturation. (b) Ratio between filamentous and globular actin decreases upon differentiation of oligodendrocytes. HEK-293 cells without and with Latrunculin A were used as a control.

\section{Generation of a mouse model to study actin dynamics in-vivo}

We were wondering of actin depolymerization in oligodendrocytes is indeed relevant for oligodendrocyte differentiation and myelination in-vivo. Hence, we aimed to generate a mouse model in which actin depolymerization is distrubed in myelinating cells.

The actin depolymerizing factor ADF/Destrin and Cofilin-1 (Cfl1) are the two major proteins that regulate actin depolymerization and both proteins are expressed in oligodendrocytes (data not shown). Therefore, we generated knockout mice in which Cfl1-expression was specifically impaired in myelinating glia using CNP-Cre. 
Furthermore, we generated double knockout mice (DKO) which we also devoid of ADF/Destrin (Fig. 5.2 a, b).

A
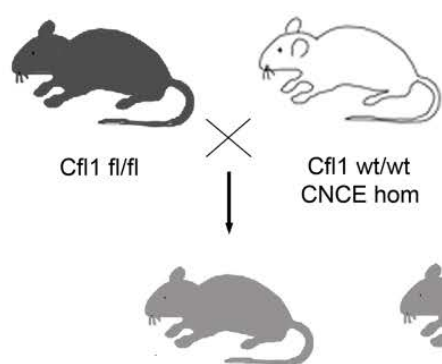

Cfl1 fl/wt CNCE het
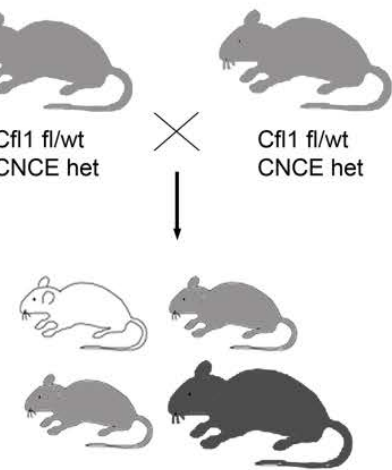

C

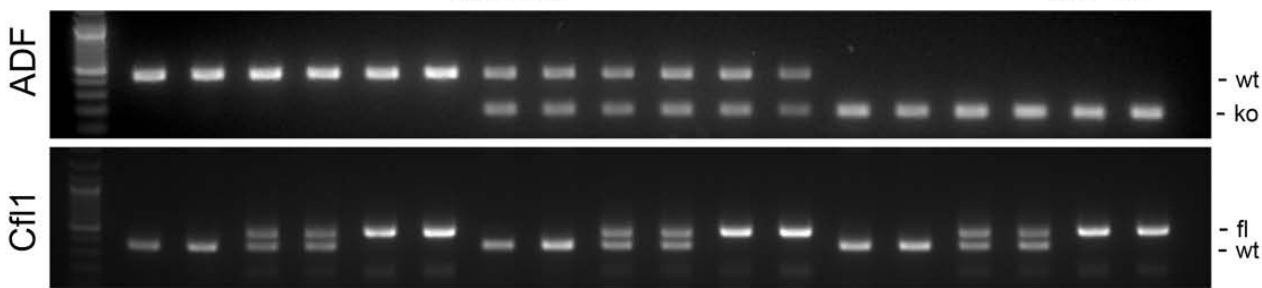

岂

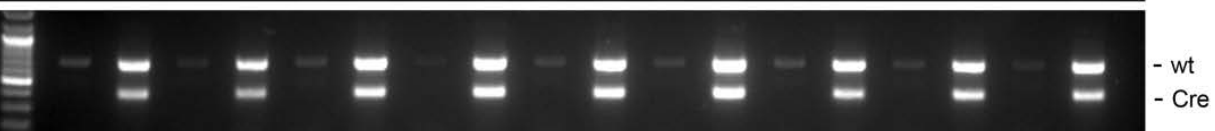

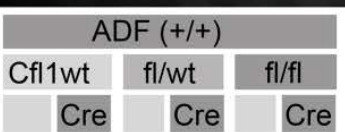
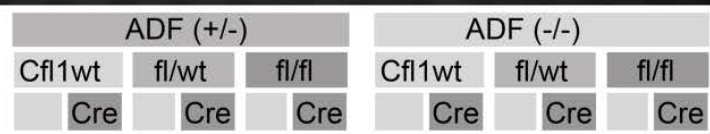

D

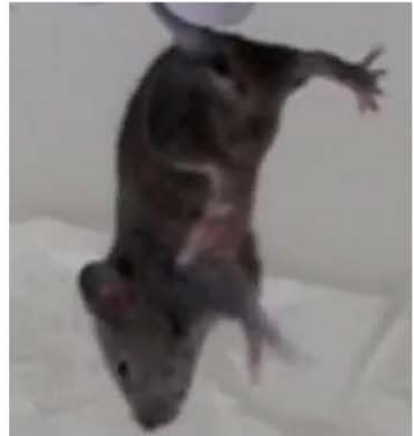

wildtype

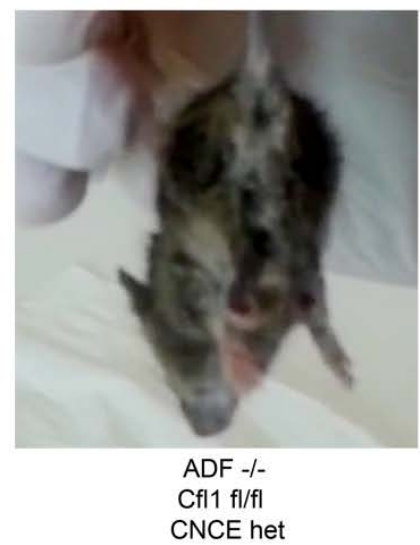

Fig. 5.2: Generation of ADF/Cfl1-knockout mice to study the role of actin dynamics in oligodendrocytes. (A) Breeding scheme for the generation of conditional Cfl1 knockout mice. (B) Scheme for the breeding of ADF/Cfl1-double knockout mice. (C) Genotyping of the different knockout mice. (D) Wildtype (left) and ADF/Cfl1-double knockout mouse (right) at P17. Double knockout mice show growth retardation, hindlimb clasping and die around P20. 
The single knockout mice of ADF/Destrin were viable and did not show obvious clinical symptoms. The same was true for conditional Cfl1-knockout mice. Double knockout mice, in contrast, showed drastic symptoms of dysmyelination: The animals developed normally during the first week of life. Then, growth was retarded and subsequently the animals showed hindlimb clasping, paralysis of hindlimbs and shivering (Fig. 5.2 D). All of the double knockout mice died within the first three weeks of life. These findings show that actin depolymerization is indeed essential for the outgrowth of the myelin membrane, while stabilizing actin by knockout out depolymerizing factors results in disturbances in myelination. 


\section{References}

Aggarwal S, Snaidero N, Pähler G, Frey S, Sánchez P, Zweckstetter M, Janshoff A, Schneider A, Weil MT, Schaap IA, Görlich D, Simons M (2013) Myelin membrane assembly is driven by a phase transition of myelin basic proteins into a cohesive protein meshwork. PLoS Biol., 11(6):e1001577.

Ahlgren SC, Wallace H, Bishop J, Neophytou C, Raff MC (1997) Effects of thyroid hormone on embryonic oligodendrocyte precursor cell development in vivo and in vitro. Mol Cell Neurosci., 9(5-6):420-32.

Aldaz CM, Liao QY, LaBate M, Johnston DA (1996) Medroxyprogesterone acetate accelerates the development and increases the incidence of mouse mammary tumors induced by dimethylbenzanthracene. Carcinogenesis, 17(9):2069-72.

Armstrong RC, Migneault A, Shegog ML, Kim JG, Hudson LD, Hessler RB (1997) High-grade human brain tumors exhibit increased expression of myelin transcription factor 1 (MYT1), a zinc finger DNA-binding protein. J Neuropathol Exp Neurol., 56(7):772-81.

Arnett HA, Fancy SP, Alberta JA, Zhao C, Plant SR, Kaing S, Raine CS, Rowitch DH, Franklin RJ, Stiles CD (2004) bHLH transcription factor Olig1 is required to repair demyelinated lesions in the CNS. Science, 306(5704):2111-5.

Baas D, Legrand C, Samarut J, Flamant F (2002) Persistence of oligodendrocyte precursor cells and altered myelination in optic nerve associated to retina degeneration in mice devoid of all thyroid hormone receptors. Proc Natl Acad Sci USA, 99(5):290711.

Beardsley DI, Kowbel D, Lataxes TA, Mannino JM, Xin H, Kim WJ, Collins C, Brown KD (2003) Characterization of the novel amplified in breast cancer-1 (NABC1) gene product. Exp Cell Res., 290(2):402-13.

Becks L, Prince M, Burson H, Christophe C, Broadway M, Itoh K, Yamamoto M, Mathis M, Orchard E, Shi R, McLarty J, Pruitt K, Zhang S, Kleiner-Hancock HE (2010) Aggressive mammary carcinoma progression in Nrf2 knockout mice treated with 7,12-dimethylbenz[a]anthracene. BMC Cancer, 8;10:540.

Berndt JA, Kim JG, Tosic M, Kim C, Hudson LD (2001) The transcriptional regulator Yin Yang 1 activates the myelin PLP gene. J Neurochem, 77(3):935-42.

Boggs JM (2006) Myelin basic protein: a multifunctional protein. Cell Mol Life Sci., 63(17):1945-61.

Budde H, Schmitt S, Fitzner D, Opitz L, Salinas-Riester G, Simons M (2010) Control of oligodendroglial cell number by the miR-17-92 cluster. Development, 137(13):2127-32.

Buser AM, Schmid D, Kern F, Erne B, Lazzati T, Schaeren-Wiemers N (2009) The myelin protein MAL affects peripheral nerve myelination: a new player influencing p75 neurotrophin receptor expression. Eur J Neurosci., 29(12):2276-90.

Cahoy JD, Emery B, Kaushal A, Foo LC, Zamanian JL, Christopherson KS, Xing Y, Lubischer JL, Krieg PA, Krupenko SA, Thompson WJ, Barres BA (2008) A 
transcriptome database for astrocytes, neurons, and oligodendrocytes: a new resource for understanding brain development and function. J Neurosci., 28(1):264-78.

Chen Y, Wang H, Yoon SO, Xu X, Hottiger MO, Svaren J, Nave KA, Kim HA, Olson EN, Lu QR (2011) HDAC-mediated deacetylation of NF-KB is critical for Schwann cell myelination. Nat Neurosci., 14(4):437-41.

Chernoff GF (1981) Shiverer: an autosomal recessive mutant mouse with myelin deficiency. J Hered., 72(2):128.

Chow E, Mottahedeh J, Prins M, Ridder W, Nusinowitz S, Bronstein JM (2005) Disrupted compaction of CNS myelin in an OSP/Claudin-11 and PLP/DM20 double knockout mouse. Mol Cell Neurosci., 29(3):405-13.

Coetzee T, Fujita N, Dupree J, Shi R, Blight A, Suzuki K, Suzuki K, Popko B (1996) Myelination in the absence of galactocerebroside and sulfatide: normal structure with abnormal function and regional instability. Cell, 86(2):209-19.

de Castro F and Bribián A (2005) The molecular orchestra of the migration of oligodendrocyte precursors during development. Brain Res Brain Res Rev., 49(2):22741.

de Castro F, Bribián A, Ortega MC (2013) Regulation of oligodendrocyte precursor migration during development, in adulthood and in pathology. Cell Mol Life Sci., 70(22):4355-68.

Chen R, Li M, Zhang Y, Zhou Q, Shu HB (2012) The E3 ubiquitin ligase MARCH8 negatively regulates IL-1 $\beta$-induced NF-KB activation by targeting the IL1RAP coreceptor for ubiquitination and degradation. Proc Natl Acad Sci USA, 109(35):1412833.

Collins C, Rommens JM, Kowbel D, Godfrey T, Tanner M, Hwang SI, Polikoff D, Nonet G, Cochran J, Myambo K, Jay KE, Froula J, Cloutier T, Kuo WL, Yaswen P, Dairkee S, Giovanola J, Hutchinson GB, Isola J, Kallioniemi OP, Palazzolo M, Martin C, Ericsson C, Pinkel D, Albertson D, Li WB, Gray JW (1998) Positional cloning of ZNF217 and NABC1: genes amplified at 20q13.2 and overexpressed in breast carcinoma. Proc Natl Acad Sci USA, 95(15):8703-8.

Correa RG, de Carvalho AF, Pinheiro NA, Simpson AJ, de Souza SJ (2000) NABC1 (BCAS1): alternative splicing and downregulation in colorectal tumors. Genomics, 65(3):299-302.

Cox J and Mann M (2008) MaxQuant enables high peptide identification rates, individualized p.p.b.-range mass accuracies and proteome-wide protein quantification. Nat Biotechnol., 26(12):1367-72.

Delarasse C, Daubas P, Mars LT, Vizler C, Litzenburger T, Iglesias A, Bauer J, Della Gaspera B, Schubart A, Decker L, Dimitri D, Roussel G, Dierich A, Amor S, Dautigny A, Liblau R, Pham-Dinh D (2003) Myelin/oligodendrocyte glycoproteindeficient (MOG-deficient) mice reveal lack of immune tolerance to MOG in wild-type mice. J Clin Invest., 112(4):544-53.

Dugas JC, Ibrahim A, Barres BA (2007) A crucial role for p57(Kip2) in the intracellular timer that controls oligodendrocyte differentiation. J Neurosci., 27(23):6185-96. 
Edgar JM, McLaughlin M, Werner HB, McCulloch MC, Barrie JA, Brown A, Faichney AB, Snaidero N, Nave KA, Griffiths IR (2009) Early ultrastructural defects of axons and axon-glia junctions in mice lacking expression of Cnp1. Glia, 57(16):181524.

Dumont D, Noben JP, Moreels M, Vanderlocht J, Hellings N, Vandenabeele F, Lambrichts I, Stinissen P, Robben J (2007) Characterization of mature rat oligodendrocytes: a proteomic approach. J Neurochem., 102(2):562-76.

Eckert and Kartenbeck (1996) Proteine: Standardmethoden der Molekular- und Zellbiologie. Springer Labormanual.

Edgar JM, McLaughlin M, Yool D, Zhang SC, Fowler JH, Montague P, Barrie JA, McCulloch MC, Duncan ID, Garbern J, Nave KA, Griffiths IR (2004) Oligodendroglial modulation of fast axonal transport in a mouse model of hereditary spastic paraplegia. J Cell Biol., 166(1):121-31.

Edgar JM, McLaughlin M, Werner HB, McCulloch MC, Barrie JA, Brown A, Faichney AB, Snaidero N, Nave KA, Griffiths IR (2009) Early ultrastructural defects of axons and axon-glia junctions in mice lacking expression of Cnp1. Glia, 57(16):181524.

Emery B, Agalliu D, Cahoy JD, Watkins TA, Dugas JC, Mulinyawe SB, Ibrahim A, Ligon KL, Rowitch DH, Barres BA (2009) Myelin gene regulatory factor is a critical transcriptional regulator required for CNS myelination. Cell, 138(1):172-85.

Flores Al, Narayanan SP, Morse EN, Shick HE, Yin X, Kidd G, Avila RL, Kirschner DA, Macklin WB (2008) Constitutively active Akt induces enhanced myelination in the CNS. J Neurosci., 28(28):7174-83.

Fruttiger M, Karlsson L, Hall AC, Abramsson A, Calver AR, Boström H, Willetts K, Bertold CH, Heath JK, Betsholtz C, Richardson WD (1999) Defective oligodendrocyte development and severe hypomyelination in PDGF-A knockout mice. Development, 126(3):457-67.

Fushimi K, Troeberg L, Nakamura H, Lim NH, Nagase H (2008) Functional differences of the catalytic and non-catalytic domains in human ADAMTS-4 and ADAMTS-5 in aggrecanolytic activity. J Biol Chem., 283(11):6706-16.

Genoud S, Lappe-Siefke C, Goebbels S, Radtke F, Aguet M, Scherer SS, Suter U, Nave KA, Mantei N (2002) Notch1 control of oligodendrocyte differentiation in the spinal cord. J Cell Biol., 158(4):709-18.

Gobert RP, Joubert L, Curchod ML, Salvat C, Foucault I, Jorand-Lebrun C, Lamarine $M$, Peixoto $H$, Vignaud $C$, Frémaux $C$, Jomotte $T$, Françon $B$, Alliod $C$, Bernasconi L, Abderrahim H, Perrin D, Bombrun A, Zanoguera F, Rommel C, Hooft van Huijsduijnen R (2009) Convergent functional genomics of oligodendrocyte differentiation identifies multiple autoinhibitory signaling circuits. Mol Cell Biol., 29(6):1538-53.

Golan N, Adamsky K, Kartvelishvily E, Brockschnieder D, Möbius W, Spiegel I, Roth AD, Thomson CE, Rechavi G, Peles E (2008) Identification of Tmem10/Opalin as an oligodendrocyte enriched gene using expression profiling combined with genetic cell ablation. Glia, 56(11):1176-86. 
Gow A, Davies C, Southwood CM, Frolenkov G, Chrustowski M, Ng L, Yamauchi D, Marcus DC, Kachar B (2004) Deafness in Claudin 11-null mice reveals the critical contribution of basal cell tight junctions to stria vascularis function. J Neurosci., 24(32):7051-62.

Gow A, Southwood CM, Li JS, Pariali M, Riordan GP, Brodie SE, Danias J, Bronstein JM, Kachar B, Lazzarini RA (1999) CNS myelin and sertoli cell tight junction strands are absent in Osp/claudin-11 null mice. Cell, 99(6):649-59.

Griffith AJ, Sprunger LK, Sirko-Osadsa DA, Tiller GE, Meisler MH, Warman ML (1998) Marshall syndrome associated with a splicing defect at the COL11A1 locus. Am J Hum Genet., 62(4):816-23.

Guillemot F, Lo LC, Johnson JE, Auerbach A, Anderson DJ, Joyner AL (1993) Mammalian achaete-scute homolog 1 is required for the early development of olfactory and autonomic neurons. Cell, 75(3):463-76.

Harauz G, Ishiyama N, Hill CM, Bates IR, Libich DS, Farès C (2004) Myelin basic protein-diverse conformational states of an intrinsically unstructured protein and its roles in myelin assembly and multiple sclerosis. Micron, 35(7):503-42.

He Y, Dupree J, Wang J, Sandoval J, Li J, Liu H, Shi Y, Nave KA, CasacciaBonnefil P (2007) The transcription factor Yin Yang 1 is essential for oligodendrocyte progenitor differentiation. Neuron, 55(2):217-30.

Heng MY, Lin ST, Verret L, Huang Y, Kamiya S, Padiath QS, Tong Y, Palop JJ, Huang EJ, Ptácxek LJ, Fu YH (2013) Lamin B1 mediates cell-autonomous neuropathology in a leukodystrophy mouse model. J Clin Invest., 123(6):2719-29.

Hu QD, Ang BT, Karsak M, Hu WP, Cui XY, Duka T, Takeda Y, Chia W, Sankar N, Ng YK, Ling EA, Maciag T, Small D, Trifonova R, Kopan R, Okano H, Nakafuku M, Chiba S, Hirai H, Aster JC, Schachner M, Pallen CJ, Watanabe K, Xiao ZC (2003) F3/contactin acts as a functional ligand for Notch during oligodendrocyte maturation. Cell, 115(2):163-75.

Huang JK, Jarjour AA, Nait Oumesmar B, Kerninon C, Williams A, Krezel W, Kagechika H, Bauer J, Zhao C, Baron-Van Evercooren A, Chambon P, FfrenchConstant C, Franklin RJ (2011) Retinoid X receptor gamma signaling accelerates CNS remyelination. Nat Neurosci., 14(1):45-53.

Innos J, Philips MA, Leidmaa E, Heinla I, Raud S, Reemann P, Plaas M, Nurk K, Kurrikoff K, Matto V, Visnapuu T, Mardi P, Kõks S, Vasar E (2011) Lower anxiety and a decrease in agonistic behaviour in Lsamp-deficient mice. Behav Brain Res, 217(1):21-31.

Innos J, Philips MA, Raud S, Lilleväli K, Kõks S, Vasar E. (2012) Deletion of the Lsamp gene lowers sensitivity to stressful environmental manipulations in mice. Behav Brain Res., 228(1):74-81.

Ishii A, Dutta R, Wark GM, Hwang SI, Han DK, Trapp BD, Pfeiffer SE, Bansal R (2009) Human myelin proteome and comparative analysis with mouse myelin. Proc Natl Acad Sci USA, 106(34):14605-10.

Jahn O, Tenzer S, Werner HB (2009) Myelin proteomics: molecular anatomy of an insulating sheath. Mol Neurobiol., 40(1):55-72. 
Jung M, Krämer E, Grzenkowski M, Tang K, Blakemore W, Aguzzi A, Khazaie K, Chlichlia K, von Blankenfeld G, Kettenmann H, et al (1995) Lines of murine oligodendroglial precursor cells immortalized by an activated neu tyrosine kinase show distinct degrees of interaction with axons in vitro and in vivo. Eur $\mathrm{J}$ Neurosci., 7(6):1245-65.

Karim SA, Barrie JA, McCulloch MC, Montague P, Edgar JM, Kirkham D, Anderson TJ, Nave KA, Griffiths IR, McLaughlin M (2007) PLP overexpression perturbs myelin protein composition and myelination in a mouse model of PelizaeusMerzbacher disease. Glia, 55(4):341-51.

Kim JG, Armstrong RC, v Agoston D, Robinsky A, Wiese C, Nagle J, Hudson LD (1997) Myelin transcription factor 1 (Myt1) of the oligodendrocyte lineage, along with a closely related $\mathrm{CCHC}$ zinc finger, is expressed in developing neurons in the mammalian central nervous system. J Neurosci Res., 15;50(2):272-90.

Kippert A, Trajkovic K, Fitzner D, Opitz L, Simons M (2008) Identification of Tmem10/Opalin as a novel marker for oligodendrocytes using gene expression profiling. BMC Neurosci., 25;9:40.

Kitajiri S, Miyamoto T, Mineharu A, Sonoda N, Furuse K, Hata M, Sasaki H, Mori Y, Kubota T, Ito J, Furuse M, Tsukita S (2004) Compartmentalization established by claudin-11-based tight junctions in stria vascularis is required for hearing through generation of endocochlear potential. J Cell Sci., 117(Pt 21):5087-96.

Koenning M, Jackson S, Hay CM, Faux C, Kilpatrick TJ, Willingham M, Emery B (2012) Myelin gene regulatory factor is required for maintenance of myelin and mature oligodendrocyte identity in the adult CNS. J Neurosci., 32(36):12528-42.

Kuhlmann T, Miron V, Cui Q, Wegner C, Antel J, Brück W (2008) Differentiation block of oligodendroglial progenitor cells as a cause for remyelination failure in chronic multiple sclerosis. Brain, 131(Pt 7):1749-58.

Lai EC (2004). Notch signaling: control of cell communication and cell fate. Development, 131 (5): 965-73.

Lander ES, Linton LM, Birren B, Nusbaum C, Zody MC, Baldwin J, Devon K, Dewar K, Doyle M, FitzHugh W, Funke R, Gage D, Harris K, Heaford A, Howland J, Kann L, Lehoczky J, et al.; International Human Genome Sequencing Consortium (2001) Initial sequencing and analysis of the human genome. Nature, 409(6822):860921.

Landry CF1, Pribyl TM, Ellison JA, Givogri MI, Kampf K, Campagnoni CW, Campagnoni AT (1998) Embryonic Expression of the Myelin Basic Protein Gene: Identification of a Promoter Region That Targets Transgene Expression to Pioneer Neurons. J Neurosci., 18(18):7315-27.

Lappe-Siefke C, Goebbels S, Gravel M, Nicksch E, Lee J, Braun PE, Griffiths IR, Nave KA (2003) Disruption of Cnp1 uncouples oligodendroglial functions in axonal support and myelination. Nat Genet., 33(3):366-74.

Li C, Trapp B, Ludwin S, Peterson A, Roder J (1998) Myelin associated glycoprotein modulates glia-axon contact in vivo. J Neurosci Res., 51(2):210-7. 
Liu A, Li J, Marin-Husstege M, Kageyama R, Fan Y, Gelinas C, Casaccia-Bonnefil $\mathbf{P}$ (2006) A molecular insight of Hes5-dependent inhibition of myelin gene expression. EMBO J., 25(20):4833-42.

Lodyga M, De Falco V, Bai XH, Kapus A, Melillo RM, Santoro M, Liu M (2009) XB130, a tissue-specific adaptor protein that couples the RET/PTC oncogenic kinase to PI 3-kinase pathway. Oncogene, 28(7):937-49.

Luber CA, Cox J, Lauterbach H, Fancke B, Selbach M, Tschopp J, Akira S, Wiegand M, Hochrein H, O'Keeffe M, Mann M (2010) Quantitative proteomics reveals subset-specific viral recognition in dendritic cells. Immunity, 32(2):279-89.

Lyons DA, Naylor SG, Scholze A, Talbot WS (2009) Kif1b is essential for mRNA localization in oligodendrocytes and development of myelinated axons. Nat Genet., 41(7):854-8.

Marin-Husstege M, Muggironi M, Liu A, Casaccia-Bonnefil P (2002) Histone deacetylase activity is necessary for oligodendrocyte lineage progression. J Neurosci., 22(23):10333-45.

McKinnon RD, Matsui T, Dubois-Dalcq M, Aaronson SA (1990) FGF modulates the PDGF-driven pathway of oligodendrocyte development. Neuron, 5(5):603-14.

Montag D, Giese KP, Bartsch U, Martini R, Lang Y, Blüthmann H, Karthigasan J, Kirschner DA, Wintergerst ES, Nave KA, et al. (1994) Mice deficient for the myelinassociated glycoprotein show subtle abnormalities in myelin. Neuron, 13(1):229-46.

Musse AA, Gao W, Homchaudhuri L, Boggs JM, Harauz G (2008) Myelin basic protein as a "PI(4,5)P2-modulin": a new biological function for a major central nervous system protein. Biochemistry, 47(39):10372-82.

Nadon NL, Duncan ID, Hudson LD (1990) A point mutation in the proteolipid protein gene of the 'shaking pup' interrupts oligodendrocyte development. Development, 110(2):529-37.

Nagaraj N, Wisniewski JR, Geiger T, Cox J, Kircher M, Kelso J, Pääbo S, Mann M (2011) Deep proteome and transcriptome mapping of a human cancer cell line. Mol Syst Biol., 7:548.

Nave KA, Lai C, Bloom FE, Milner RJ (1986) Jimpy mutant mouse: a 74-base deletion in the mRNA for myelin proteolipid protein and evidence for a primary defect in RNA splicing. PNAS, 83(23):9264-8.

Nielsen JA, Berndt JA, Hudson LD, Armstrong RC (2004) Myelin transcription factor 1 (Myt1) modulates the proliferation and differentiation of oligodendrocyte lineage cells. Mol Cell Neurosci., 25(1):111-23.

Parras CM, Galli R, Britz O, Soares S, Galichet C, Battiste J, Johnson JE, Nakafuku M, Vescovi A, Guillemot F (2004) Mash1 specifies neurons and oligodendrocytes in the postnatal brain. EMBO J., 23(22):4495-505.

Pennisi E (2001) The human genome. Science, 291(5507):1177-80. 
Raff MC, Lillien LE, Richardson WD, Burne JF, Noble MD (1988) Platelet-derived growth factor from astrocytes drives the clock that times oligodendrocyte development in culture. Nature, 333(6173):562-5.

Rajasekharan S (2008) Intracellular signaling mechanisms directing oligodendrocyte precursor cell migration. J Neurosci., 28(50):13365-7.

Rappsilber J, Mann M, Ishihama Y (2007) Protocol for micro-purification, enrichment, pre-fractionation and storage of peptides for proteomics using StageTips. Nat Protoc., 2(8):1896-906.

Rasband MN, Tayler J, Kaga Y, Yang Y, Lappe-Siefke C, Nave KA, Bansal R (2005) CNP is required for maintenance of axon-glia interactions at nodes of Ranvier in the CNS. Glia, 50(1):86-90.

Readhead C, Schneider A, Griffiths I, Nave KA (1994) Premature arrest of myelin formation in transgenic mice with increased proteolipid protein gene dosage. Neuron,12(3):583-95.

Rees S and Inder T ( 2005) Fetal and neonatal origins of altered brain development. Early Hum Dev., 81(9):753-61.

Regen T, van Rossum D, Scheffel J, Kastriti ME, Revelo NH, Prinz M, Brück W, Hanisch UK (2011) CD14 and TRIF govern distinct responsiveness and responses in mouse microglial TLR4 challenges by structural variants of LPS. Brain Behav Immun., 25(5):957-70.

Richards AJ, Yates JR, Williams R, Payne SJ, Pope FM, Scott JD, Snead MP (1996) A family with Stickler syndrome type 2 has a mutation in the COL11A1 gene resulting in the substitution of glycine 97 by valine in alpha 1 (XI) collagen. Hum Mol Genet., 5(9):1339-43.

Saher G, Rudolphi F, Corthals K, Ruhwedel T, Schmidt KF, Löwel S, Dibaj P, Barrette B, Möbius W, Nave KA (2012) Therapy of Pelizaeus-Merzbacher disease in mice by feeding a cholesterol-enriched diet. Nat Med., 18(7):1130-5.

Sakagami H, Aoki J, Natori Y, Nishikawa K, Kakehi Y, Natori Y, Arai H (2005) Biochemical and molecular characterization of a novel choline-specific glycerophosphodiester phosphodiesterase belonging to the nucleotide pyrophosphatase/phosphodiesterase family. J Biol Chem., 280(24):23084-93.

Sambrook J and Russell DW (2000) Molecular Cloning: A Laboratory Manual, Cold Spring Harbor Laboratory press, $3^{\text {rd }}$ edition.

Saugier-Veber P, Munnich A, Bonneau D, Rozet JM, Le Merrer M, Gil R, Boespflug-Tanguy O (1994) X-linked spastic paraplegia and Pelizaeus-Merzbacher disease are allelic disorders at the proteolipid protein locus. Nat Genet., 6(3):257-62.

Schaeren-Wiemers N, Bonnet A, Erb M, Erne B, Bartsch U, Kern F, Mantei N, Sherman D, Suter U (2004) The raft-associated protein MAL is required for maintenance of proper axon--glia interactions in the central nervous system. $\mathrm{J}$ Cell Biol., 166(5):731-42.

Schneider A, Schulz-Schaeffer W, Hartmann T, Schulz JB, Simons M (2006) Cholesterol depletion reduces aggregation of amyloid-beta peptide in hippocampal neurons. Neurobiol Dis., 23(3):573-7. 
Shevchenko A, Tomas H, Havlis J, Olsen JV, Mann M (2006) In-gel digestion for mass spectrometric characterization of proteins and proteomes. Nat Protoc., 1(6):285660.

Siegel GJ (editor) (1998) Basic Neurochemistry - Molecular, Cellular and Medical Aspects. Lippincott Williams \& Wilkins, $6^{\text {th }}$ edition.

Simons M, Kramer EM, Macchi P, Rathke-Hartlieb S, Trotter J, Nave KA, Schulz JB (2002) Overexpression of the myelin proteolipid protein leads to accumulation of cholesterol and proteolipid protein in endosomes/lysosomes: implications for Pelizaeus-Merzbacher disease. J Cell Biol., 157(2):327-36.

Snaidero N, Möbius W, Czopka T, Hekking LH, Mathisen C, Verkleij D, Goebbels S, Edgar J, Merkler D, Lyons DA, Nave KA, Simons M (2014) Myelin membrane wrapping of CNS axons by $\mathrm{PI}(3,4,5) \mathrm{P} 3$-dependent polarized growth at the inner tongue. Cell, 156(1-2):277-90.

Soundarapandian MM, Selvaraj V, Lo UG, Golub MS, Feldman DH, Pleasure DE, Deng W (2011) Zfp488 promotes oligodendrocyte differentiation of neural progenitor cells in adult mice after demyelination. Sci Rep., 1:2. doi: 10.1038/srep00002.

Sprinkle TJ (1989) 2',3'-cyclic nucleotide 3'-phosphodiesterase, an oligodendrocyteSchwann cell and myelin-associated enzyme of the nervous system. Crit Rev Neurobiol. , 4(3):235-301.

Sugimori M, Nagao M, Parras CM, Nakatani H, Lebel M, Guillemot F, Nakafuku M (2008) Ascl1 is required for oligodendrocyte development in the spinal cord. Development, 135(7):1271-81.

Tokumoto YM, Apperly JA, Gao FB, Raff MC (2002) Posttranscriptional regulation of p18 and p27 Cdk inhibitor proteins and the timing of oligodendrocyte differentiation. Dev Biol., 245(1):224-34.

Trajkovic K, Dhaunchak AS, Goncalves JT, Wenzel D, Schneider A, Bunt G, Nave KA, Simons M (2006) Neuron to glia signaling triggers myelin membrane exocytosis from endosomal storage sites. J Cell Biol., 172(6):937-48.

Trapp BD and Nave KA (2008) Multiple sclerosis: an immune or neurodegenerative disorder? Annu Rev Neurosci., 31:247-69.

Trempe GL (1976) Human breast cancer in culture. Recent Results Cancer Res, (57):33-41.

Vana AC, Lucchinetti CF, Le TQ, Armstrong RC (2007) Myelin transcription factor 1 (Myt1) expression in demyelinated lesions of rodent and human CNS. Glia, 55(7):68797.

Vela JM, Molina-Holgado E, Arévalo-Martín A, Almazán G, Guaza C (2002) Interleukin-1 regulates proliferation and differentiation of oligodendrocyte progenitor cells. Mol Cell Neurosci., 20(3):489-502.

Walters SN and Morell P (1981) Effects of altered thyroid states on myelinogenesis. J Neurochem., 36(5):1792-801. 
Wang $H$, Yang $H$, Shivalila CS, Dawlaty MM, Cheng AW, Zhang F, Jaenisch $R$ (2013) One-step generation of mice carrying mutations in multiple genes by CRISPR/Cas-mediated genome engineering. Cell, 153(4):910-8.

Wang S, Sdrulla AD, diSibio G, Bush G, Nofziger D, Hicks C, Weinmaster G, Barres BA (1998) Notch receptor activation inhibits oligodendrocyte differentiation. Neuron, 21(1):63-75.

Wang SZ, Dulin J, Wu H, Hurlock E, Lee SE, Jansson K, Lu QR (2006) An oligodendrocyte-specific zinc-finger transcription regulator cooperates with Olig2 to promote oligodendrocyte differentiation. Development, 133(17):3389-98.

Weider M, Reiprich S, Wegner M (2013) Sox appeal - Sox10 attracts epigenetic and transcriptional regulators in myelinating glia. Biol Chem, 394(12):1583-93.

Werner HB, Krämer-Albers EM, Strenzke N, Saher G, Tenzer S, Ohno-Iwashita Y, De Monasterio-Schrader P, Möbius W, Moser T, Griffiths IR, Nave KA (2013) A critical role for the cholesterol-associated proteolipids PLP and M6B in myelination of the central nervous system. Glia, 61(4):567-86.

Westling J, Gottschall PE, Thompson VP, Cockburn A, Perides G, Zimmermann DR, Sandy JD (2004) ADAMTS4 (aggrecanase-1) cleaves human brain versican V2 at Glu405-GIn406 to generate glial hyaluronate binding protein. Biochem J., 377(Pt 3):787-95.

Wieser GL, Gerwig UC, Adamcio B, Barrette B, Nave KA, Ehrenreich H, Goebbels $\mathbf{S}$ (2013) Neuroinflammation in white matter tracts of Cnp1 mutant mice amplified by a minor brain injury. Glia, 61(6):869-80.

Wiśniewski JR, Zougman A, Nagaraj N, Mann M (2009) Universal sample preparation method for proteome analysis. Nat Methods., 6(5):359-62.

Wiśniewski JR, Duś K, Mann M (2013) Proteomic workflow for analysis of archival formalin-fixed and paraffin-embedded clinical samples to a depth of 10000 proteins. Proteomics Clin Appl., 7(3-4):225-33.

Wolswijk G (2000) Oligodendrocyte survival, loss and birth in lesions of chronic-stage multiple sclerosis. Brain,123 ( Pt 1):105-15.

Xin M, Yue T, Ma Z, Wu FF, Gow A, Lu QR (2005) Myelinogenesis and axonal recognition by oligodendrocytes in brain are uncoupled in Olig1-null mice. J Neurosci., 25(6):1354-65.

Xu J, Bai XH, Lodyga M, Han B, Xiao H, Keshavjee S, Hu J, Zhang H, Yang BB, Liu M (2007) XB130, a novel adaptor protein for signal transduction. J Biol Chem., 282(22):16401-12.

Yang B, Cao L, Liu B, McCaig CD, Pu J (2013) The transition from proliferation to differentiation in colorectal cancer is regulated by the calcium activated chloride channel A1. PLoS One, 8(4):e60861.

Yang H, Wang H, Shivalila CS, Cheng AW, Shi L, Jaenisch R (2013) One-step generation of mice carrying reporter and conditional alleles by CRISPR/Cas-mediated genome engineering. Cell, 154(6):1370-9. 
Yool DA, Edgar JM, Montague P, Malcolm S (2000) The proteolipid protein gene and myelin disorders in man and animal models. Hum Mol Genet, 9(6):987-92.

Yoshikawa F, Sato Y, Tohyama K, Akagi T, Hashikawa T, Nagakura-Takagi Y, Sekine Y, Morita N, Baba H, Suzuki Y, Sugano S, Sato A, Furuichi T (2008) Opalin, a transmembrane sialylglycoprotein located in the central nervous system myelin paranodal loop membrane. J Biol Chem., 283(30):20830-40.

Zamvil SS and Steinman L (1990) The Tlymphocyte in experimental allergic encephalomyelitis. Annu Rev Immunol., 8:579-621.

Zhou Q and Anderson DJ (2002) The bHLH transcription factors OLIG2 and OLIG1 couple neuronal and glial subtype specification. Cell, 109(1):61-73.

Zolova OE and Wight PA (2011) YY1 negatively regulates mouse myelin proteolipid protein (Plp1) gene expression in oligodendroglial cells. ANS Neuro, 3;3(4) 


\section{Curriculum vitae}

Sebastian Schmitt

Frankenstraße 15, 53175 Bonn

E-Mail: sebastian.schmitt@gmx.at

\section{Education}

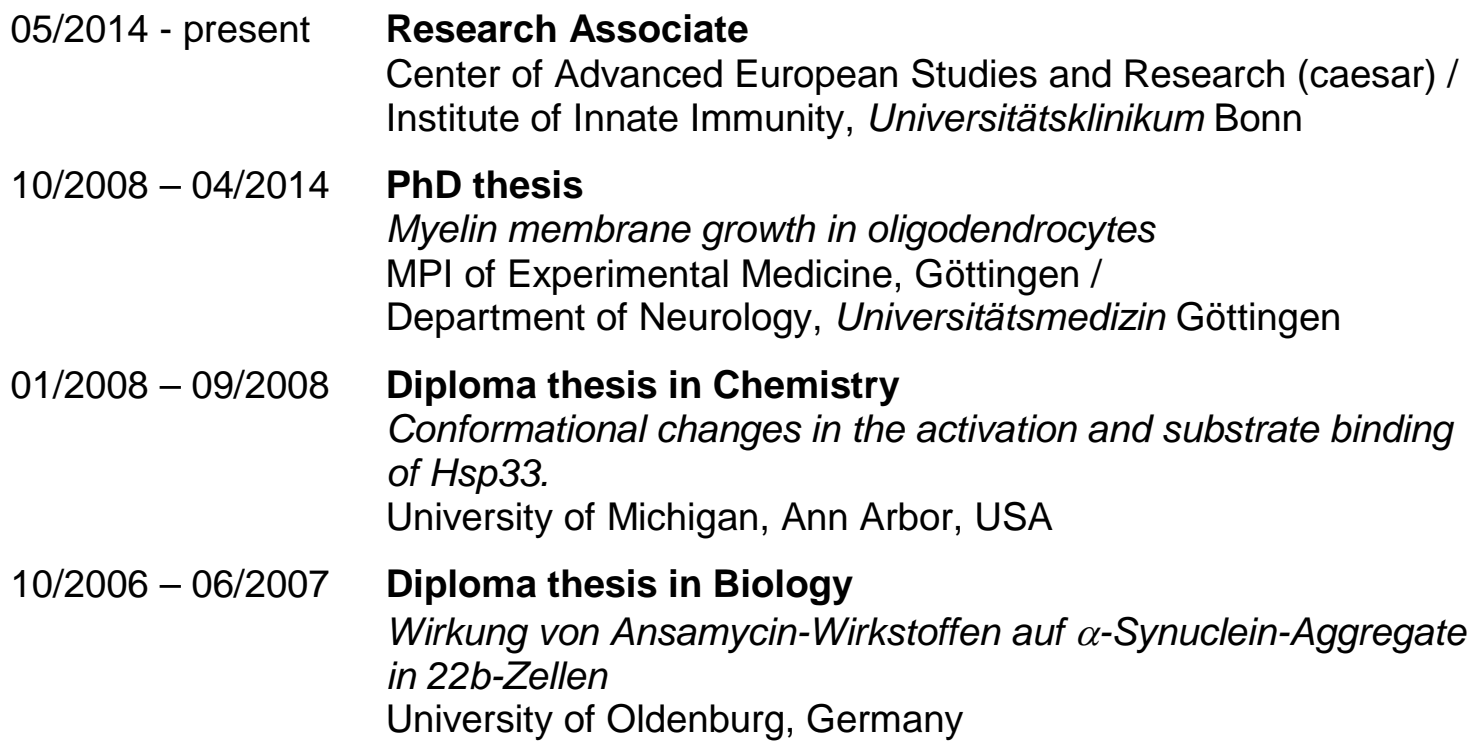

$06 / 2001$

Abitur, Herbartgymnasium Oldenburg

\section{Publications}

Budde H, Schmitt S, Fitzner D, Opitz L, Salinas-Riester G, Simons M (2010) Control of oligodendroglial cell number by the miR-17-92 cluster. Development. 137(13):2127-32.

Riedel M, Goldbaum O, Schwarz L, Schmitt S, Richter-Landsberg C (2010) 17-AAG induces cytoplasmic alpha-synuclein aggregate clearance by induction of autophagy. PLoS One. 5(1):e8753.

Xu Y, Schmitt S, Tang L, Jakob U, Fitzgerald MC (2010) Thermodynamic analysis of a molecular chaperone binding to unfolded protein substrates. Biochemistry. 49(6):134653.

Brandes N, Schmitt S, Jakob U (2009) Thiol-based redox switches in eukaryotic proteins. Antioxid Redox Signal. 11(5):997-1014.

\section{Awards \& Scholarships}

$\begin{array}{ll}2009-2012 & \text { PhD scholarship of the Boehringer-Ingelheim Fonds } \\ 2009 & \text { Travel stipend of the International Society of Neurochemistry } \\ 2008 & \text { DAAD Scholarship } \\ 2007 & \text { Degussa Scholarship } \\ 2006 & \text { OLB/EWE Award }\end{array}$

